\title{
Molecular Cloning and Characterization of Nitrate Reductase from Ricinus communis L. Heterologously Expressed in Pichia pastoris
}

\author{
Dissertation zur Erlangung des \\ naturwissenschaftlichen Doktorgrades \\ der Bayerischen Julius-Maximilians-Universität Würzburg
}

Vorgelegt von

Chyn-Bey Tsai

Aus

Taiwan

Würzburg 2003 


\section{Thanks and dedication to}

My parents............... without them I could not be here

Buddha Shakyamuni....... without him I would never appreciate the truth 


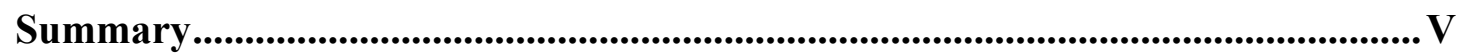

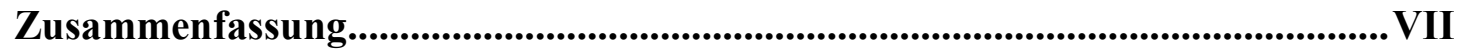

1. Introduction ............................................................................................................... 1

1.1 Overview of nitrate assimilation in higher plants ................................... 1

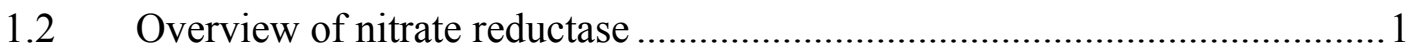

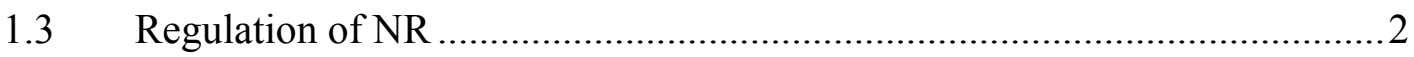

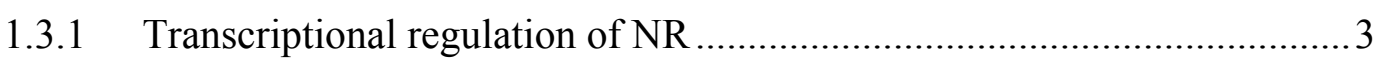

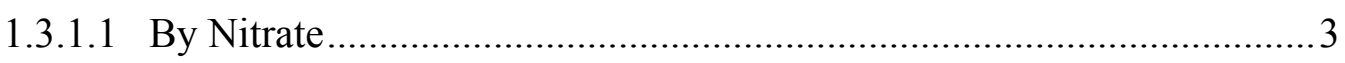

1.3.1.2 By Light and carbohydrates .........................................................

1.3.2 Post-transcriptional regulation of NR .................................................

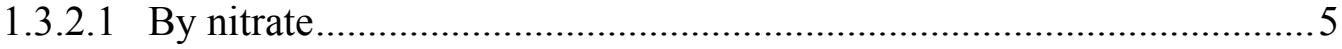

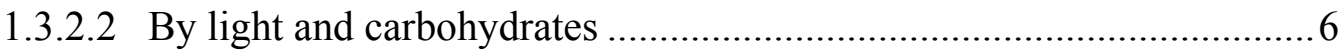

1.3.3 Mechanism of the post-translational regulation of NR in higher plants ....6

1.3.4 The role of the $\mathrm{N}$-terminal domain in NR regulation .............................. 8

1.4 An exceptional example from Ricinus..................................................

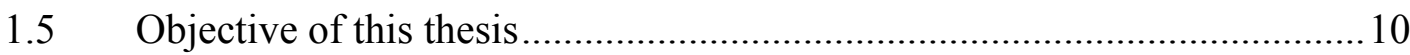

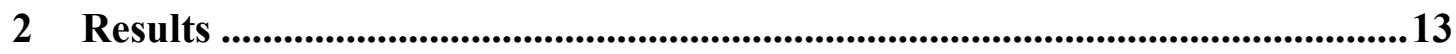

2.1 Molecular cloning of NR gene from Ricinus.......................................... 13

2.1.1 The primary Ricinus NR gene sequence obtained by RT-PCR ............... 13

2.1.2 The Full-length Ricinus NR gene .................................................... 14

2.1.3 Analysis of the deduced amino acids sequence ...................................... 15

2.2 Heterologous expression of RcNR in Pichia pastoris ................................. 17

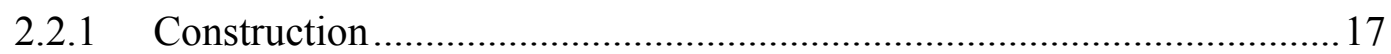

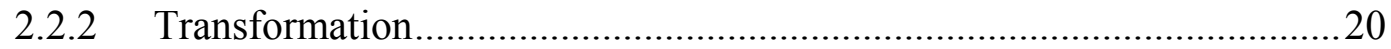

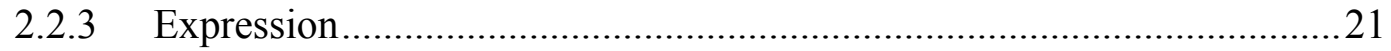

2.3 Characterization of recombinant Ricinus NR .............................................2 24

2.3.1 Modulation of NRs from plant leaves..................................................24

2.3.2 Modulation of NRs from yeast cells ....................................................25

2.3.3 RcNR has a high $\mathrm{Mg}^{2+}$-sensitivity when mixed with NR-free extracts from Ricinus leaves at $\mathrm{pH} 7.6$, but not at $\mathrm{pH}$ 6.5 ...............................................2. 27

2.3.4 Protein fractionation by ammonium sulfate..........................................28 


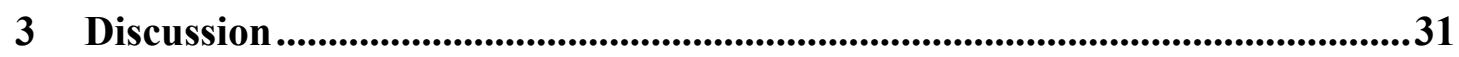

3.1 Deduced protein sequence of Ricinus NR .................................................. 31

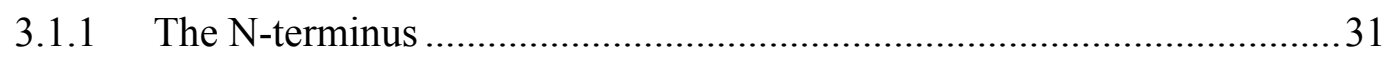

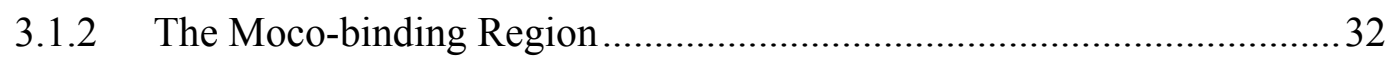

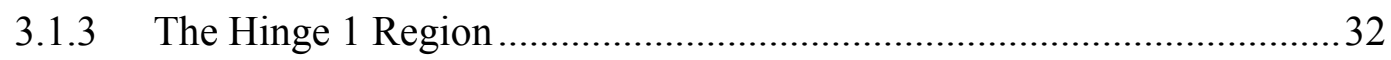

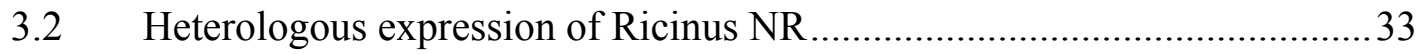

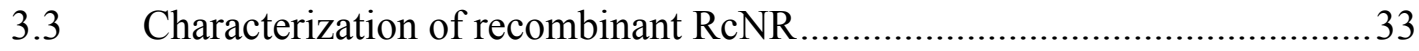

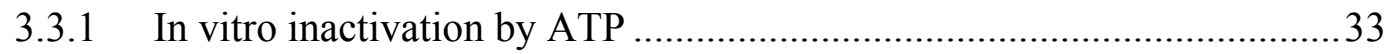

3.3.2 Specific protein factor(s) for high $\mathrm{Mg}^{2+}$-sensitivity of RcNR .................34

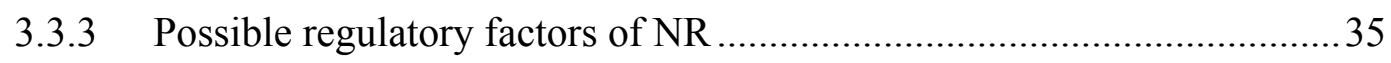

3.4 The comparison of Ricinus and squash nitrate reductase ...........................36

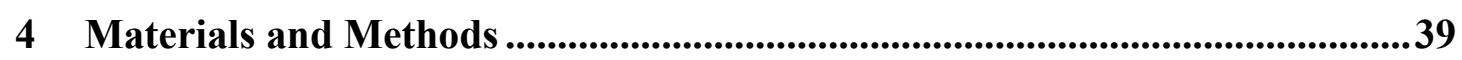

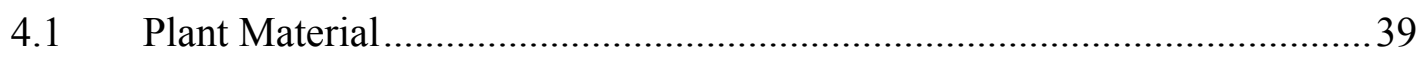

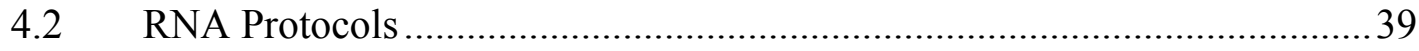

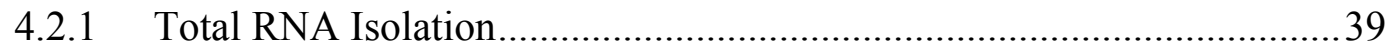

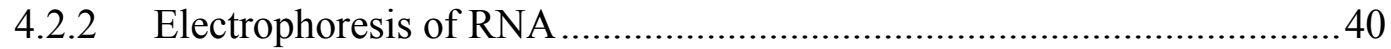

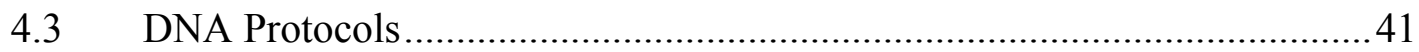

4.3.1 Isolation of Plasmid-DNA from Escherichia coli .................................41

4.3.2 Restriction Endonucleases Digestion................................................. 41

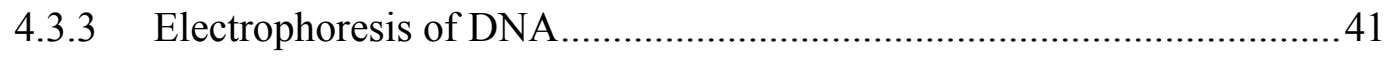

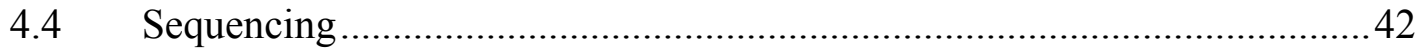

4.5 Molecular Cloning of Ricinus NR by RT-PCR ....................................... 42

4.6 Amplification of full-length Ricinus NR cDNA by RACE ........................44

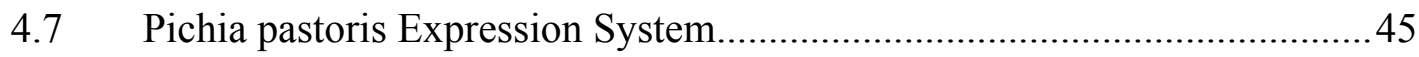

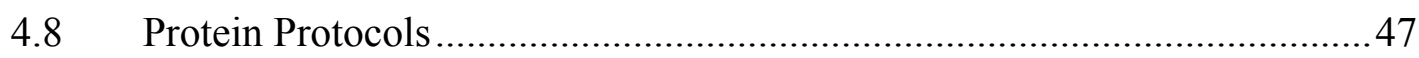

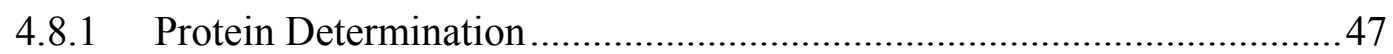

4.8.2 SDS-Polyacrylamide Gelelectrophoresis (SDS-PAGE) ........................ 47

4.8.3 Western Blot and Immunodetection of NR ....................................... 48

4.8.4 Ammonium Sulfate Fractionation....................................................... 48

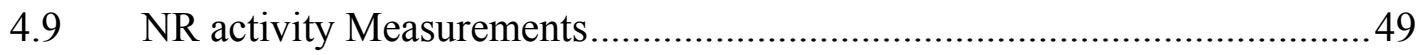

4.9.1 Determination of NR activity in yeast cells (in vivo) ............................49

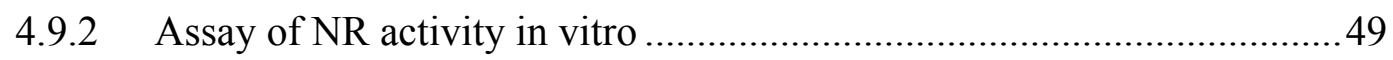

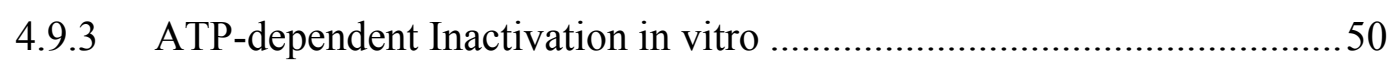




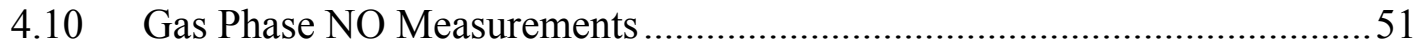

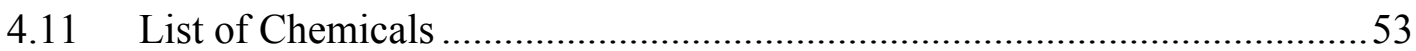

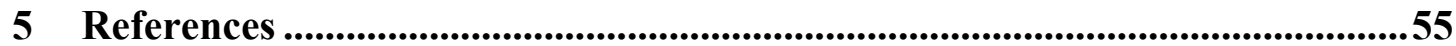

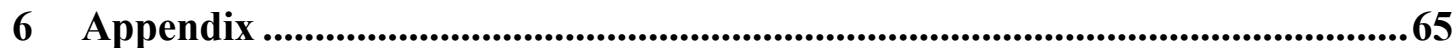

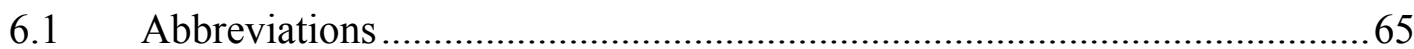

6.2 Oligo Nucleotide Primers ......................................................................6 66

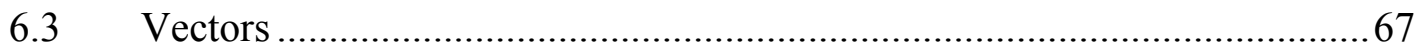

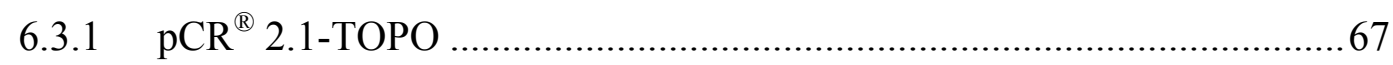

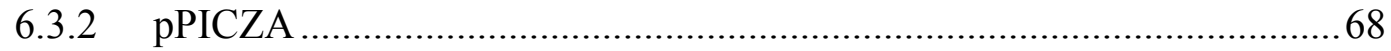

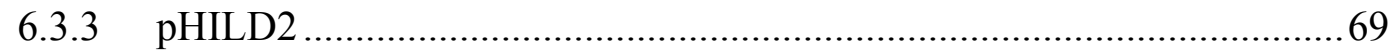

6.4 Key invariant residues in Ricinus NR ....................................................... 70

6.5 Amino acid sequence alignments (N-terminus) ..................................... 71

6.6 Amino acid sequence alignments (without N-terminus) ............................72

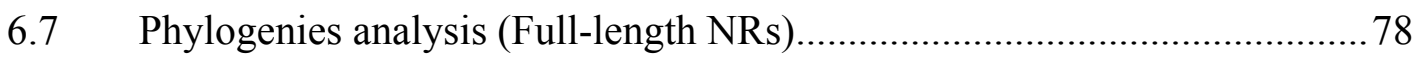

$6.8 \quad$ Phylogenies analysis (N-terminus of NRs) …......................................... 79 


\section{Summary}

Background: In a previous study, nitrate reductase (NR, EC 1.6.6.1) from leaves of Ricinus communis L. showed different regulatory properties from most other higher plants NR's by an unusually strong $\mathrm{Mg}^{2+}$-sensitivity, a different $\mathrm{pH}$-activity profile and only little ATP-dependent inactivation.

The aim of this work was to elucidate the deviating properties of Ricinus NR in more details, from both molecular and physiological aspects. For that purpose, the NR gene from $R$. communis was cloned, expressed heterologously and characterized.

Results: The deduced protein sequence showed that Ricinus NR shared high similarity with other NRs, apart from the N-terminal region. In the N-terminal region, the Ricinus NR possesses an acidic stretch which is conserved only in higher plants. Within the Moco-binding domain the Ricinus NR contained few amino acid residues which were unique in comparison with 17 plant NRs, including His103, Gln123, Val266 and Ala284 where other NRs possess asparagine, arginine, aspartate and proline.

In the Dimer interface and Hinge 1 regions, the Ricinus NR also had some unique residues like Asn460 and Ala498 where other NRs have isoleucine and glycine instead. The Ricinus NR possesses an Arg482 which provides an additional predicted Trypsin cleavage site within ${ }^{481} \mathrm{KRHK}^{484}$ (while most of plant-NRs possess KPHK). Additionally, the Ricinus NR contains a serine phosphorylation site (Ser-526) within the potential 14-3-3 binding motif ${ }^{523} \mathrm{KSVS}^{*} \mathrm{TP}^{528}$, which is a common characteristic of nitrate reductases. In the C-Terminus of Ricinus NR a sequence ${ }^{886} \mathrm{CGPPP}^{890}$ confirmed that Ricinus NR is a NADH-specific enzyme.

Functional Ricinus NR protein was expressed in Pichia pastoris and compared with the features of Arabidopsis NR2 synthesized by the same expression system (AtNR2). The recombinant Ricinus NR (RcNR) itself was unresponsive to the incubation with MgATP, and so was AtNR2. As yeast extracts might lack factors required for NR regulation, desalted leaf extracts containing NR kinases and 14-3-3s were prepared from 4-day darkened (and therefore NR-free) leaves of Arabidopsis (ADL), spinach (SDL) and Ricinus (RDL), and added to the assay of RcNR and AtNR2 to check for 
ATP-dependent inactivation and $\mathrm{Mg}^{2+}$-sensitivity. When RcNR was combined with the NR-free extracts described above, it's unusually high $\mathrm{Mg}^{2+}$-sensitivity was restored only by incubation with RDL, but it remained unresponsive to ATP. In contrast, AtNR2 became inactive when incubated with the protein mixtures and ATP. It is obvious that one or some factors existing in RDL could interact with RcNR and therefore provide its high $\mathrm{Mg}^{2+}$-sensitivity. Interestingly, incubation of AtNR2 with different NR-free leaf extracts gave a significant activation of the enzyme activities, both in $\mathrm{Mg}^{2+}$ and EDTA, which were not observed in the case of RcNR. Moreover, using ammonium sulfate to fractionation the RDL revealed that about $0.2 \mathrm{mg}$ of the protein factor(s) from $0-35 \%$ of ammonium sulfate precipitation was sufficient to provide the maximum inhibition of the RcNR.

Conclusions: The insensitivity to ATP appears an inherent property of Ricinus NR, whereas the high $\mathrm{Mg}^{2+}$-sensitivity depends on one or several factors in Ricinus leaves. This as yet unknown factor(s) was boiling-sensitive and could be precipitated by ammonium sulfate. It appeared to interact specifically with recombinant Ricinus-NR to provide the $\mathrm{Mg}^{2+}$-sensitivity of the authentic leaf enzyme. Presumably, there is also a positive regulatory factor(s) for nitrate reductase existing in the leaves of higher plants. 


\section{Zusammenfassung}

Hintergrund: In einer vorhergehenden Studie wurde gezeigt, dass die Nitratreduktase (NR, EC 1.6.6.1) aus Blättern von Ricinus communis L. im Vergleich zu NRs der meisten anderen höheren Pflanzen durch verschiedene Faktoren unterschiedlich reguliert wird. Die Aktivität ist ungewöhnlich $\mathrm{Mg}^{2+}$-sensitiv, zeigt ein verändertes $\mathrm{pH}-\mathrm{Profil}$ und ist nur gering ATP-abhängig inaktivierbar.

Das Ziel dieser Arbeit war, die abweichenden Eigenschaften von Ricinus NR, aus molekularer und physiologischer Sicht detaillierter aufzuklären. Zu diesem Zweck wurde das NR Gen von $R$. communis geklont, heterolog exprimiert und charakterisiert.

Ergebnisse: Die abgeleitete Proteinsequenz zeigte, dass Ricinus NR hohe Ähnlichkeit mit anderem NRs teilte, abgesehen von der N-terminalen Region. In der N-terminalen Region besitzt die Ricinus NR eine säurehaltige Sequenz, die nur in den höheren Pflanzen konserviert ist. In der Moco-bindenden Region waren einige in 17 Pflanzen NRs konservierte Aminosäurepositionen verändert. Zu diesen Positionen gehörten His103, Gln123, Val266 und Ala284, die Asparagin, Arginin, Aspartat und Prolin in den anderen Pflanzen ersetzten. Auch an der Dimerisierungs- und Hinge 1-Region, zeigte die Ricinus NR eine veränderte Aminosäuresequenz. Anstatt Isoleucin und Glycin, besaß die Ricinus NR an den Stellen 460 und 498 Asparagin und Alanin. Durch ein Arg an der Stelle 482 kommt es zu einer zusätzliche Trypsinschnittstelle innerhalb des ${ }^{481} \mathrm{KRHK}^{484-}$ Motivs (die meisten NR besitzen hier KPHK).

Zusätzlich enthält die Ricinus NR eine Serinphosphorylierungsstelle (Ser-526) innerhalb des möglichen 14-3-3 Bindemotivs ${ }^{523} \mathrm{KSVS}^{*} \mathrm{TP}^{528}$, was eine allgemeine Eigenschaft von Nitratreduktasen ist. Im C-Terminus von Ricinus NR bestätigte die Sequenz ${ }^{886} \mathrm{CGPPP}^{890}$, dass die Ricinus NR ein NADH-spezifisches Enzym ist.

Die Ricinus NR und Arabidopsis NR2 (AtNR2) wurden in Pichia pastoris funktionell exprimiert und die Eigenschaften miteinander verglichen. Die rekombinante Ricinus NR (RcNR) selbst wurde nicht durch die Inkubation mit MgATP inhibiert, ebenso AtNR2. Da der Hefeextrakt vermutlich die Faktoren zur Regulierung der NR nicht enthält, wurden entsalzte Blattextrakte von Arabidopsis (ADL), Spinat (SDL) und 
Ricinus (RDL) zugesetzt, die Kinasen und 14-3-3 Proteine enthielten. Damit keine endogenen NRs sich im Extrakt befinden wurden die Blätter vor Extraktion 4 Tage im Dunkeln gehalten.

In Bezug auf die Inhibierung der NR durch ATP wurde festgestellt, dass die RcNR gegenüber einer solchen Inhibierung unempfindlich ist, AtNR2 dagegen in jedem Fall durch ATP inaktiviert wird. Bei Kombination von RcNR mit NR-freien Extrakten aus Pflanzen zeigte sich die erhöhte $\mathrm{Mg}^{2+}$-Sensitivität nur, wenn man RcNR mit RDL inkubierte, nicht aber wenn man RcNR mit SDL oder ADL inkubierte. Es liegt auf der Hand, dass ein oder einige Faktoren in RDL vorkommen, die mit RcNR interagieren und seine hohe $\mathrm{Mg}^{2+}$-Sensitivität hervorrufen.

Außerdem, ergab eine Inkubation von AtNR2 mit unterschiedlichen NR-freien Blattextrakten eine bedeutende Aktivierung der Enzymaktivitäten, sowohl in Anwesenheit von $\mathrm{Mg}^{2+}$ als auch EDTA. Dies wurde jedoch nicht für die RcNR festgestellt. Nach Verwendung von Ammoniumsulfat zur Fraktionierung des RDL, fand man zusätzlich heraus, dass ungefähr 0,2 mg des Proteins der Fraktion die mit 0$35 \%$ Ammoniumsulfat gefällt wurde ausreichten die maximale Hemmung des RcNR hervorzurufen.

Schlussfolgerungen: Die Unempfindlichkeit gegenüber ATP erscheint eine angeborene Eigenschaft von Ricinus $\mathrm{NR}$, während die hohe $\mathrm{Mg}^{2+}$-Sensitivität von einem oder einigen Faktoren in den Blättern von Ricinus abhängt. Diese(r) bis jetzt unbekannte Faktor(en) war Hitze-sensitiv und konnte durch Ammoniumsulfat ausgefällt werden. Er scheint spezifisch auf die rekombinante Ricinus-NR einzuwirken, und liefert eine $\mathrm{Mg}^{2+}$-Sensitivität vergleichbar dem authentischen Blattenzym. Außerdem gibt es vermutlich auch positiv regulierende Faktor(en) für die Nitratreduktase aus Blättern höherer Pflanzen. 


\section{Introduction}

\subsection{Overview of nitrate assimilation in higher plants}

Nitrogen is one of the most important mineral elements that plants require. There are two routes of biological $\mathrm{N}$ acquisition: nitrate assimilation and nitrogen fixation. The nitrate assimilation pathway is the main entry for inorganic nitrogen which is later incorporated into organic compounds. Before entering the assimilation pathway, nitrate has to be taken up by the cell. Following its uptake from the soil by plant roots, nitrate is reduced to ammonium prior to assimilation into organic compounds.

The first step of this process is a two-electron reduction of nitrate to nitrite, catalyzed by nitrate reductase (NR; EC 1.6.6.1-3).

$$
\mathrm{NO}_{3}{ }^{-}+\mathrm{NAD}(\mathrm{P}) \mathrm{H}+\mathrm{H}^{+}+2 \mathrm{e}^{-} \rightarrow \mathrm{NO}_{2}^{-}+\mathrm{NAD}(\mathrm{P})^{+}+\mathrm{H}_{2} \mathrm{O}
$$

The second step is a six-electron reduction of nitrite to ammonium, catalyzed by nitrite reductase (NiR; EC 1.7.7.1).

$$
\mathrm{NO}_{2}^{-}+6 \mathrm{Fd}_{\text {red }}+8 \mathrm{H}^{+}+6 \mathrm{e}^{-} \rightarrow \mathrm{NH}_{4}^{+}+6 \mathrm{Fd}_{\mathrm{ox}}+2 \mathrm{H}_{2} \mathrm{O}
$$

Subsequently, ammonium is incorporated into amino acids, catalysed primarily by glutamine synthetase (GS) and glutamate synthase (GOGAT) (for reviews, see Crawford, 1995; Lam et al., 1996; Stitt, 1999).

\subsection{Overview of nitrate reductase}

Nitrate reductase is a complex enzyme containing several prosthetic groups. Recent data on 3D structure of NR (Lu et al., 1994; Campbell, 1996), once thought to contain only 3 domains, indicate that it actually contains 5 structurally distinct domains. From the $\mathrm{N}$-terminus to the C-terminus, these are: molybdenum cofactor (Moco), dimer interface, cytochrome $\mathrm{b}(\mathrm{Cb}), \mathrm{FAD}$ and NADH (Figure 1.1). When the FAD and $\mathrm{NADH}$ domains are combined, the cytochrome $\mathrm{b}$ reductase fragment $(\mathrm{CbR})$ is formed. If the $\mathrm{Cb}$ domain is connected to $\mathrm{CbR}$, it is called the cytochrome c reductase fragment $(\mathrm{CcR})$. On the other hand, there are three sequence regions with no similarity to another protein and varying in sequence among NRs. Those are the Nterminal regions, which are rich in acidic residues; Hinge 1, which contains a phosphorylation site and a trypsin proteolytic site; Hinge 2, which also contains a protease site. 


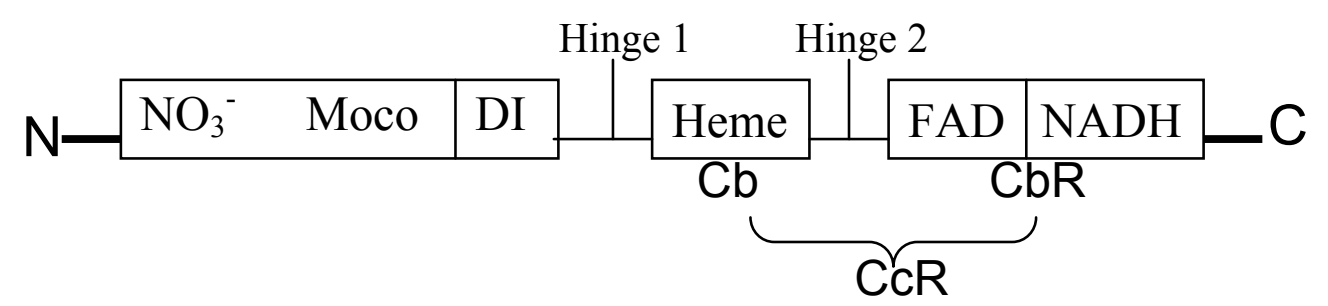

Figure 1.1 Sequence model of the enzyme. DI, dimer interface. (Campbell, 1999; modified)

The native enzyme is a homodimer or a homotetramer (in case of Chlorella) (Howard and Solomonson, 1982). In higher plants, the size of a monomer is ranging from 100 to $115 \mathrm{kDa}$. The intracellular location of NR is still discussed, but most evidence points to a cytosolic localization (for a review, see Solomonson and Barber, 1990).

The first higher plant NR cloned was from barley (Cheng et al., 1986) and later a number of Nia sequences (including cDNA and genomic DNA) have been identified from different organisms. Three forms of nitrate reductase have been found in eukaryotes. The most common form in higher plants is a NADH-specific NR (EC 1.6.6.1). A NAD(P)H-bispecific NR (EC 1.6.6.2) has been identified in several plants, existing as the sole isoform in Betula pendula (Friemann et al., 1991) or a second isoform along with the NADH-specific NR as in soybean and monocot species including maize, rice and barley (Kleinhofs and Warner, 1990). The third form is NADPH-specific (EC 1.6.6.3) which is present in fungi and in mosses.

In addition to catalyze the formation of nitrite from nitrate, NR also has a secondary function in that it catalyses the production of nitric oxide (NO) from nitrite, and of molecular oxygen to superoxide (Dean and Harper, 1988; Yamasaki and Sakihama, 2000). With the discovery of this novel function for NR, the biological significance of $\mathrm{NR}$ as a NO emitter and the induction of NR in response to pathogen attack or other stimuli known to induce NO production are drawing more and more attention in recent years.

\subsection{Regulation of NR}

Assimilatory nitrate reductase of higher plants is tightly regulated in a very complex manner. Some of the regulatory patterns are summarized in Figure 1.2. Nitrate 
reductase is regulated at both the transcriptional and the post-translational level. The regulation of NR expression by nitrate, light and carbohydrates, the mechanism of its post-translational modulation and the role of its $\mathrm{N}$-terminal domain in that regulation are described in the following sections.

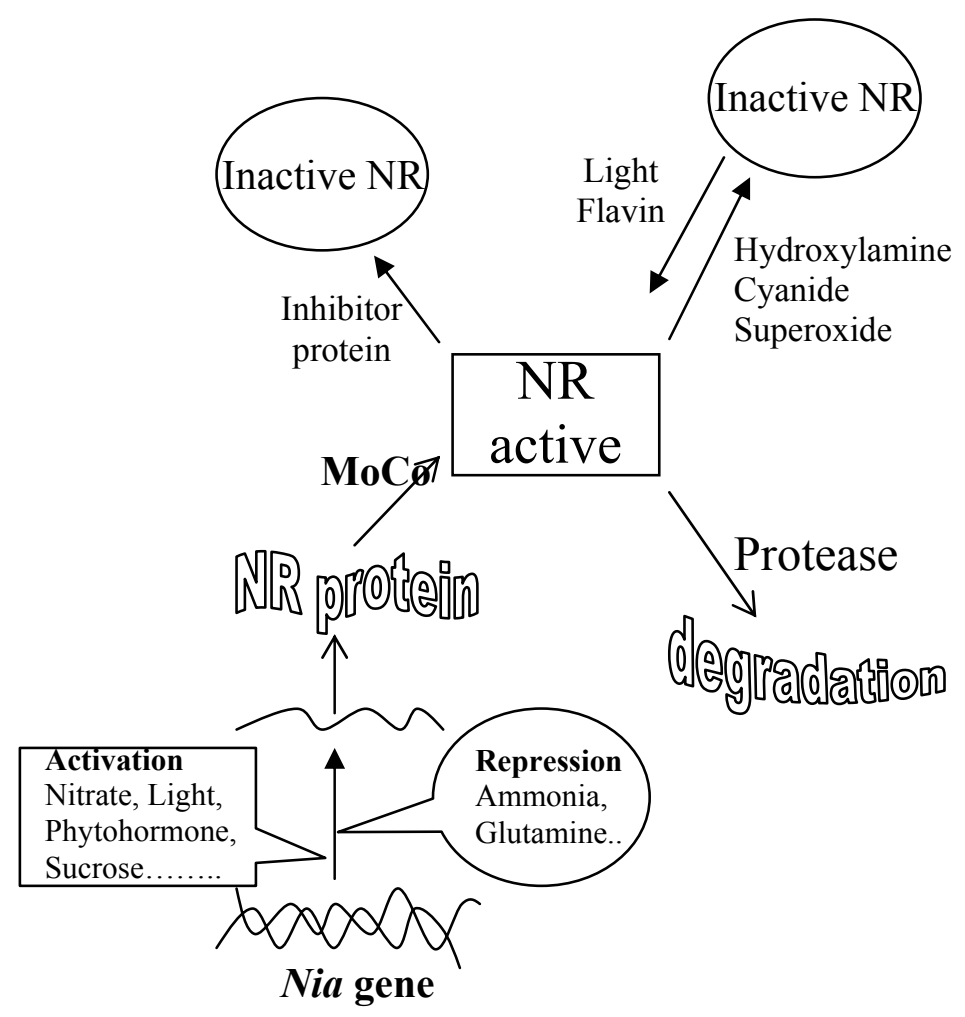

Figure 1.2 Schematic summary of the regulation of NR. The various signaling pathways include positive and negative effectors for gene expression and for posttranscriptional regulation, NR protein synthesis and degradation and Molybdenum cofactor (Moco) incorporation (Solomonson, 1990; modified).

\subsubsection{Transcriptional regulation of NR}

\subsubsection{By Nitrate}

As a signal, nitrate reprograms nitrogen and carbon metabolism and the expression of a selected group of genes (for reviews, see Crawford, 1995; Stitt, 1999; Tischner, 2000). It has been known for decades that nitrate uptake and nitrate reductase activity increase after adding nitrate. In the absence of nitrate, NR mRNA was not detected in leaves and only low levels were present in barley roots, but could be detected in roots and leaves within 40 min after supplying nitrate to roots (Melzer et al., 1989). Very recently, microarray and RNA gel blot analyses were performed to identify Arabidopsis genes that responded to nitrate. The overall finding was that genes involved directly or indirectly in nitrate and nitrite reduction were the most highly 
induced by nitrate. These results are not difficult to understand, because nitrite is toxic to plants and is usually not allowed to accumulate (Wang et al., 2000).

Pretreatment of seedlings with cycloheximide to block cytosolic protein synthesis did not prevent nitrate induction of Nia mRNA in maize leaves (Gowri et al., 1992). In the case of Arabidopsis, nitrate increased the transcription of both Nial and Nia2 genes. The 5' flanking regions of Nial deleted to -238 (NP1) and Nia2 deleted to -330 (NP2) were demonstrated to be sufficient to confer reporter gene expression comparable to that of the entire regions prior to deletion (Lin et al., 1994). A further identification of the positive nitrate-response elements within NP1 and NP2 by performing a linker-scanning (LS) analysis has been reported (Hwang et al., 1997). Additionally, a cis-acting element which is necessary for nitrate-dependent transcription has been found in the promoter of NR gene from birch (Strater and Hachtel, 2000).

\subsubsection{By Light and carbohydrates}

Light is a major factor enhancing expression of NR genes as well as of many carbon fixation genes at different levels. In many species, Nia mRNA was rapidly increased when etiolated plants or dark-adapted green plants were transferred to light.

In etiolated squash cotyledons, a red light pulse induced NR mRNA and a far-red light pulse reversed the induction (Rajasekhar et al., 1988). Blue light also induced NR mRNA accumulation in etiolated barley seedlings (Melzer et al., 1989). These limited findings suggest that light, acting via the photoreceptor phytochrome and perhaps the blue-light receptor plays a direct role in NR gene regulation in etiolated plants. However, Arabidopsis plants those were in continuous darkness for 16 days and were supplemented with sucrose, accumulated Nial mRNA to the same extent as those grown in light conditions. This is an indication that sucrose alone is sufficient to induce the full expression of the nitrate reductase gene in etiolated Arabidopsis plants. A subsequent exposure of the plants to light lead to no increase in Nial mRNA after $12 \mathrm{hr}$ of light treatment, some increase was observed after $24 \mathrm{hr}$ (Cheng et al., 1992). In green plants, the effect of light is quite different from that on the etiolated seedlings. Only white light, but not red or blue light, stimulated NR mRNA accumulation in barley seedlings (Melzer et al., 1989). Using dark-adapted green plants, the Arabidopsis Nial gene was induced by white light. Like in the case of etiolated plants, sucrose could replace light in eliciting an increase of Nial mRNA accumulation in 
dark-adapted green Arabidopsis plants (Cheng et al., 1992). Besides sucrose, glucose or fructose also induced NR mRNA as well as NR protein and activity in detached leaves of dark-adapted, sugar-depleted tobacco plants (Vincentz et al., 1993).

Vincentz and Caboche (1991) demonstrated that CaMV 35S-NR transgenic tobacco plants accumulated high levels of the transcript that was not affected by dark treatment, indicating that light indeed plays a role in transcriptional regulation of NR gene. Furthermore, a 2.7-kb region of the 5' flanking sequence of the Arabidopsis Nial promoter could confer the light and sucrose response (Cheng et al., 1992), and the tobacco Nial promoter expressed the reporter gene in a sugar-inducible way (Vincentz et al., 1993). More recently, the light-responsive region of NR promoter from birch was identified (Strater and Hachtel, 2000).

On the other hand, during a $24 \mathrm{hr}$ light-dark regime, it has been reported that both tomato and tobacco NR mRNA increased drastically before the end of the dark period and reached a maximum at the beginning of the day. At the end of the day, the level of NR mRNA was then markedly decreased. No obvious correlation was detected between levels of NR mRNA and NR activity (Galangau et al., 1988). A similar phenomenon was also found in maize leaves in which NR mRNA levels were low at the end of the dark period, peaked within $2 \mathrm{~h}$ in the light and decreased thereafter, whereas NR activity generally remained high (Huber et al., 1994). Apparently, the positive feed-forward induction of NR genes by sugars, and the negative feedback by nitrogen compound(s) from nitrate assimilation results in the diurnal oscillation of NR mRNA.

\subsubsection{Post-transcriptional regulation of NR}

\subsubsection{By nitrate}

In addition to the transcriptional control of NR genes by nitrate, NR activity is also affected by nitrogen availability at the post-transcriptional level. One example from earlier studies was that in tomato plants after $8 \mathrm{~d}$ of growth in the absence of nitrate, NR activity and protein decreased to lesser than $10 \%$ of the initial values, while Nia mRNA remained at a level close to normal (Galangau et al., 1988). More recently, tobacco suspension cells were used to determine the response of NR activity to exogenous nitrate levels. In this case, a long-distance transport of nitrate from roots to shoots is not required. The NR activity was found to increase as cell nitrate increased. The increase of NR activity appeared related, but not directly proportional, to the 
intracellular level of nitrate (Zhang and MacKown, 1993). On the other hand, when nitrate supply to barley plants stopped and the internal nitrate concentrations became extremely low, NR protein and activity decreased very drastically during the day (Man et al., 1999).

\subsubsection{By light and carbohydrates}

Kaiser and Förster (1989) demonstrated that nitrate reductase activity in spinach leaves was rapidly decreased within minutes when rates of photosynthesis were decreased, e.g. by closure of stomata, or after lowering the external $\mathrm{CO}_{2}$ concentration. . NR activity decreased rapidly to about $15 \%$ of the control with a halftime of only 2 min after darkening of spinach leaves (Riens and Heldt, 1992). This rapid response to darkness shifting might help plants to avoid a build-up of nitrite, which is toxic to the cells. The inactivation of $\mathrm{NR}$ in response to $\mathrm{CO}_{2}$-deficiency indicates that photosynthetic fixation of $\mathrm{CO}_{2}$ appeared necessary for maximal NR activity (Klepper et al., 1971; Kaiser and Brendel-Behnisch, 1991). Additionally, $\mathrm{CO}_{2}$ enrichment markedly elevated nitrate reductase activity in young, but not old, tobacco plants, presumably because growth rates were much greater in the younger plants and they needed the extra nitrogen provided by this phenomenon to maintain their heightened level of development (Geiger et al., 1998). The demonstration that light is an effective regulator of NR at the post-translational level by reversible protein phosphorylation (Kaiser et al., 1992; Huber et al., 1994), has been a major breakthrough in our knowledge on NR regulation. Thus, more details on this aspect are given below.

\subsubsection{Mechanism of the post-translational regulation of NR in higher plants}

A remarkable discovery in recent years has been the demonstration that in vivo NR activity is rapidly modulated by reversible protein phosphorylation and 14-3-3binding in the presence of divalent cations (Figure 1.2; for reviews, see Kaiser and Huber, 2001; MacKintoch and Meek, 2001; Kaiser et al., 2002). 


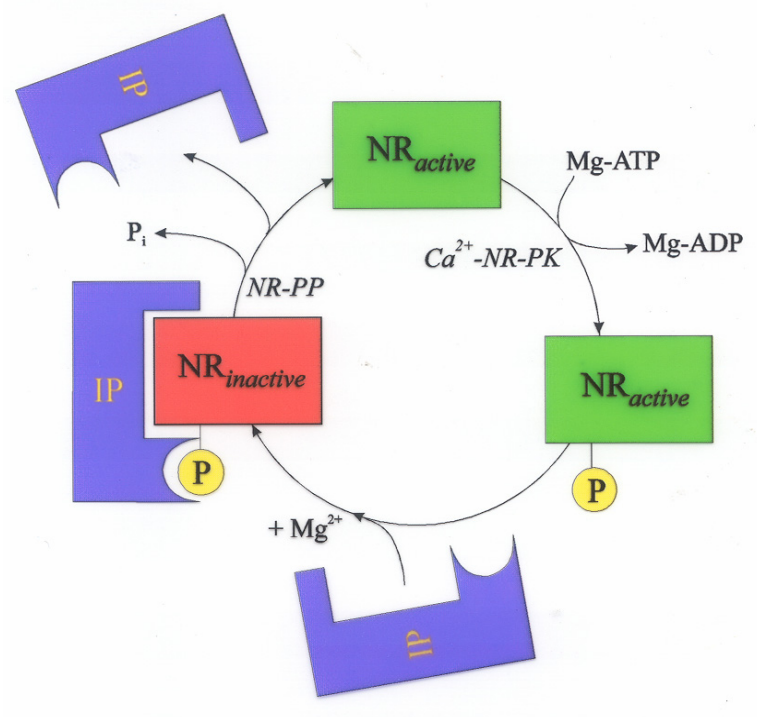

Figure 1.3 Post-translational regulation of NR. Explanations in the text.

As already mentioned, NR activity in leaf extracts was rapidly reduced when plants were transferred to darkness or to low $\mathrm{CO}_{2}$ and $\mathrm{NR}$ activity was restored when the light was turned on or when plants were brought back to normal $\mathrm{CO}_{2}$ levels (Kaiser and Brendle-Behnish, 1991). Subsequently, Kaiser and Spill (1991) found out that NR was probably regulated by reversible protein phosphorylation. They further found that phosphorylation of NR per se was not sufficient for its inactivation, and two proteins were partially purified that appeared involved in the ATP-dependent inactivation process (Spill and Kaiser, 1994). In 1995, a protein termed "inhibitor protein (IP)" or "NR inhibitor protein (NIP)" was found, eluting with about $70 \mathrm{kDa}$ from a sizing column (Bachmann et al., 1995; Glaab and Kaiser, 1995; MacKintosh et al., 1995). The "NR inhibitor protein" inactivated only phospho-NR, and this inactivation required divalent cations. After immunopurification and sequencing of a tryptic peptide, IP was identified for the first time as a member of the eukaryotic 14-3-3 protein family (Bachmann et al., 1996a). Meanwhile, many studies highlight how phosphorylation inhibits NR activity, by identifying the regulatory phosphorylation site in the NR molecule and by determining the association between 14-3-3s and spinach phospho-NR in an isoform specific manner (Douglas et al., 1995; Bachmann et al., 1996b and 1996c; Moorhead et al., 1996; Su et al., 1996). Hence, a two-step regulation model of spinach NR was proposed (compare figure 1.3). According to this 
model, spinach NR is first phosphorylated on Ser-543, which is conserved among higher plant NRs, by a $\mathrm{Ca}^{2+}$-dependent NR-kinase (Douglas et al., 1997 and 1998) and then becomes inactivated upon binding of 14-3-3s in the presence of divalent cations. Therefore, in the presence of $\mathrm{mM}$ concentrations of free $\mathrm{Mg}^{2+}$, the remaining enzymatic activity represents that of the native free $\mathrm{NR}\left(\mathrm{NR}_{\mathrm{act}}\right)$. In contrast, with excess EDTA, no 14-3-3-binding occurred and the measured activity therefore reflects the total amount of $\mathrm{NR}\left(\mathrm{NR}_{\max }\right)$. Originally it appeared that $14-3-3 \mathrm{~s}$ bind directly to phosphoserine and divalent cations promote this binding (Athwal et al., 2000). However, it is not yet certain, whether divalent cations are required for 14-3-3 binding to phospho-NR, or whether they are needed for switching the complex from an active into an inactive form or both (Weiner and Kaiser, 2000).

\subsubsection{The role of the $\mathrm{N}$-terminal domain in $\mathrm{NR}$ regulation}

Most of the NR protein sequence is well conserved among higher plants and other organisms, apart from the N-terminal region, which varies both in sequence and length among species. Therefore, to elucidate the potential role of the N-terminal domain in higher plants may contribute to unravel the complex networks of NR regulation.

It has been shown that a tobacco NR with an internal deletion of 56 amino acids in the $\mathrm{N}$-terminal domain (termed $\Delta \mathrm{NR}$ ) was no longer regulated by light-dark transition. Placing wild-type and transgenic plants $\mathrm{C1}$ (transformed with CaMV 35S-NR construct) or $\mathrm{del}$ (transformed with CaMV 35S- $\Delta \mathrm{NR}$ construct) in the dark for $30 \mathrm{~min}$ revealed that in vivo inactivation by darkness occurred in wild-type and $\mathrm{C} 1$, but was completely absent in $\triangle \mathrm{NR}$ plants. Moreover, in vitro inactivation by MgATP was also abolished in $\Delta$ NR plant extracts (Nussaume et al., 1995). However, $\Delta$ NR appeared to be phosphorylated in the dark and endogenous 14-3-3 proteins could copurify with both NR and $\triangle$ NR (Lillo et al., 1997; Provan et al., 2000), indicating that they bound to both forms.

Loss of the first 45 amino acids by proteolysis during purification of spinach NR resulted in an enzyme that could no longer be fully inhibited by 14-3-3-binding, although the truncated enzyme could be phosphorylated by NR kinase on Ser-543 at the same rate as intact NR (Douglas et al., 1995).

The 56 amino acid region within the N-terminal domain of NR contains an "acidic stretch" conserved only in higher plants. Removal of the acidic stretch led to an active 
enzyme which was more thermosensitive than the wild-type NR, but it was relatively insensitive to the inactivation by phosphorylation in the dark. The acidic stretch seemed to be required but not sufficient for the inactivation of NR (Pigaglio et al., 1999). In addition, the deletion of 56 amino acids in the N-terminal domain showed that NADH to $\mathrm{CcR}$ activity (needs active FAD and heme-binding domains, compare Figure 1.1) was similar in $\mathrm{C} 1$ and del plants, but the terminal activity (associates with the MoCo-binding domain) was inactivated, indicating that the $\mathrm{N}$-terminal region may be important for stabilizing the Moco-binding domain (Provan et al., 2000).

Taken together, these data suggest that the N-terminal region of NR is in some way involved in and is required for the inactivation of the enzyme by phosphorylation. However, the exact role of this region is still under debate.

\subsection{An exceptional example from Ricinus}

Ricinus communis, or Castor Bean, is not a true bean, but a member of the spurge family or Euphorbiaceae. It is a very fast growing plant, it habitats ranging from cool temperate through tropical desert to wet forest life zones. Ricinus is reported to tolerate annual temperatures of 7.0 to $27.8^{\circ} \mathrm{C}$ and a wide range of soil $\mathrm{pH}$ from 4.5 to 8.3 (Duke, 1983).

In a previous study, NR from leaves and roots of hydroponically grown Ricinus behaved differently from all other NR studied so far (Kandlbinder et al., 2000). So far, NRs from different taxa of higher plants followed the light-dark transition or the diurnal fluctuation pattern, in which both $\mathrm{NR}_{\text {act }}$ and $\mathrm{NR}_{\max }$ were low during the night and increased during the first half of the day, with a significant decrease during the second half. In Ricinus, however, $\mathrm{NR}_{\max }$ (indicating total active $\mathrm{NR}$ protein) underwent a similar pattern as, for example, spinach NR, whereas $\mathrm{NR}_{\text {act }}$ was always extremely low with only little difference in light and dark. Therefore, the resulting activation state $\left(\mathrm{NR}_{\mathrm{act}} \times 100 / \mathrm{NR}_{\max }\right)$ of Ricinus $\mathrm{NR}$ was always very low, usually less than $10 \%$ of $\mathrm{NR}_{\max }$ throughout the day.

Secondly, Ricinus NR had a different pH-profile in comparison with spinach NR. $\mathrm{NR}_{\text {act }}$ in extracts from Ricinus was strongly increased by $\mathrm{pH}$ values below 7 , and was extremely low at $\mathrm{pH} \geq 7.3$. This effect was actually caused by $\mathrm{pH}$-dependent changes in the $\mathrm{Mg}^{2+}$-sensitivity of Ricinus NR. At pH 7.6 and $\mathrm{pH} 6.8,50 \%$ inhibition of NR in spinach leaf extracts occurred at $3 \mathrm{mM}$ and $1 \mathrm{mM} \mathrm{Mg}^{2+}$, respectively. With Ricinus 
leaf extracts, $50 \%$ inhibition was obtained at less than $0.2 \mathrm{mM} \mathrm{Mg}^{2+}$ at $\mathrm{pH} 7.6$, but 5 $\mathrm{mM} \mathrm{Mg}^{2+}$ was required at $\mathrm{pH} 6.8$.

Moreover, NR from spinach and other plants can be rapidly inactivated in vitro in the presence of MgATP. As described above, this inhibition requires protein kinase and 14-3-3s. However, preincubation of Ricinus NR with MgATP gave very little additional inactivation. Removal of $14-3-3 \mathrm{~s}$ by partial purification of NR, which activates NR from spinach, did not activate Ricinus NR. When $\mathrm{pH}$ values above 7 , Ricinus NR appeared very $\mathrm{Mg}^{2+}$-sensitive and this high $\mathrm{Mg}^{2+}$-sensitivity does not require 14-3-3's binding as in other plant NRs. On the other hand, peptide antisera against the sequence around serine 543 of the spinach-NR cross-reacted with Ricinus NR indicating that Ricinus NR possesses the same potential 14-3-3 binding motif as spinach NR. Therefore, the molecular basis and the physiological relevance for the deviating properties of the Ricinus enzyme are not yet understood.

\subsection{Objective of this thesis}

The basic objective of this thesis was to elucidate the reasons behind the unusual regulatory properties of nitrate reductase from Ricinus communis L. both with respect to molecular and physiological aspects

For that purpose, the first aim of this study was to clone the NR gene from Ricinus and eventually use a heterologous expression system to study the molecular properties of Ricinus NR, and to investigate the following problems:

\section{(1) Does the primary sequence of Ricinus NR differ from other NRs?}

Once the Ricinus NR gene was obtained, its deduced amino acid sequence could be used for sequence alignments to predict whether Ricinus NR would contain any unusual motifs or unique residues. For example, is the N-terminus of Ricinus NR sufficiently different from other NRs to provide its unresponsiveness to MgATP (as in the N-terminally deleted tobacco mutants where the ATP inactivation is abolished; Nussaume et al., 1995)? Furthermore, does a potential 14-3-3 binding motif exist in the Ricinus NR sequence, as already indicated by immunological studies? 
(2) Heterologous expression of Ricinus NR in Pichia pastoris

Transformation of the Ricinus NR gene into a heterologous expression system would provide an easy way to purify this enzyme for functional and regulatory studies. In addition, a heterologous expression system would be also advantageous for mutagenesis experiments.

\section{(3) Characterization of recombinant Ricinus NR}

Biologically similar recombinant NR's (e.g. Arabidopsis) expressed in Pichia could be used for a comparison with Ricinus NR from the same expression system. This would provide insight whether the different features of Ricinus NR are based on the NR protein itself or on some other factors. 


\section{Results}

\subsection{Molecular cloning of NR gene from Ricinus}

\subsubsection{The primary Ricinus NR gene sequence obtained by RT-PCR}

A partial Ricinus NR cDNA was obtained by RT-PCR (reverse transcriptionpolymerase chain reaction). The main limitation of this technique is the need for precise sequence information from the target gene for the design of specific and efficient PCR primer. Therefore, based on sequence comparison we choose two regions where the amino acid sequences are entirely identical in 10 different NRsequences. The deduced protein sequences of these two regions are "IGGRMVKW" and "GMMNNCWF" which locate at 316 to 323 and 484 to 491 in spinach, respectively. The Ricinus communis' codon usage was subsequently used to backtranslate these amino acid sequences into nucleotide sequences and for the design of sense-primers. RT-PCR with RcNR-S1 (backtranslate from IGGRMVKW) and an appropriate antisense-primer from Arabidopsis Nial sequence yielded a cDNAfragment of the expected size of ca. $440 \mathrm{bp}$ (Figure 2.1). Subsequently, this PCR product was cloned and sequenced and compared to database entries. The sequence shared high homology with NR known from many higher plants in the GenBank.

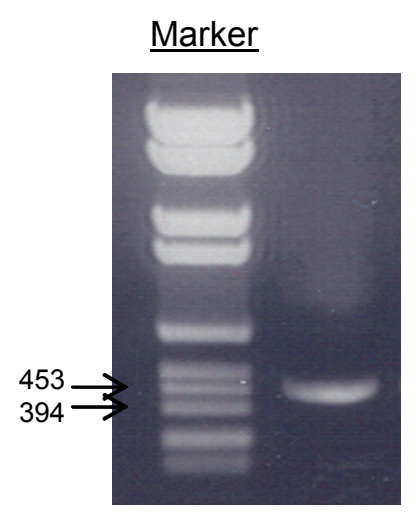

Figure 2.1 A cDNA fragment of Ricinus NR gene was amplified by RT-PCR. Total RNA was used as the template for reverse transcription. Combination of the specific sense-primer for Ricinus NR gene and an antisense-primer from Arabidopsis Nial gene revealed a ca. 440 bp cDNA fragment. The first lane is a DNA-marker with two indicated fragments, 453 and $394 \mathrm{bp}$. 


\subsubsection{The Full-length Ricinus NR gene}

Since the primary sequence of NR from Ricinus is known, we used so-called 5'-

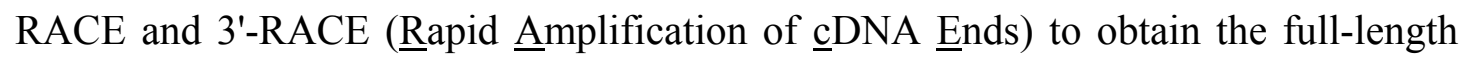
Ricinus NR cDNA. 25mer gene specific primers for 5'-RACE (RcNR-AS-RACE) and 3'-RACE (RcNR-S-RACE) PCR reaction were chosen from the partial Ricinus cDNA sequence mentioned above. Total RNA from Ricinus leaves was used as starting material for the amplification of full-length cDNA (Figure 2.2).

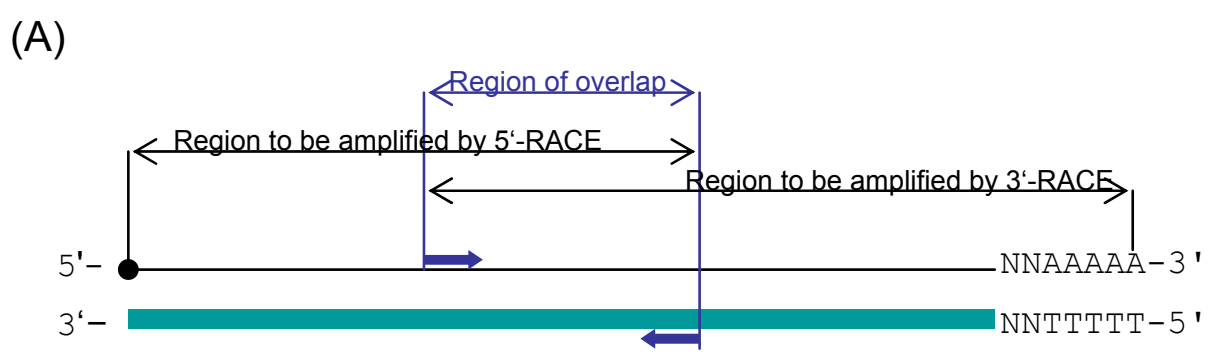

(B)

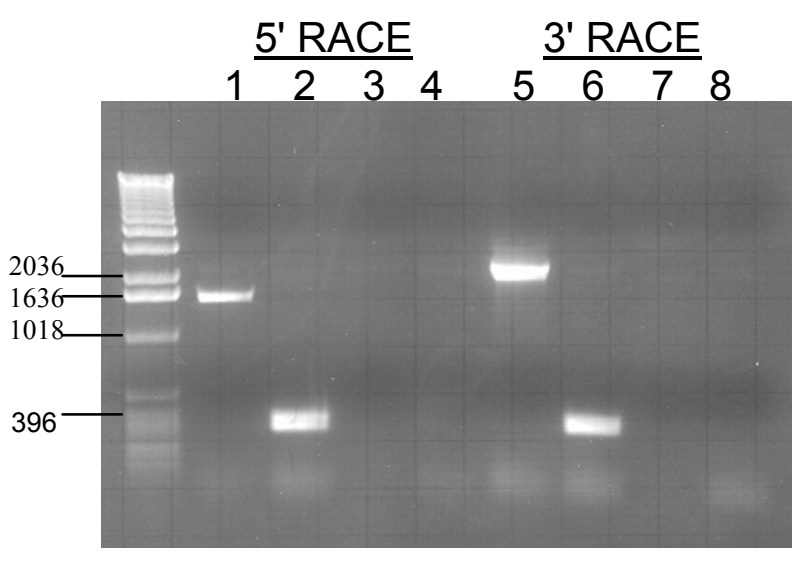

Figure 2.2 Amplification of Ricinus NR cDNA fragments by 5'-RACE and 3'RACE PCR reaction. (A) Schematic representation of the relationship of gene specific primers to the cDNA template. (B) Analysis of PCR products from RACE. Lane 1 and lane 5 represent the Ricinus NR cDNA fragments amplified through 5'and 3'-directions. Lane 2 and 6 show the overlapping region amplified by the gene specific primers. Lane 3, 4, 7 and 8 are the negative control which used only one of the primer pairs used in 5'- and 3'-RACE. DNA-markers with indicated sizes are shown on the left side.

Combination of the cDNA fragments amplified by 5'-RACE and 3'-RACE revealed a length of 3021 nucleotides. An open reading frame of 914 amino acids was encoded, starting with the sequence MAASV that is conserved throughout all higher plant 
nitrate reductases (Miyazaki et al., 1991) except NRs from maize (Zea mays, MSTCV), Arabidopsis NR1 (MATSV) and Brassica napus (MATSV).

\subsubsection{Analysis of the deduced amino acids sequence}

Searching for the ORF of the Ricinus NR sequence against the Conserved Domain Database with the RPS-BLAST program revealed that Ricinus NR can be divided into distinct functional domains that bind a molybdenum-pterin cofactor (Moco), heme-Fe or FAD (flavin adenine dinucleotide) as in other higher plants. In Ricinus NR, the three prosthetic domains Molybdenum-MPT, heme-Fe and FAD are located at amino acid positions 92 to 321,536 to 612 and 661 to 768 and are composed of 230, 77 and 108 amino acids, respectively (Figure 2.3).

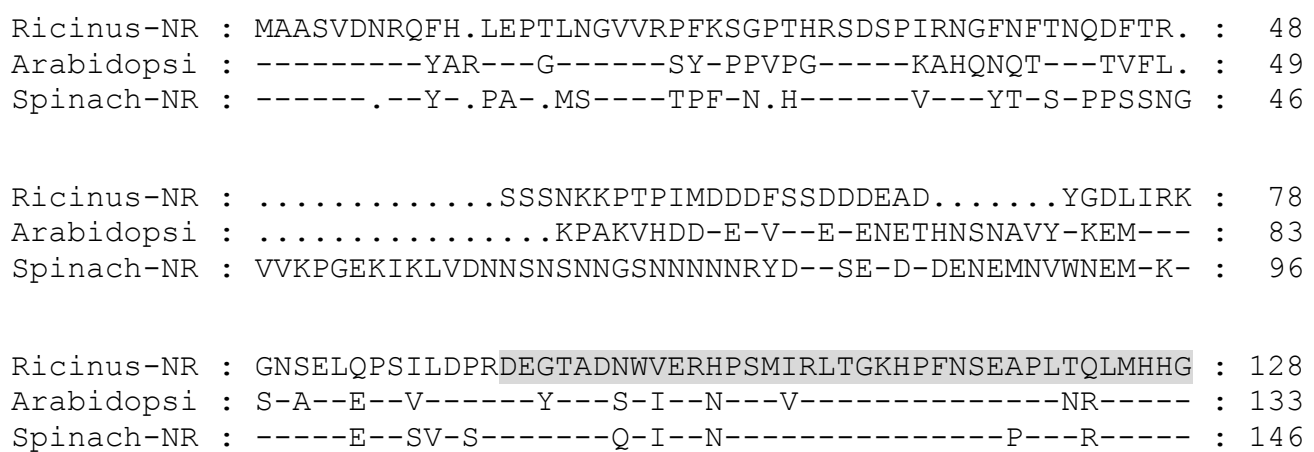

Ricinus-NR : RVLPSHVDAELANAEAWWYKPEYIINELNINSVITTPSHEEVLPINSWTT : 375 Arabidopsi : -----L------DE-G------------------C---I----AF-- : 383 Spinach-NR : -----------S-----Q-------V-----S-C---I----A--- : 393

Ricinus-NR : QRPYTLKGYAYSGGGKKVTRVEVTMDGGDTWQVCSLDHPEKPNKYGKYWC : 425 Arabidopsi : ------------------------V---E--N--A---Q--------F-- : 433 Spinach-NR : -----MR--------R-------------DI-E---Q-RGS----F-- : 443 


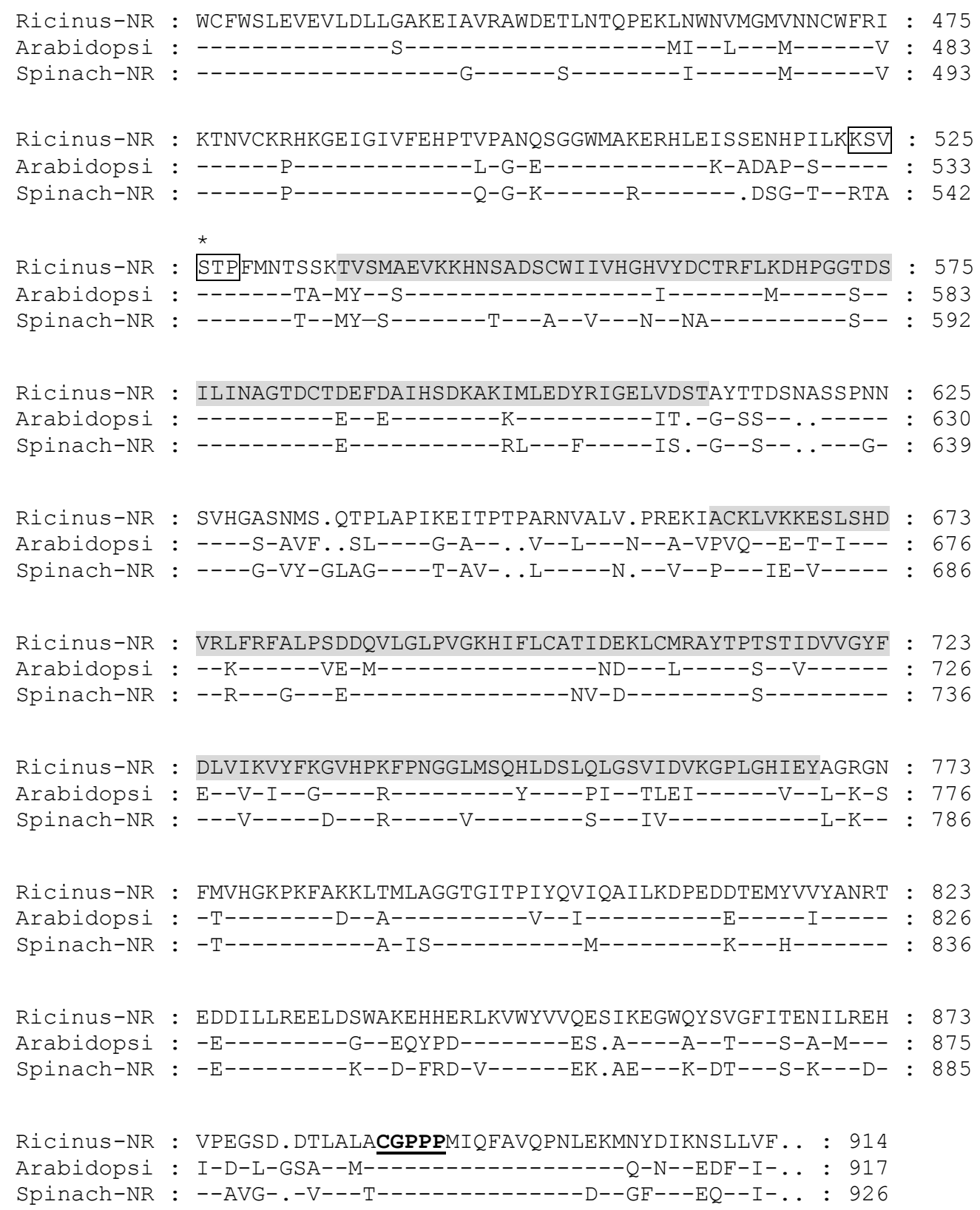

Figure 2.3 Deduced amino acid sequences alignments. Amino acid sequences of Arabidopsis NR2 and spinach NR were compared to Ricinus NR (GenBank accession number AF314093). Like other plant NRs, Ricinus NR consists of three prosthetic domains which are marked by a shadow. The Mo-MPT domain with the nitratereducing site spans from 92 to 321, the cytochrome b domain from 536 to 612 and the FAD domain from 661 to 768 . Identical sequences are indicated by a dash, and gaps introduced for alignment purposes by a dot. Amino acids in a block represent the 143-3 binding motif, where the phosphorylated serine residue is marked by an asterisk. A sequence involved in the character for a NADH:NR is underlined.

The deduced amino acid sequence showed that Ricinus NR mRNA encodes a protein of $102.8 \mathrm{kDa}$ with a high degree of similarity to NRs from other higher plants. The 
highest similarity was found to the NR amino acid sequence from winter squash (78\% identity, $87 \%$ similarity), petunia (78\% identity, $86 \%$ similarity), tomato (77\% identity, $87 \%$ similarity) and tobacco (78\% identity, $87 \%$ similarity). Moreover, Ricinus NR shared 75\% identity (85\% similarity) with Arabidopsis NR2 or spinach NR and $73 \%$ identity (84\% similarity) with Arabidopsis NR1.

In contrast to the larger part of the sequence, the N-terminal regions of the NR sequences varied considerably (see Appendix 6.5). The molybdenum-MPT domain of Ricinus NR for example contains a cysteine residue (Cys-186) which is present in all eukaryotic NRs and is a part of a highly conserved region ${ }^{183}$ TLVCAGNRRKEQNM $^{196}$ (Figure 2.3). This key residue has been proposed to provide a ligand to molybdenum in the Moco binding region and is essential for NR activity (Barber and Neame, 1990; Solomonson and Barber, 1990; Garrett and Rajagopalan, 1994; Garde et al., 1995; Su et al., 1997).

In the hinge region between molybdenum-MPT and heme-Fe domains, Ricinus NR possesses a conserved phosphorylation serine residue (Ser-526), which is within the 14-3-3s binding motif ${ }^{523} \mathrm{KSVS}^{*} \mathrm{TP}^{528}$ (Figure 2.3). This confirmed the result from our previous immunodecoration experiment where peptide antisera against the sequence around serine 543 of the spinach-NR cross-reacted with Ricinus NR (Kandlbinder et al., 2000). Moreover, within the FAD domain Ricinus NR possesses the motif ${ }^{886} \mathrm{CGPPP}^{890}$, characteristic for NADH-specific NRs (Schöndorf and Hachtel, 1995). In NAD(P)H NR-forms such as those of barley and birch only two proline residues are present (CGPPA). It has been demonstrated that substitution of a proline by alanine in the birch NAD(P)H-NR greatly increased preference for NADH. In the case of Ricinus NR, we have tested whether the recombinant enzyme could utilize NADPH as the reductant, but the recombinant protein had no NADPH:NR activity (not shown).

\subsection{Heterologous expression of RcNR in Pichia pastoris}

\subsubsection{Construction}

The full-length cDNA of Ricinus NR (RcNR) was cloned into the pPICZA Pichia pastoris expression vector using Sac II and Apa I restriction enzyme sites. The plasmid was further transformed into E. coli for replication. The first evidence for the successful construction of pPICZA-RcNR clone was using gene and vector specific primers to check the construct by PCR (Figure 2.4). 
(A)

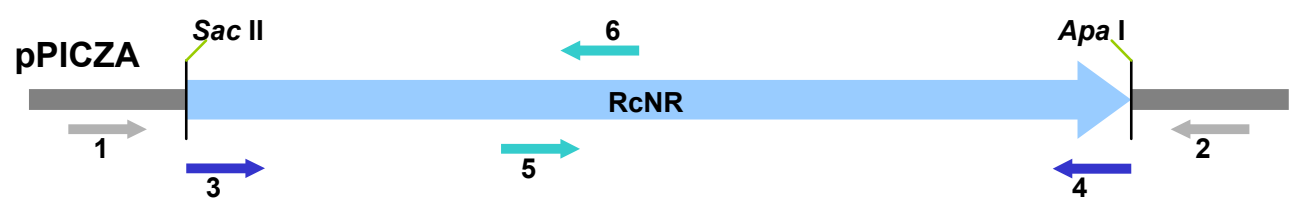

(B)

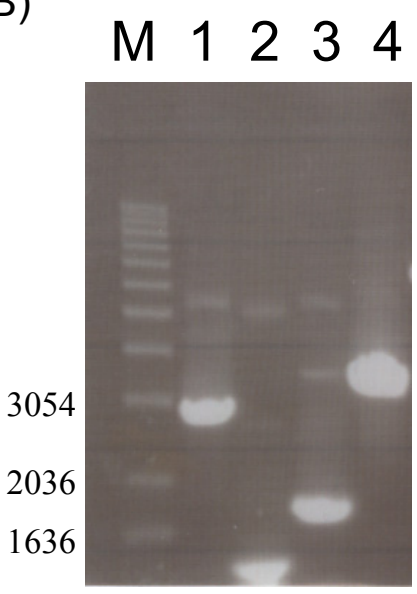

Figure 2.4 Determination of the construct pPICZA-ReNR by PCR. Primers specific for the Ricinus NR gene and the vector pPICZA were chosen to perform the PCR reaction using the plasmid pPICZA-RcNR as the template. (A) Schematic representation of the construct pPICZA-RcNR and the positions of the primers. (B) Analysis of the PCR products using 1\% agarose gel. M: DNA-marker. More details in the text.

Primers 1 and 2 (5' and $\left.3^{\prime} A O X I\right)$ were vector specific which would amplify a DNA fragment of $2977 \mathrm{bp}$ (see lane 4, Figure 2.4 B). Primers 3 to 6 were specific for the Ricinus NR gene. Combination of primers 3 and 4 (RcNR-SF-2 and RcNR-ASF) revealed a full-length RcNR DNA fragment of 2764 bp (lane 1, Figure 2.4 B). Using internal gene specific primer 5 (RcNR-S-RACE) together with primer 4 amplified a DNA fragment of $1736 \mathrm{bp}$ (lane 3, Figure $2.4 \mathrm{~B}$ ). Another combination of primer 3 and 6 (RcNR-AS-RACE) amplified a DNA fragment of 1344 bp (lane2, Figure 2.5 B). These precise DNA fragments amplified by gene and vector specific primers confirmed that the construct was successfully created.

The second evidence was the digestion pattern of the plasmid by Nco I restriction enzyme. Ricinus NR cDNA contains 3 Nco I restriction enzyme sites as well as one in pPICZA vector. Therefore, after Nco I digestion it would reveal 4 DNA fragments if the construct was correct (Figure 2.5). The predicted size of 4 DNA fragments is 2928, 
1968, 874 and $291 \mathrm{bp}$ (which is in total $6061 \mathrm{bp}$ ), respectively. Analysis of the digestion mixture revealed that 4 DNA fragments were precisely produced by Nco I digestion.

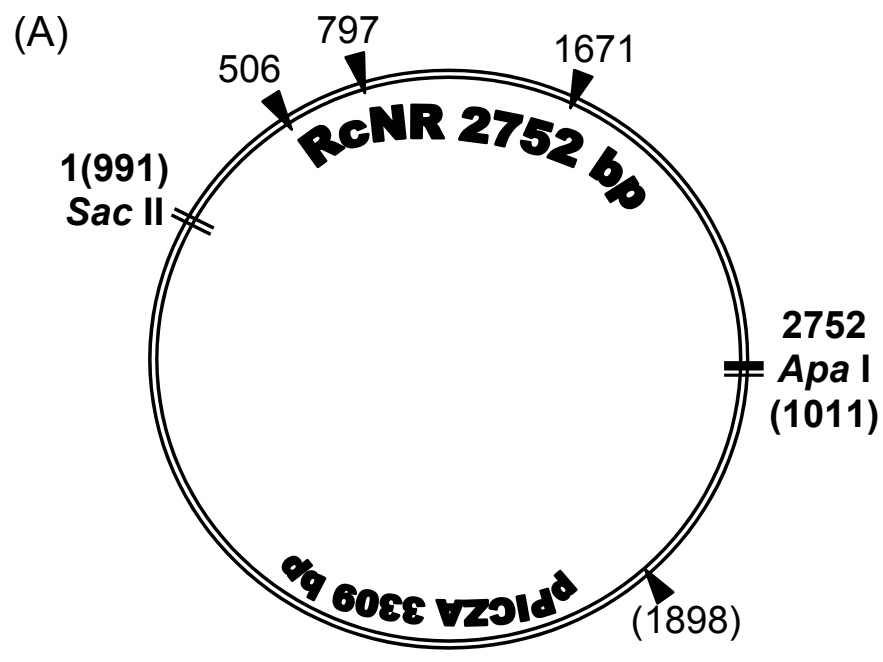

(B)

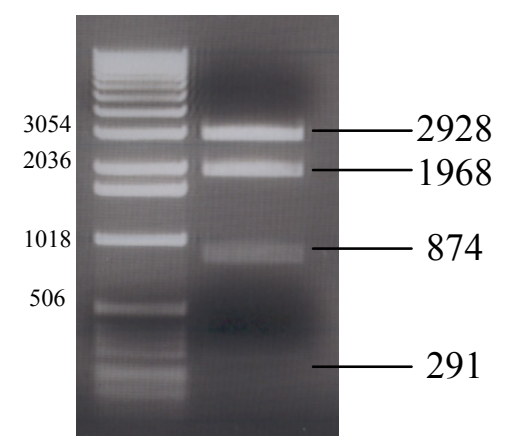

Figure 2.5 Nco I restriction enzyme digestion of the construct pPICZA-RcNR. Panel A illustrated the restriction enzyme sites of Nco I in the pPICZA-RcNR construct. Triangles labeled with numbers represent Nco I enzyme sites. Numbers with or without brackets indicate the positions corresponding to the pPICZA and RcNR sequence, respectively. Panel B showed the verification of DNA fragments after digestion of Nco I in 1\% agarose gel. Sizes of the DNA-marker and the PCR fragments are indicated.

In addition to the evidence mentioned above, the construct was also sequenced by using appropriate sequencing primers. The partial sequence of the construct obtained from the sequencing revealed that the cloning process was successful. It is noteworthy that in the construct a yeast consensus sequence was added to the RcNR sequence 
right before the initiation ATG. This sequence is necessary for the yeast to initiate the translation and also appeared in the partial sequence (not shown).

\subsubsection{Transformation}

Having confirmed the correct construct pPICZA-RcNR, it was then linearized with Sac I restriction enzyme, transformed in $P$. pastoris to be integrated into the $P$. pastoris genome. At this stage, a direct PCR screening was used to identify whether the transformation was accomplished. Pichia transformants were tested for insertion of the Ricinus NR gene by using 5'- and $3^{\prime}-A O X 1$ sequencing primers located at the vector pPICZA, as well as the internal gene specific primers (Figure 2.6).

The unique $S a c$ I restriction site would permit linearization of the construct at the $A O X 1$ locus for efficient integration into the Pichia genome. After the digestion of Sac I restriction enzyme, the construct was linearized and revealed a total length of 6061 bp (Figure 2.6A). This linearized plasmid was then used for transformation by using chemically produced competent Pichia cells and yielded 12 colonies. It is worth to mention that this alternative to electroporation is rapid and convenient but the transformation efficiency is low ( $3 \mu \mathrm{g}$ plasmid DNA yields about 50 colonies). Genomic DNA of Pichia transformants, in the case of direst PCR screening, was used as the template and tested by PCR. The internal gene specific primers and 5'- and 3'$A O X 1$ sequencing primers should amplify DNA fragments of 1344 and $2977 \mathrm{bp}$, respectively (Figure $2.6 \mathrm{~B}$ and $\mathrm{C}$ ). However, using 5'- and $33^{\prime}-A O X 1$ sequencing primers, an additional DNA fragment of about $2 \mathrm{~kb}$ was also amplified. No homologous sequence to $5^{\prime}$ - and $3^{\prime}-A O X 1$ sequencing primers was found in the Ricinus NR gene. 


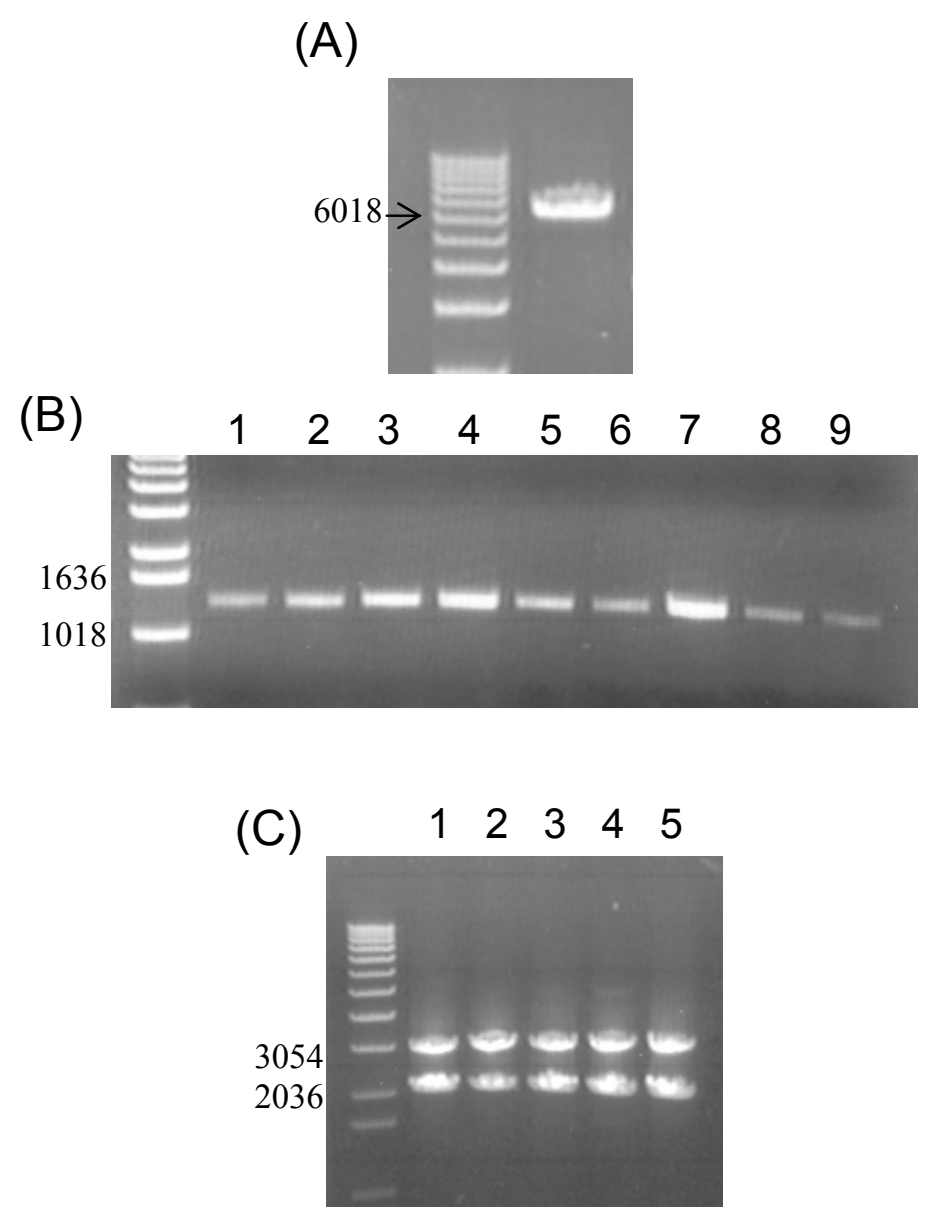

Figure 2.6 Linearization of the construct pPICZA-RcNR and direct PCR screening of Pichia clones. Pichia cells were lysed by a combined enzyme, freezing and heating treatment. The genomic DNA was used directly as a PCR template. (A) Linearized construct with Sac I restriction enzyme before transformation. (B) After transformation, Pichia transformants 1 to 9 were tested for the insertion of RcNR by using internal gene specific primers. (C) Selected Pichia clones 1 to 5 were further tested, using 5'- and $3^{\prime}-A O X 1$ sequencing primers.

\subsubsection{Expression}

The $P$. pastoris alcohol oxidase promoter $(A O X 1)$, which is inducible by methanol and produces alcohol oxidase up to $30 \%$ of total soluble protein, was used to drive the expression of NR cDNA. During a $72 \mathrm{hr}$ induction period, transformants were collected for checking protein expression levels by SDS polyacrylamide gel electrophoresis (SDS-PAGE). However, proteins produced were not detected in a Coomassie-stained SDS-PAGE. Indeed, we always observed only an extremely weak Ricinus NR protein signal in the predicted molecular weight (MW) region, but very strong signals appeared in the lower MW region on the SDS-PAGE. Moreover, using 
different peptide antisera to perform western blots revealed no successful results so far. One of the antisera raised against the maize NR peptide (PAESDNYYHFKDNRVLPSC) could recognize purified maize NR but failed to cross-react with recombinant Ricinus NR and Arabidopsis NR2, which was expressed in the same system. We also tried the other antisera raised against the spinach NR peptide (CGPTLKRTADTPFMNTTS), however, no signals of the predicted size for both, recombinant Ricinus and Arabidopsis NRs were detected.

In order to test whether $P$. pastoris transformed with the NR expression plasmid pPICZA-RcNR could produce a functional enzyme, NR activity was measured in yeast cells (in vivo). Pichia transformants were induced with methanol within a $72 \mathrm{hr}$ induction period. Pichia transformed with plasmid pPICZA-RcNR showed NR activity, whereas $P$. pastoris containing only a control expression plasmid (pPICZA) had no such activity throughout the induction period (Figure 2.7 ). The in vivo activity was compared with the recombinant Arabidopsis NR2 from the same system but using a different expression vector.

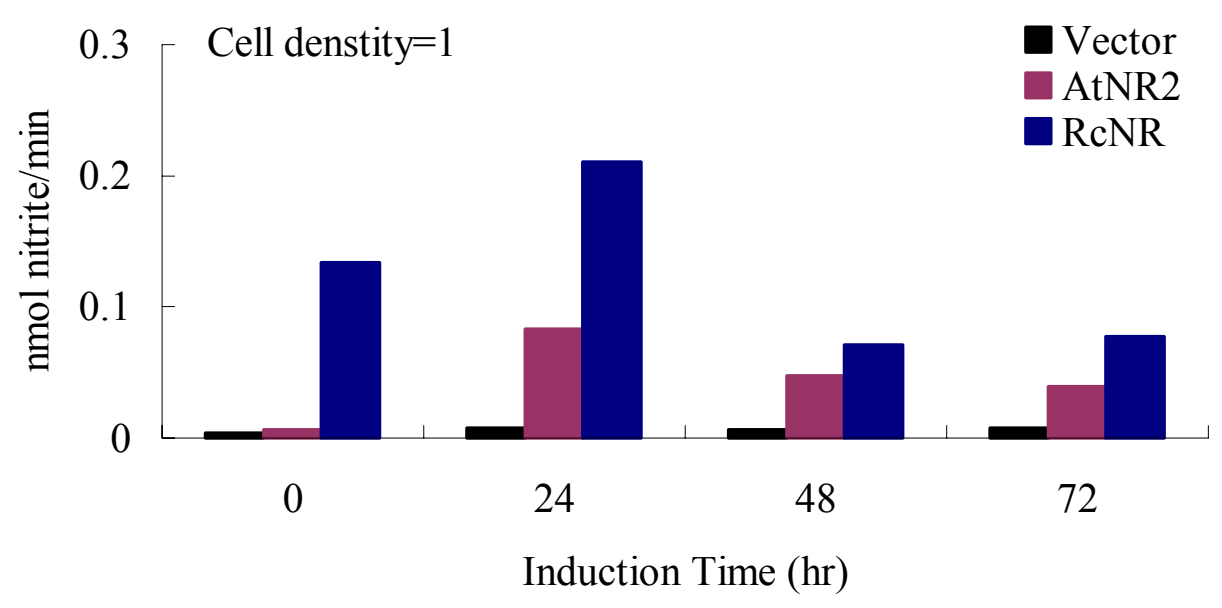

Figure 2.7 NR activity in yeast cells (in vivo). Pichia transformed with NRs from either Arabidopsis (pHILD2-AtNR2) or Ricinus (pPICZA-RcNR) and the expression vector ( $\mathrm{pPICZA}$ ) were tested for the NR activity in vivo. After incubation of the cell suspension $\left(\mathrm{OD}_{600}=1\right)$ with substrate $(50 \mathrm{mM} \mathrm{KNO} 3)$, the nitrite content in the medium was visualised with the Griess Reagent.

Before transferring Pichia transformed with the plasmid pPICZA-RcNR to the induction medium to induce expression, the Ricinus NR gene was already expressed 
in the glycerol medium (Time 0 ). The regulation of the $A O X 1$ gene is a two step process: a repression/derepression mechanism plus an induction mechanism. Growth on glycerol derepresses transcription, and is therefore optimal for induction with methanol. Theoretically, growth on glycerol alone (before induction) is not sufficient to express low levels from the $A O X 1$ gene. Only methanol is able to induce detectable levels of $A O X 1$ expression. However, a recently successful expression of tobacco NR in Hansenula Polymorpha using the MOX1 promoter also gave some expression in glycerol (personal communication). Thus, the expression of the Ricinus NR in glycerol medium could indicate that the promoter was not as tightly regulated as expected in our case.

As already mentioned, nitrate reductase also catalyses the $\mathrm{NAD}(\mathrm{P}) \mathrm{H}$-dependent reduction of nitrite to nitric oxide (NO). Therefore, $\mathrm{NO}$ emission can be used as an on-line indicator of a functional NR in Pichia transformants in vivo (Figure 2.8).

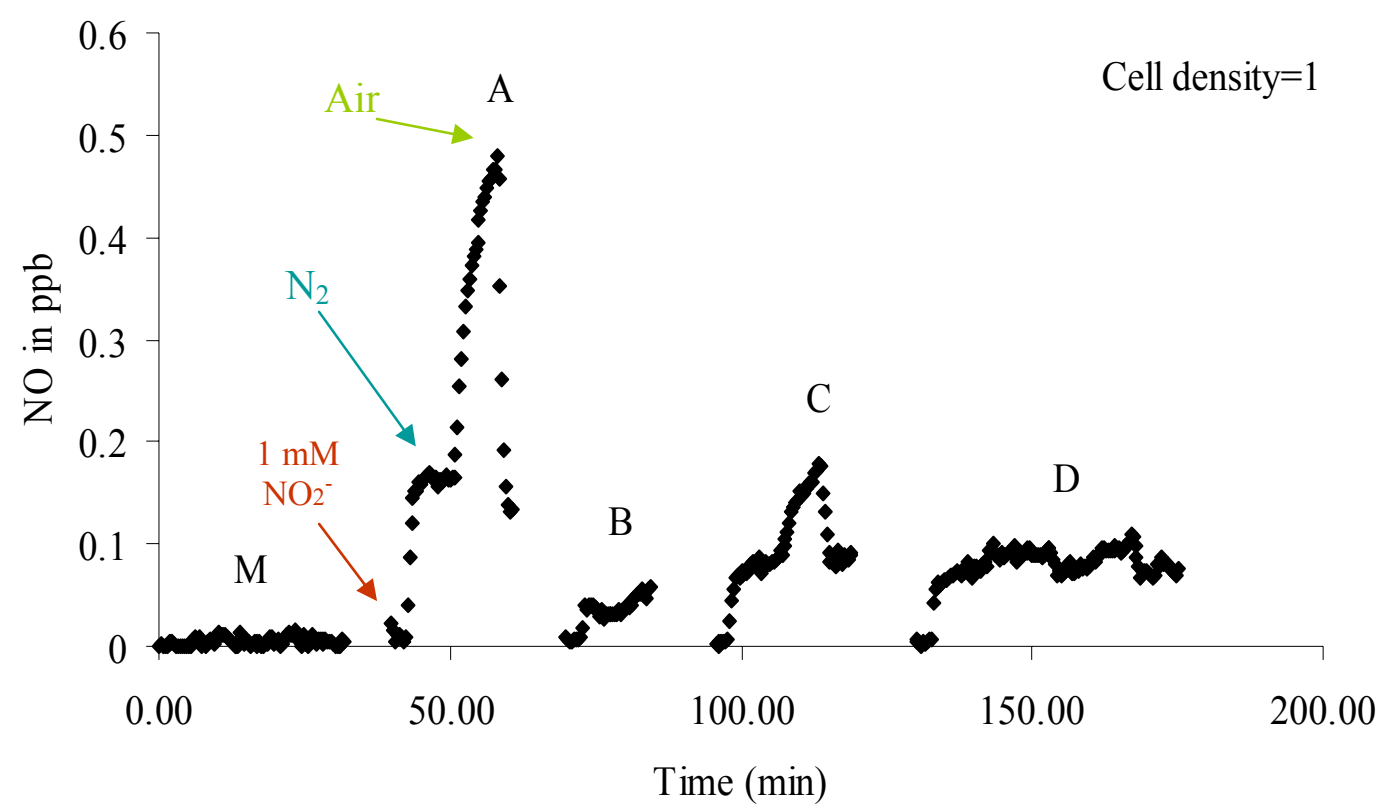

Figure 2.8 NO emission of Pichia transformants (in vivo). Pichia strains A, B, C and $\mathrm{D}$ were used to measure NO emission in the gas phase. The plasmid transformed into Pichia GS115 strain were pHILD2-AtNR2 (A), pPICZ-lacZ (B), pPICZA-RcNR (C) and pPICZA (D). M indicates the growth medium. Continuous NO-emission was measured after transfer the transformants to the induction medium for $48 \mathrm{~h}$ and each 1 $\mathrm{mM}$ nitrite was added as a substrate first in air, followed by incubation in nitrogen and subsequently by a second period in air. 
Pichia cells transformed with Arabidopsis Nia 2 gene and Ricinus NR gene produced NO right after adding of $1 \mathrm{mM}$ nitrite into the cell culture. Artificial activation of leaf NR by anoxia drastically increased NO production especially in the dark (Rockel et al., 2002). When switching back from anoxia to aerobic condition, NO emission decreased again. This typical pattern for NO emission was observed with both transformants (Figure 2.8 A and C). In contrast, Pichia clones which expressed the lac $Z$ gene or which were transformed only with the expression vector did not produce NO under the same experimental conditions. NO emission is thus an easy in vivo test system to check for a successful expression of functionally competent recombinant Arabidopsis NR2 and Ricinus NR.

\subsection{Characterization of recombinant Ricinus NR}

\subsubsection{Modulation of NRs from plant leaves}

NR from spinach and other plants can be rapidly inactivated in vitro in the presence of MgATP. This inhibition requires protein kinase and 14-3-3s. Before investigating the recombinant NRs, we first compared the ATP-dependent inactivation of NR in extracts from illuminated leaves of Arabidopsis, spinach and Ricinus (Table 1). Among these three plants, spinach NR was strongly inactivated by ATP, whereas Ricinus and Arabidopsis NR were only 9 to $25 \%$ inactivated. The initial activation state (AS) of NR in illuminated Arabidopsis and spinach leaf extracts was $70 \%$ and $80 \%$, but only $40 \%$ or less in Ricinus (Kandlbinder et al., 2000).

Table 1. ATP-dependent inactivation of NR in extracts from illuminated leaves of Arabidopsis, Spinach and Ricinus in vitro. $\mathrm{NR}_{\mathrm{act}}$ and $\mathrm{NR}_{\max }$ represent the activities in the presence of either $10 \mathrm{mM} \mathrm{Mg}{ }^{2+}$ or $10 \mathrm{mM}$ EDTA. Activation state (AS) in percentage corresponds to $\mathrm{NR}_{\text {act }} \times 100 / \mathrm{NR}_{\max }$. For further details see experimental procedures.

\begin{tabular}{|c|c|c|c|}
\hline & Arabidopsis $^{\mathrm{a}}$ & Spinach $^{\mathrm{a}}$ & Ricinus $^{\mathrm{a}}$ \\
\hline $\begin{aligned} \mathrm{NR}_{\text {act }} & \\
& -\mathrm{ATP} \\
& +\mathrm{ATP}\end{aligned}$ & $\begin{array}{l}4.0 \pm 0.5 \\
3.0 \pm 0.5\end{array}$ & $\begin{array}{l}9.2 \pm 1.3 \\
3.0 \pm 0.3\end{array}$ & $\begin{array}{l}6.5 \pm 0.8 \\
5.9 \pm 1.5\end{array}$ \\
\hline $\begin{aligned} & \mathrm{NR}_{\max } \\
&-\mathrm{ATP} \\
&+\mathrm{ATP} \\
&\end{aligned}$ & $\begin{array}{l}5.6 \pm 0.7 \\
5.9 \pm 0.7\end{array}$ & $\begin{array}{c}11.0 \pm 1.5 \\
9.4 \pm 1.2 \\
\end{array}$ & $\begin{array}{l}14.8 \pm 2.3 \\
14.9 \pm 2.7 \\
\end{array}$ \\
\hline $\begin{array}{r}\text { AS (\%) } \\
- \text { ATP } \\
+ \text { ATP }\end{array}$ & $\begin{array}{l}71 \\
51\end{array}$ & $\begin{array}{l}84 \\
32\end{array}$ & $\begin{array}{l}44 \\
40\end{array}$ \\
\hline
\end{tabular}




\subsubsection{Modulation of NRs from yeast cells}

Having determined the response to ATP in the authentic plant NRs, Table 2 demonstrates that neither recombinant Arabidopsis NR2 (AtNR2) nor recombinant Ricinus NR (RcNR) alone could be inactivated by ATP in crude yeast extracts. This might indicate that no suitable kinases exist in P. pastoris extracts, because 14-3-3 proteins are common in yeasts and are able to bind to phosphorylated spinach NR in vitro (Moorhead et al., 1996). Next, NR-free plant leaf extracts were added to the recombinant NR's in order to add suitable protein kinase(s). AtNR2 showed about 5\%, $45 \%$ and $15 \%$ of ATP-dependent inactivation in mixture with Arabidopsis darkened leaf extracts (ADL), spinach darkened leaf extracts (SDL) and Ricinus darkened leaf extracts (RDL), respectively. Moreover, $\mathrm{NR}_{\mathrm{act}}$ and $\mathrm{NR}_{\max }$ of AtNR2 were increased when mixing with NR-free extracts from leaves, but the activation states were not changed much (Table 2). In the case of the RcNR, only mixing with SDL gave a slight inhibition by MgATP. Surprisingly, the RcNR activity in the presence of $\mathrm{Mg}^{2+}$ $\left(\mathrm{NR}_{\mathrm{act}}\right)$ was dramatically decreased by incubation with RDL (with or without ATP) but not with SDL and $\mathrm{ADL}$, whereas $\mathrm{NR}_{\max }$ remained similar. Hence, the activation state dropped remarkably only when RcNR was mixed with RDL and this low activation state was similar to that of the authentic leaf enzyme, and independent of ATP. 


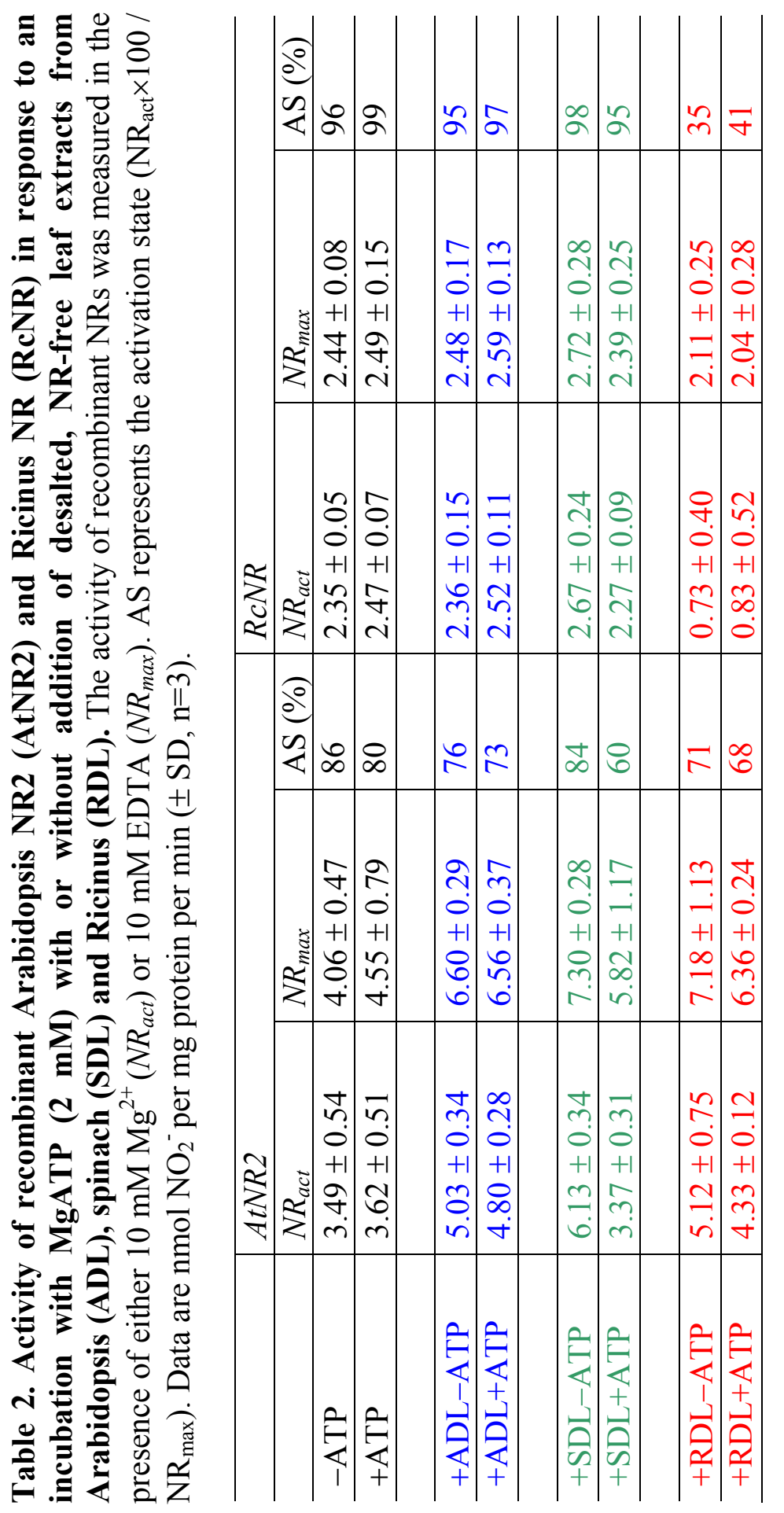




\subsubsection{RcNR has a high $\mathrm{Mg}^{2+}$-sensitivity when mixed with NR-free extracts from} Ricinus leaves at pH 7.6, but not at pH 6.5

In a previous study, nitrate reductase in extracts from hydroponically grown Ricinus leaves showed different sensitivity to $\mathrm{pH}$ and $\mathrm{Mg}^{2+}$ compared to spinach $\mathrm{NR}$. $\mathrm{NR}_{\mathrm{act}}$ from spinach had a broad optimum between $\mathrm{pH} 6.5$ and $\mathrm{pH} 7.5$, whereas $\mathrm{NR}_{\text {act }}$ from Ricinus had a distinct optimum around $\mathrm{pH} 6.5$, and activity was very low at $\mathrm{pH}$ values above pH 7.3 (Kandlbinder et al., 2000). According to these findings, we also tested RcNR with regard to this unusual property. Figure 2.9 shows the time course of RcNR $\mathrm{NR}_{\max }$ and $\mathrm{NR}_{\mathrm{act}}$ alone or after addition of a desalted, NR-free leaf extract from Ricinus (RDL). In general, no $\mathrm{Mg}^{2+}$ inhibition of the RcNR was observed without RDL. Incubation of RcNR with RDL at pH 6.5 increased both, $\mathrm{NR}_{\max }$ and $\mathrm{NR}_{\text {act. }}$. However, at $\mathrm{pH} 7.6$, the mixture of RcNR plus RDL gave almost the same $\mathrm{Mg}^{2+}$ sensitivity found with the authentic leaf extract. When AtNR2 was assayed under the same experimental conditions ( $\mathrm{pH}$ 7.6), no such $\mathrm{Mg}^{2+}$ inhibition was observed. Taken the 10 -min reaction into account, the $\mathrm{Mg}^{2+}$ inhibition caused by RDL incubation was about 60\% (Figure 2.9B), which is consistent with the result shown in Table 2.

Apparently Ricinus leaves contain a factor which specifically interacts with RcNR, providing the properties of the native NR enzyme in leaves.
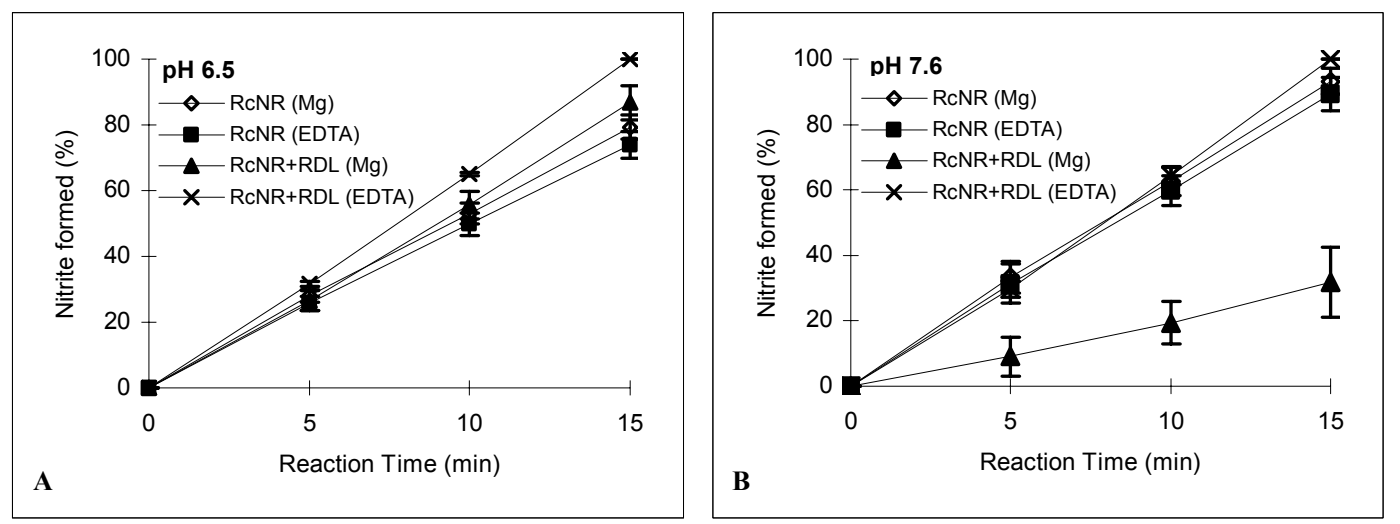

Figure 2.9 Effect of desalted crude extract from darkened Ricinus leaf (RDL) on $\mathbf{N R}_{\text {max }}$ and $\mathbf{N R}_{\text {act }}$ of recombinant Ricinus NR (RcNR). Reaction time for NR activity assays is as indicated. Vertical axis represents the nitrite formation. $100 \%$ corresponds to 22.1 and $21.5 \mathrm{nmol} \mathrm{NO}_{2}{ }^{-}$per mg protein for $\mathrm{pH} 6.5$ (a) and $\mathrm{pH} 7.6$ (b), respectively. Data are means \pm SD from 3 for $\mathrm{pH} 6.5$ or 4 for $\mathrm{pH} 7.6$ independent experiments. More details in the text. 
We further tested whether the " $\mathrm{Mg}^{2+}$-sensitivity factor" was inactivated by boiling. Figure 2.10 shows that once the RDL was briefly boiled, the effect on $\mathrm{NR}_{\text {act }}$ was eliminated. However, the supernatant of the boiled RDL somehow activated the recombinant enzyme activities, both in $\mathrm{Mg}^{2+}$ and EDTA. The same phenomenon also occurred with recombinant Arabidopsis NR2, indicating that this effect was not specific for Ricinus NR. Since the supernatant of the boiled RDL contains only low molecular weight solutes, it will be interesting to find it out which component was stimulatory.

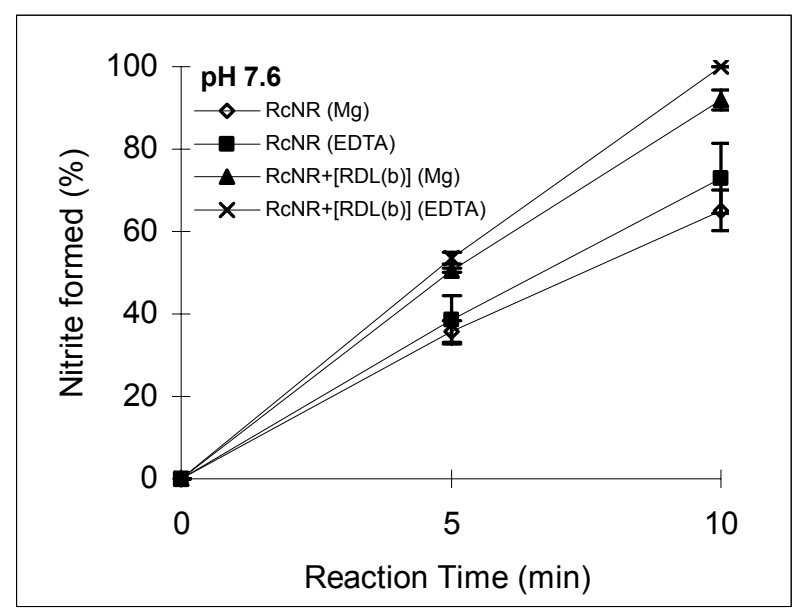

Figure 2.10 Effect of the supernatant from boiled, desalted crude extracts of NRfree Ricinus leaves [RDL(b)] on recombinant Ricinus NR (RcNR) at pH 7.6. RDL was briefly boiled $(2 \mathrm{~min})$ before adding into reactions. The nitrite formation was given by relating to the nitrite content of the 10-min time point of RcNR (EDTA). Reaction time for NR activity assays and the symbol for each line as indicated. The means and standard deviations of 3 replicates are given.

\subsubsection{Protein fractionation by ammonium sulfate}

Ricinus leaves obviously contained one or several protein factor(s) which restored the high $\mathrm{Mg}^{2+}$-sensitivity which was lost for the recombinant Ricinus NR. In a first attempt to separate such factor(s) from the crude extract, ammonium sulfate fractionation was applied providing some crude purification of proteins. A step from 0 to $35 \%(\mathrm{w} / \mathrm{v})$ of ammonium sulfate (Fraction 1) indeed pulled down the protein factor(s) responsible for the high $\mathrm{Mg}^{2+}$-sensitivity of RcNR (Figure 2.11). However, the remaining protein fraction precipitating between 35 to $53 \%$ ammonium sulfate 
(Fraction 2) also had some effect on RcNR. Brief boiling of the proteins again eliminated the effect. Interestingly, the stimulation of RcNR activity by the supernatant from boiled RDL (without ammonium sulfate fractionation) was abolished when using the supernatants from boiled Fraction 1 and 2.

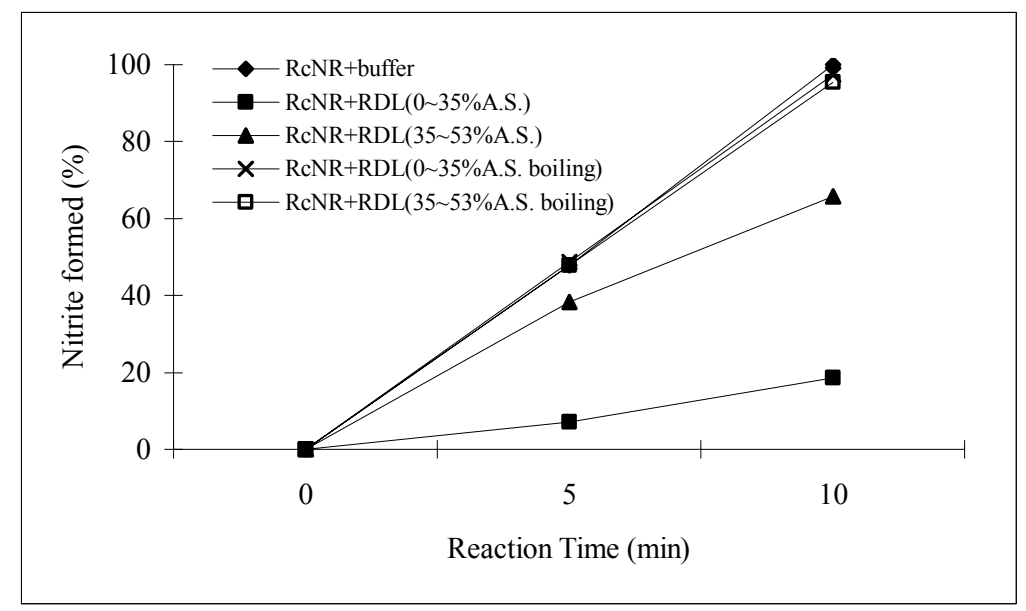

Figure 2.11 Effects of ammonium sulfate precipitation of Ricinus darkened leaf extracts on RcNR. Ricinus darkened leaf extracts (RDL) were precipitated by $0-35 \%$ (Fraction 1) and 35-53\% ammonium sulfate (AS) (Fraction 2). Pellets were resuspended in the extraction buffer followed by brief boiling or without that. Protein content of two fractions was measured. About $0.7 \mathrm{mg}$ of proteins from each fraction was used for each measurement. All reactions were carried out in $10 \mathrm{mM} \mathrm{MgCl} 2$ for the indicated time. Data are mean values of two separate experiments.

We also checked how much of Fraction 1 was required to saturate the response of RcNR to $\mathrm{Mg}^{2+}$ (Figure 2.12).

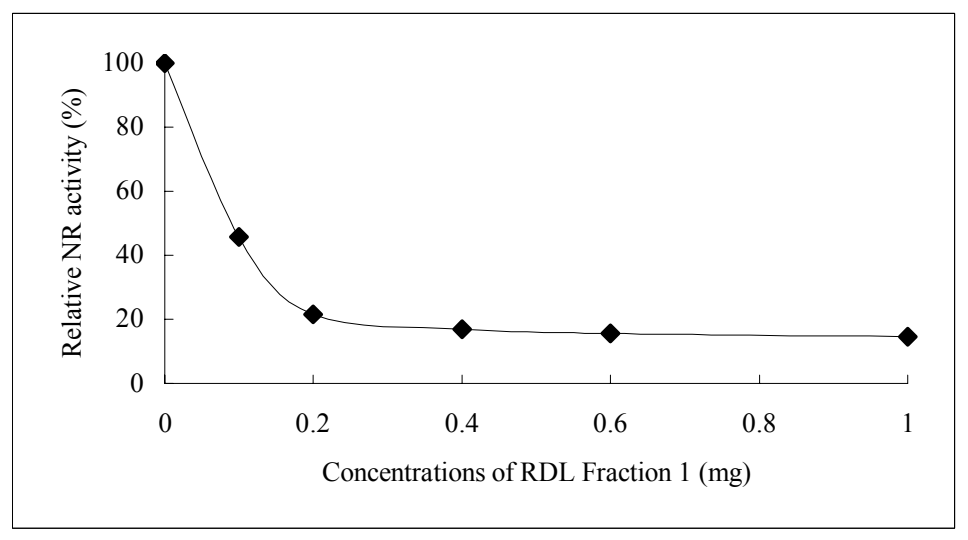

Figure 2.12 Effects of different concentrations of RDL Fraction 1 on RcNR. After $0-35 \%$ of ammonium sulfate precipitation (Fraction 1), protein was diluted in $10 \mathrm{mM}$ $\mathrm{Mg}^{2+}$ buffer to give the concentrations indicated. 
It is obvious that $0.1 \mathrm{mg}$ of Fraction 1 could provide a marked inhibition of RcNR. Moreover, $0.2 \mathrm{mg}$, which is equal to $0.02 \%(\mathrm{w} / \mathrm{v})$, already caused maximum inhibition. 


\section{Discussion}

\subsection{Deduced protein sequence of Ricinus NR}

A multi-alignment of all available NR sequences with related proteins and enzymes revealed that 21 specific residues out of 917 in Arabidopsis NR2 were invariant and played key roles NR functions (Meyer et al., 1991; Dwivedi et al., 1994; LaBrie and Crawford, 1994; Lu et al., 1995; Su et al., 1996 and 1997; Campbell, 1999). Our sequence analysis showed that Ricinus NR shares major similarities with other plant NRs and no drastic differences were identified, apart from the N-terminal region. The 21 key residues found in Arabidopsis NR2 were entirely preserved in Ricinus NR (Appendix 6.4). However, there are some differences existing in Ricinus NR, if carefully analyzing the sequence alignment data, which might give some hints on structural features responsible for the unusual regulatory properties (compare Appendix 6.5 and 6.6).

\subsubsection{The N-terminus}

In spite of the disputed role of the N-terminus in NR, the comparison of this region from Ricinus NR with other higher plant NRs revealed that some interesting features (Appendix 6.5). As already mentioned, there is an acidic stretch conserved only in plant NRs. The character of this acidic stretch is two or three consecutive Ser residues followed by some Glu and Asp residues. Such a sequence is reminiscent of a consensus CK II (casein kinase II) phosphorylation site (S/TXXE/DX; Pearson and Kemp, 1991) and appears to be efficiently phosphorylated by human CK II in vitro (Pigaglio et al., 1999). In Ricinus NR the consensus Ser (position 58) was missing which was also absent in squash, chicory and monocots like barley, rice and maize (Appendix 6.5). Interestingly, using a program for inferring phylogenies revealed that Ricinus NR was most close to squash and chicory (discussed in 3.4). However, it is unknown whether this Ser is important for NR phosphorylation in Ricinus.

Additionally, it has been shown that a tobacco NR with an internal deletion of 56 amino acids in the N-terminal domain is no longer inactivated by MgATP (Nussaume et al., 1995). Since Ricinus leaf NR was insensitive to ATP, the variant N-terminal region might contribute. 


\subsubsection{The Moco-binding Region}

The prosthetic Moco-binding region is located at amino acid position 92 to 321 in Ricinus NR. It has been shown that NR is phosphorylated on multiple sites (Huber et al., 1992; LaBrie and Crawford, 1994; Huber et al., 1994); therefore, the highly conserved Ser residues in this region could be sites for NR phosphorylation. Sequence comparison of the Moco domain revealed that Ricinus NR possesses those highly conserved Ser residues (Ser211, 253, 258, 316, 357, 387 and 430) as Arabidopsis NR2 does. A recent study on site-directed mutagenesis of these Ser residues of Pichia-expressed Arabidopsis NR2 showed that none of these Ser residues are essential for the in vitro inhibition (Su et al., 1997). On the other hand, Ricinus NR did contain some unique amino acid residues when compared with other plant NRs (Appendix 6.6). For example, there is a His 103 (basic amino acid residue) in Ricinus NR where all other NRs have aspargine (polar amino acid with uncharged R group) instead. In addition, Gln123 (others: Arg), Cys157 (most of others: Thr), Asn212 (others: Thr), Val266 (others: Asp) and Ala284 (others: Pro) were found to be the specific residues in Ricinus NR. These amino acid residues might have an influence on the incorporation of Moco into the prosthetic domain. To date, very little is known about how Moco becomes incorporated into NR. One crystallograohic analysis of the Mo-enzyme suggests that the cofactor is deeply buried within the holo-enzyme so that Moco could only have been incorporated prior to or during completion of folding and dimerization of the apoprotein (Kisker et al., 1997; Enroth et al., 2000). Nevertheless, more investigations are required in order to find out whether these amino acid residues also play a role in the regulation of Ricinus NR.

\subsubsection{The Hinge 1 Region}

The potential 14-3-3 protein binding motif is located in Hinge 1 region of NR. It has been reported that the 14-3-3 protein binds directly to the regulatory phosphorylation site on phospho-NR (Bachmann et al., 1996c). Therefore, either the compounds which can interact with 14-3-3s such as divalent ions or AICAR or the sequence expanded outside the 14-3-3 binding region may influence 14-3-3 binding (Athwal et al., 1998ab). If numbering the Ser526 of Ricinus NR as the position 0, the sequence alignments revealed that Ricinus NR has an alanine (Ala540) at position +14 where all other NRs have a serine residue (Appendix 6.6). In addition to that, the amino acid residues at minus positions (up to -18) also showed a possible role in the binding of 
NR to the 14-3-3 protein (Athwal et al., 1998b). We found that an alanine (Ala498) instead of glycine positions at -28 is unique in Ricinus NR.

Taken together, the sequence within this region of Ricinus NR showed some interesting characters. So far, we have no evidence whether 14-3-3 proteins indeed interact with NR in Ricinus. With respect to the observations mentioned above, it is likely that the interaction between Ricinus NR and 14-3-3s is different from other NRs.

\subsection{Heterologous expression of Ricinus NR}

Expression of full-length Ricinus NR in Pichia pastoris resulted in a functional enzyme. However, the levels of protein produced were not detected in a Coomassiestained SDS-PAGE. As a matter of fact, we always observed strong signals in the lower molecular weight region $(70-80 \mathrm{kDa})$. This could be caused by inappropriate treatment of protein samples, or recombinant RcNR itself was protease sensitive. Interestingly, in the Hinge 1 region of Ricinus NR a residue Arg482 which provides an additional predicted Trypsin cleavage site within ${ }^{481} \mathrm{KRHK}^{484}$ (while most of plantNRs possess KPHK) was found (Appendix 6.6). On the other hand, in recent work on heterologously expressed tobacco NR in the yeast Hansenula polymorpha the recombinant protein was also not detected on SDS-PAGE (Perdomo et al., 2002). This may indicate that only low levels of plant NRs were produced in yeasts. Moreover, the activities obtained in vitro from the recombinant Ricinus NR (RcNR) and the same system expressing Arabidopsis NR2 (AtNR2) were 2 to 4 nmol nitrite per mg protein per min, which are also very similar to tobacco NR expressed in a nitrate assimilatory yeast, Hansenula polymorpha (Perdomo et al., 2002).

\subsection{Characterization of recombinant ReNR}

\subsubsection{In vitro inactivation by ATP}

One of the unusual characters of authentic Ricinus NR was its insensitivity to preincubation with ATP (Kandlbinder et al., 2000), which contrasted sharply with the situation in spinach and other plants (Kaiser and Spill, 1991; Huber et al., 1994). It has been shown previously that under continuous darkness for up to 6 days, spinach NR protein was almost completely degraded. However, NR kinase(s), NR phosphatase(s) and 14-3-3 proteins were still present (Glaab and Kaiser, 1996). Mixing AtNR2 (which, by itself, was not inactivated by preincubation with ATP) with 
a NR-free spinach leaf extract (4-day darkness) resulted in significant inactivation of AtNR2 with ATP. In contrast, RcNR was never inactivated with ATP, neither after addition of Arabidopsis darkened leaf extract nor darkened leaf extract from Ricinus. As deduced from the sequencing data, Ricinus NR has a normal phosphorylation site in hinge 1. Consequently, lack of ATP-inactivation in a mixture of RcNR and leaf extracts may either reflect absence of a specific protein kinase activity, or a lack of specific 14-3-3 proteins. It has been shown previously that Ricinus leaves do contain 14-3-3s (Kandlbinder et al., 2000), and so do yeast cells (Van Heusden et al., 1992; Gelperin et al., 1995). Addition of recombinant yeast 14-3-3s (up to $20 \mu \mathrm{g}$ per $\mathrm{mL}$ ), which efficiently inactivates phospho-NR from spinach (Moorhead et al., 1996), partially purified NR from spinach, transgenic tobacco plants and squash (Lillo et al., 1997) and Arabidopsis cell extracts (Moorhead et al., 1999) did not at all affect RcNR activity (not shown). It seems obvious that the insensitivity to ATP is not due to the absence of the regulatory phosphorylation site nor to a lack of 14-3-3 proteins, but to some as yet unidentified structural deviations in the less well conserved parts of the protein, i.e. N-terminal domain. Therefore, the conclusion is that this ATPinsensitivity is an inherent property of Ricinus NR.

\subsubsection{Specific protein factor(s) for high $\mathrm{Mg}^{2+}$-sensitivity of $\operatorname{RcNR}$}

In crude yeast extracts, RcNR lacked the high $\mathrm{Mg}^{2+}$-sensitivity typically observed for NR in crude extracts from Ricinus leaves at $\mathrm{pH} 7.3$, and was not much different in that respect from AtNR2 (Table 2). Loss of the unusual $\mathrm{Mg}^{2+}$-sensitivity of Ricinus NR might have two reasons: i) factors contained in the yeast extract might interact with $\mathrm{NR}$ to render it $\mathrm{Mg}^{2+}$ insensitive, or ii) the yeast extracts lacked factors required for the high $\mathrm{Mg}^{2+}$-sensitivity.

Our data suggest that the latter explanation is correct. Leaves from Ricinus, as from spinach, can be made virtually NR free by exposing them to continuous darkness for 4 days. Addition of such Ricinus extracts from darkened leaves (RDL) almost fully restored the high $\mathrm{Mg}^{2+}$-sensitivity of the authentic leaf enzyme. Boiling of the extracts prior to addition prevented the restoration of $\mathrm{Mg}^{2+}$-sensitivity, indicating that the required factor was probably a protein. This was further confirmed by using ammonium sulfate to successfully precipitate the factor(s). In conclusion, the unusual high $\mathrm{Mg}^{2+}$-sensitivity of Ricinus NR appears not an inherent property of the NR 
protein itself. Rather, it is the consequence of an yet unidentified protein contained in Ricinus leaves that interacts with NR.

We do not know whether Ricinus NR and the unidentified protein are in contact within the intact leaf cells, or whether they are separated by subcellular compartmentation. In the latter case, the high $\mathrm{Mg}^{2+}$-sensitivity of Ricinus NR observed in leaf extracts would represent an artifact due to homogenization of the leaf cells for extraction. But on the other hand, addition of RDL to AtNR2 did not increase the $\mathrm{Mg}^{2+}$-sensitivity of the latter. Thus, the interaction of the above-mentioned protein factor from Ricinus leaves with RcNR appeared specific for RcNR, pointing to the probability of a natural, non-artificial interaction.

\subsubsection{Possible regulatory factors of NR}

Incubation of AtNR2 with different NR-free leaf extracts gave a significant activation of the enzyme activities, both in $\mathrm{Mg}^{2+}$ and EDTA. This could be due to either a general positive factor for NR existing in leaves, or recombinant Arabidopsis NR2 may contain special features in its sequence. However, such activation was not observed in RcNR (Table 2). If the first assumption is correct, in case of RDL, the disappearance of the positive effect in RcNR might be somehow counterbalanced by the negative factor(s) mentioned above. Mixing RcNR with ADL and SDL, however, should give the same activation, when the positive factor is common in plant leaves. Therefore, it seems that the second speculation is more likely, that Arabidopsis NR2 possesses special structural characters. Nevertheless, it is also likely that Ricinus NR does not interact with that common factor, if there is any, because of its yet unidentified structural difference from other NRs.

In addition to that, Ricinus leaf extracts apparently contained non-protein components that were able to increase both, $\mathrm{NR}_{\max }$ and $\mathrm{NR}_{\text {act }}$ of RcNR. It is yet unclear whether these components would abolish potentially negative effects of yeast compounds, or if they would directly interact with NR. The nature of these compounds is also unknown at present.

Altogether, the unknown protein factor which renders $\mathrm{RcNR} \mathrm{Mg}^{2+}$-sensitive is most probably not a 14-3-3 protein, nor appears the high $\mathrm{Mg}^{2+}$-sensitivity related to NR protein phosphorylation. In summary, our original conclusions that Ricinus NR has some unusual properties are confirmed by the above presented data. Additionally, Ricinus leaf cells contain a protein factor which appeared to interact specifically with 
Ricinus NR to provide the unusual $\mathrm{pH}$ - and $\mathrm{Mg}^{2+}$-response. More investigations are required to identify the structural components in the RcNR protein that are responsible, to identify the protein factor and also to elucidate the physiological background and consequences of these extraordinary regulatory properties.

\subsection{The comparison of Ricinus and squash nitrate reductase}

Since we observed the unusual regulatory properties from Ricinus NR, one question arises regarding the physiological meaning of the specific properties of Ricinus NR. We are still not able to answer this question from our present data. From the evolutionary point of view, however, to figure out the phylogenies of Ricinus NR might give some hints. Using PHYLIP package to compare $18 \mathrm{NADH}$-specific nitrate reductases revealed that Ricinus NR was most close to squash NR (Cucurbita maxima) with respect to both full-length amino acid sequence and $\mathrm{N}$-terminus comparisons (Appendix 6.7 and 6.8).

Squash NR was first cloned in 1986 and a protein of 918 amino acids was encoded (Crawford et al., 1986; Hyde et al., 1991). Some studies in squash NR were done by Lillo and coworkers. They found that squash NR can be activated by substrates, a so called hysteretic behavior (Lillo and Ruoff, 1992). Two forms of NR, high and low activity forms, existing in squash crude extracts and purified enzyme in response to light-dark transition. The light form (high activity) was not inhibited by $\mathrm{Ca}^{2+}$ and $\mathrm{Mg}^{2+}$. The dark form (low activity) was in contrary strongly inactivated by both divalent cations (Lillo, 1993 and 1994). NR activity in crude extracts from lightexposed plants or partially purified NR could be inhibited by $\mathrm{Mg}^{2+}$ after foregoing incubation with MgATP. Therefore, the inhibition by $\mathrm{Mg}^{2+}$ or $\mathrm{Ca}^{2+}$ was related to phosphorylation or a phosphorylated form of NR (Kaiser and Spill, 1991; Huber et al., 1992; MacKintosh, 1992). However, squash NR can be converted to a form susceptible to $\mathrm{Ca}^{2+}$ and $\mathrm{Mg}^{2+}$ inhibition without preincubation with MgATP. Hence, for squash, no MgATP was necessary for converting the high activity form of the enzyme into low activity form. Assumption of a phosphorylation process resulting in decreased NR activity was irrelevant for squash NR.

Furthermore, in the absence of $\mathrm{Mg}^{2+}$ the increase of NR activity of squash crude extracts by substrates was observed when made from dark-exposed leaves but not from leaves in the light. Partially purified squash NR, however, was found no 
difference between NR extracted from leaves in the dark and light with respect to substrate activation (Lillo et al., 1997).

Taken together, their conclusion was that an additional way of regulating NR independently of the phosphorylation state of the enzyme might exist. It was interesting that purified squash NR differed from the enzyme in crude extracts. Does that point to the existence in crude extracts of a possible regulatory factor for squash NR, similar as described above for RcNR? In summary, it may seem that Ricinus NR and squash NR share similar regulatory properties which appear in some way different from the common post-translational modulation. Certainly, it would be interesting to compare both enzymes in more details, especially under the same experimental conditions. 


\section{Materials and Methods}

\subsection{Plant Material}

Spinach (Spinacia oleracea L. cv. Polka F1) was grown in soil culture in the greenhouse. The mean daylength was $11 \mathrm{~h}$ with supplementary illumination (HQi, 400W; Schreder, Winterbach, Germany) at a total photon flux density of 250 to 400 $\mu \mathrm{mol} \mathrm{m} \mathrm{m}^{-2}$ photosynthetically active radiation. Air humidity varied from 60 to $80 \%$, and day/night temperature from 20 to $26^{\circ} \mathrm{C}$ and 16 to $22^{\circ} \mathrm{C}$. The plants were fed with a commercial nitrate fertilizer.

Seeds of Ricinus (Ricinus communis L.) were germinated in soil and grown in the greenhouse under the conditions mentioned above. Plants were used for experiments after about 5 weeks (if not mentioned otherwise).

Arabidopsis (Arabidopsis thaliana ecotype Columbia) was grown in soil (Type P, Gebr. Hagera Handelsges.m.b.H., Sinntal-Jossa, Germany) and exposed to white light for $8 \mathrm{~h}$ per day at $160 \mu \mathrm{mol} \mathrm{m} \mathrm{m}^{-2} \mathrm{~s}^{-1}$.

\subsection{RNA Protocols}

\subsubsection{Total RNA Isolation}

Total RNA, for use as a template for cDNA synthesis, was isolated from the leaf tissue of nitrate-treated Ricinus plants using the Qiagen RNeasy Plant Mini Kit (Qiagen, Hilden, Germany). The procedure is based on the selective binding properties of a silica-gel-based membrane in a microspin column system. A specialized high-salt buffer system allows the binding of up to $100 \mu \mathrm{g}$ of total RNA longer than $200 \mathrm{bp}$ to the membrane.

Leaf material was ground in the nitrogen to a fine powder using a mortar and pestle. $100 \mathrm{mg}$ of tissue powder was mixed with $900 \mu \mathrm{L}$ Lysis buffer. The lysate was applied to a QIAshredder spin column and centrifuged for 2 min at maximum speed twice. The flow-through fraction was mixed with $450 \mu \mathrm{L}$ of ethanol and transferred to an RNeasy spin column for absorption of RNA to membrane. After several washing and brief centrifugation the RNA was eluted in $30 \mu \mathrm{L}$ DEPC-treated $\mathrm{H}_{2} \mathrm{O}$ twice. The concentration of RNA was read in a spectrophotometer (GeneQuqnt II, Pharmacia 
Biotech) by measuring the absorbance at $260 \mathrm{~nm}$. A ratio between $\mathrm{A}_{260}$ and $\mathrm{A}_{280}$ with a value of 2 was used as a criterion for pure preparation of RNA. The RNA was stored at $-80^{\circ} \mathrm{C}$.

\subsubsection{Electrophoresis of RNA}

Total RNA was used for a denaturing electrophoresis using formaldehyde-agarose gels. Formaldehyde forms unstable Schiff bases with the single imino group of guanine residues. These adducts maintain RNA in the denatured state by preventing intrastrand Watson-Crick base pairing.

$4 \mu \mathrm{L}$ of formaldehyde gel-loading buffer was added to $6 \mu \mathrm{g}$ total RNA and incubated at $65^{\circ} \mathrm{C}$ for $10 \mathrm{~min}$. RNA samples were chilled for $2 \mathrm{~min}$ on ice and loaded in a formaldehyde-agarose gel. After electrophoresis of RNA (at 80V) in the presence of ethidium bromide, the $28 \mathrm{~S}$ and $18 \mathrm{~S}$ species of rRNA should be visible under UV illumination (ImageMaster VDS, Pharmacia Biotech). Distinct clear bands and the $28 \mathrm{~S}$ band should be stained at approximately twice the intensity of the $18 \mathrm{~S}$ band prove the quality of the preparation.

10× MEN-buffer:

0.2 M MOPS

$0.01 \mathrm{M}$ EDTA

$0.05 \mathrm{M}$ Sodium acetate

Gel loading buffer:

$720 \mu \mathrm{L}$ Formamide

$160 \mu \mathrm{L} 10 \times$ MEN

$260 \mu \mathrm{L} \mathrm{37 \%}$ Formaldehyde

$180 \mu \mathrm{L} \mathrm{H} \mathrm{H}_{2} \mathrm{O}$

$100 \mu \mathrm{L} 80 \%$ Glycerol

$80 \mu \mathrm{L} \mathrm{2 \%}$ Bromophenol blue

$3 \mu \mathrm{L} \mathrm{1 \%}$ Ethidium bromide

Formaldehyde-agarose gel $(30 \mathrm{~mL})$ :

$0.3 \mathrm{~g}$ Agarose

$3 \mathrm{~mL} 10 \times$ MEN

$25.5 \mathrm{~mL}$ DEPC-treated $\mathrm{H}_{2} \mathrm{O}$

(Dissolved in the microwave, cooling to $50^{\circ} \mathrm{C}$ )

$1.62 \mathrm{~mL} \mathrm{37 \%} \mathrm{Formaldehyde}$ 


\subsection{DNA Protocols}

\subsubsection{Isolation of Plasmid-DNA from Escherichia coli}

Plasmid DNA isolation is based on alkaline lysis of bacterial cells followed by selective precipitation of genomic bacterial DNA and proteins by lowering the $\mathrm{pH}$.

$1.5 \mathrm{~mL}$ of overnight grown plasmid containing E. coli culture in LB was harvested and lysed with $300 \mu \mathrm{L}$ of P1 buffer. After addition of $300 \mu \mathrm{L}$ of P2 buffer and gentle mixing by inversion, the mixture was incubated at RT for 3 min. Subsequently, 300 $\mu \mathrm{L}$ of chilled P3 buffer were added, mixed and incubated on ice for $10 \mathrm{~min}$. The cell debris and chromosomal DNA were precipitated with SDS and potassium acetate. After pelleting the debris the plasmid DNA was precipitated from the supernatant with $600 \mu \mathrm{L}$ isopropanol. The DNA pellet was washed in cold $70 \%$ ethanol. After careful and complete removal of ethanol, the DNA was air-dried and then resuspended in TE buffer. The concentration of DNA was determined by UV spectroscopy at $260 \mathrm{~nm}$. A ratio between $A_{260}$ and $A_{280}$ with a value of 1.8 was used as a criterion for pure preparation of DNA. The plasmid-DNA was stored at $-20^{\circ} \mathrm{C}$.

LB medium: $1 \%$ Tryptone; $0.5 \%$ Yeast extract; $1 \% \mathrm{NaCl} ; \mathrm{pH} 7.0$. P1: $50 \mathrm{mM}$ Tris-HCl pH 8.0; $10 \mathrm{mM}$ EDTA; $100 \mu \mathrm{g} / \mathrm{ml}$ RNase A P2: $200 \mathrm{mM} \mathrm{NaOH} ; 1 \%$ SDS P3: $3 \mathrm{M}$ Potassium acetate $\mathrm{pH} 5.5$

TE buffer: $10 \mathrm{mM}$ Tris-HCl pH 8.0; $1 \mathrm{mM}$ EDTA

\subsubsection{Restriction Endonucleases Digestion}

In most cases two units of enzyme were used to completely digest $1 \mu \mathrm{g}$ plasmid DNA during $1 \mathrm{~h}$ at $37^{\circ} \mathrm{C}$. In the case of Sac II and Apa I double cleavage, buffer B+ (MBI Fermentas) was used for optimal condition (maximum activity) of both enzymes. Addition of 1/5 volume of loading buffer to stop the reaction and the digested mixture was subjected to electrophoresis.

\subsubsection{Electrophoresis of DNA}

Agarose gel electrophoresis is the easiest and most common way of separating and analyzing DNA. Most agarose gels are made between $0.7 \%$ and 2\%. A $0.7 \%$ gel will show good separation (resolution) of large DNA fragments (5 to $10 \mathrm{~kb}$ ) and a $2 \%$ gel will show good resolution for small fragments $(0.2$ to $1 \mathrm{~kb})$. Routinely, $1 \%$ gels which 
are suitable for a molecule range of 0.5 to $12 \mathrm{~kb}$ were used. The agarose was melted in $1 \times$ TAE and mixed with $0.2 \mu \mathrm{g} / \mathrm{mL}$ ethidium bromide after cooling to $50^{\circ} \mathrm{C}$. The DNA sample was mixed with an appropriate amount of loading buffer and subjected to electrophoresis, performed in a $1 \times$ TAE buffer system at a voltage of 5 to $10 \mathrm{~V} / \mathrm{cm}$. $1 \mathrm{~kb}$ Ladder was used as molecule size marker (Gibco BRL, Eggenstein, Germany). The DNA could be checked by the fluorescence of the DNA-intercalating dye ethidium bromide under UV illumination.

50× TAE buffer: 2 M Tris-Acetic acid pH 8.0; 50 mM EDTA pH 8.0

Loading buffer (6x): $50 \%$ Glycerol; $7.5 \mathrm{mM}$ EDTA; 0.4\% Xylenxyanol; $0.4 \%$ Bromophenol blue

\subsection{Sequencing}

Sequence information was obtained by the Sanger-Coulson method using the “Thermo Sequence fluorescent labeled primer cycle" sequencing-kit with 7-deazadGTP” (Amersam Pharmacia Biotech, Freiburg, Germany). Software for the sequencing was Base Imagir 4.0 (L1-COR, MWG-Biotech GmbH, Ebersberg, Germany). To compare the new sequences with already known entries the BLASTAlgorithms (Altschul et al., 1990) of NCBI (http://www.ncbi.nlm.nih.gov/BLAST/) were used. ClustalX and Genedoc software was used for sequence alignments.

\subsection{Molecular Cloning of Ricinus NR by RT-PCR}

RT-PCR (reverse transcription-polymerase chain reaction) was used for cloning the NR gene from Ricinus. The technique consists of two parts: synthesis of cDNA from RNA by reverse transcription (RT) and amplification of a specific cDNA by polymerase chain reaction (PCR). The first task when using RT-PCR for mRNA analysis is RNA isolation. The RNA should be high quality and free from genomic DNA contamination. Every RT-PCR begins with a reverse transcriptase reaction. The RT reaction uses a RNA template (typically either a total or poly(A) RNA sample), a primer (random or oligo dT primers), dNTPs, buffer and a reverse transcriptase (MMLV or AMV RT). After synthesis of the first-strand cDNA, a pair of specific primers is then used to amplify the target region via PCR. 
PCR is a powerful technique that allows amplifying a specific DNA sequence millions of times in a few hours. During PCR, there are three basic steps. First, the target genetic material must be denatured, that is, the strands of its helix must be unwound and separated by heating to $90-96^{\circ} \mathrm{C}$. The second step is hybridization or annealing, in which the primers bind to their complementary bases on the now singlestranded DNA. The third is DNA synthesis by a polymerase. Starting from the primer, the polymerase can read a template strand and match it with complementary nucleotides very quickly. The result are two new helixes in place of the first, each composed of one of the original strands plus its newly assembled complementary strand.

A Ricinus partial NR cDNA was amplified by RT-PCR. For reverse transcription a 18mer oligo-dT oligonucleotide was used as the 3'primer. cDNA was synthesized from $6 \mu \mathrm{L}$ of total RNA (c.a. $1 \mu \mathrm{g}$ mRNA) with SuperScript ${ }^{\mathrm{TM}}$ II RNase $\mathrm{H}^{-}$MMLV Reverse Transcriptase (Gibco BRL, Eggenstein, Germany) using the procedure detailed in the RETROscript ${ }^{\mathrm{TM}}$ kit for the first-strand synthesis (Ambion).

$\underline{20 \mu \mathrm{L} \text { reaction: }}$

$$
\begin{aligned}
& 1 \mu \mathrm{g} \text { mRNA } \\
& 1 \mu \mathrm{L} \text { oligo dT }{ }_{18}(50 \mu \mathrm{M}) \\
& 4 \mu \mathrm{L} \mathrm{H} \mathrm{H}_{2} \mathrm{O}
\end{aligned}
$$

Mix the above components and heat the mixture at $70^{\circ} \mathrm{C}$ for $10 \mathrm{~min}$. Remove tube(s) to ice; spin briefly, replace on ice. Subsequently add $4 \mu \mathrm{L} 5 \times$ first strand buffer

$2 \mu \mathrm{LDTT}(0.1 \mathrm{M})$

$2 \mu \mathrm{L}$ dNTPs $(5 \mathrm{mM}$ each)

Mix gently, spin briefly. Incubate the mixture at $37^{\circ} \mathrm{C}$ for 2 min for equilibration. Then add $1 \mu \mathrm{L}$ (200 units) of SuperScript RT and incubate at $42^{\circ} \mathrm{C}$ for one hour.

For PCR amplification an oligonucleotide corresponding to the conserved sequence 5'-ATTGGTGGAAGAATGGTAAAGTGG matching positions 898 to 921 of the potato Nia gene coding sequence (Harris et al., 2000) was selected as a 5 ' genespecific primer. A 21 mer oligonucleotide 5'-CACGAACAATCTCTTTGGCAC corresponding to the Arabidopsis Nial gene at positions 1343 to 1363 was used as the 3'-primer. The component of the reaction was as the followings:

$\underline{50 \mu \mathrm{L} \text { reaction: }}$

$1 \mu \mathrm{L}$ RT reaction (see above)

$5 \mu \mathrm{L} 10 \times$ PCR buffer

$2.5 \mu \mathrm{L} \mathrm{MgCl}_{2}(50 \mathrm{mM})$ 


\section{$2.5 \mu \mathrm{L}$ dNTPs (5 mM each) \\ $1 \mu \mathrm{L} 5$ ' gene-specific primer $(20 \mu \mathrm{M})$ \\ $1 \mu \mathrm{L} 3$ '-primer $(20 \mu \mathrm{M})$ \\ $0.2 \mu \mathrm{L}$ Taq DNA polymerase $(5 \mathrm{U} / \mu \mathrm{L})$ \\ $36.8 \mu \mathrm{L} \mathrm{dH_{2 } \mathrm { O }}$}

Amplification was performed using an annealing temperature of $55^{\circ} \mathrm{C}$. The cycling parameters were (a) heat 5 min., $94^{\circ} \mathrm{C}$; (b) cycle $30: 94^{\circ} \mathrm{C}, 30 \mathrm{sec} . ; 55^{\circ} \mathrm{C}, 30 \mathrm{sec}$; $72^{\circ} \mathrm{C}, 30 \mathrm{sec}$; (c) hold $5 \mathrm{~min} ., 72^{\circ} \mathrm{C}$. It produced a cDNA fragment of the expected size (ca. $440 \mathrm{bp}$ based on the positions of the oligonucleotide sequence in the potato Nia gene sequence) which was subcloned into the $\mathrm{pCR}^{\circledR} 2.1$-TOPO vector (Invitrogen, Groningen, the Netherlands) for DNA sequencing.

\subsection{Amplification of full-length Ricinus NR cDNA by RACE}

Following reverse transcription, the first-strand cDNA can be used in 5'-RACE and 3'-

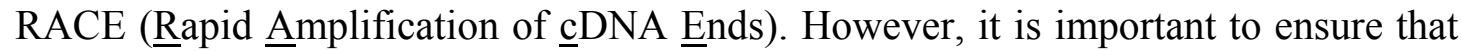
the first-strand cDNA reaches the end of an RNA template. This is achieved by using MMLV reverse transcriptase (RT). When certain MMLV RT variants reach the end of an RNA template, they exhibit a terminal transferase activity that adds 3-5 residues (predominantly $\mathrm{dC}$ ) to the 3 ' end of the first-strand cDNA (Figure 4.1).

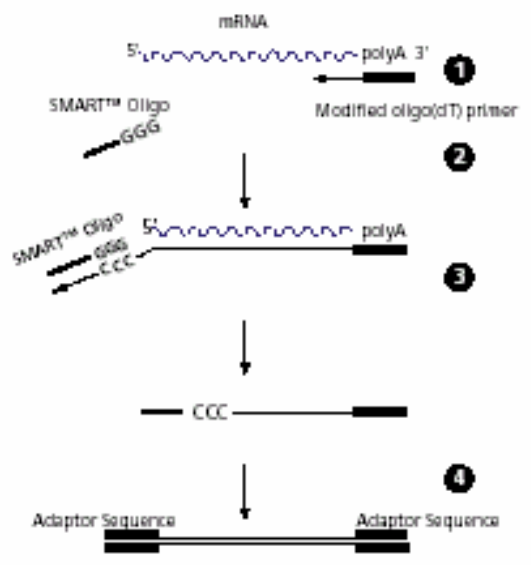

Figure 4.1 Mechanism of SMART cDNA synthesis. (1) First-strand synthesis is primed using a modified oligo(dT) primer. (2) After reverse transcription reaches the end of the mRNA template, it adds several dC residues. (3) The SMART II oligonucleotide anneals to the tail of the cDNA and serves as an extended template for RT. After RT switches templates from the mRNA molecule to the SMART oligo, a complete cDNA copy of the original RNA is synthesized with the additional SMART sequence at the end. (4) The complete first-strand cDNA then would have an adaptor sequence at both ends. 
In the SMART technology (BD Biosciences Clontech, Heidelberg, Germany), this activity is harnessed by the SMART oligo whose terminal stretch of $\mathrm{dG}$ residues can anneal to the dC-rich cDNA tail and serve as an extended template for RT. After RT switches templates from the mRNA molecule to the SMART oligo, a complete cDNA copy of the original RNA is synthesized with the additional SMART sequence at the end. Since the dC-tailing activity of RT is most efficient if the enzyme has reached the end of the RNA template, the SMART sequence is typically added only to complete first-strand cDNAs. This process guarantees that the use of high quality RNA will result in the formation of a set of cDNAs that has a maximum amount of 5 ' sequence. The only requirement for SMART RACE cDNA amplification is that at least 23-28 nucleotides of sequence information is known in order to design gene-specific primers for the 5'- and 3'-RACE reactions.

The full-length Ricinus NR cDNA was obtained by following the manufacturer's instructions (BD Biosciences Clontech, Heidelberg, Germany). $6 \mu \mathrm{g}$ of total RNA were used for preparation of either SMART ${ }^{\mathrm{TM}}$ first-strand cDNA synthesis (5'-RACEReady cDNA) or standard first-strand cDNA synthesis (3'-RACE-Ready cDNA), depending on the presence of SMART II oligo (5'AAGCAGTGGTAACAACGCAGAGTACGCGGG-3') in the reaction or not. After generating RACE-Ready cDNAs, 5'-RACE and 3'-RACE were performed with the Advantage $^{\circledR} 2$ Polymerase Mix (BD Biosciences Clontech, Heidelberg, Germany). PCR reaction was performed by using the gene specific primers 5'TCTCTTTGGCACCAAGGAGGTCCAG-3' for 5'-RACE and 5'GCTGAAGCATGGTGGTATAAGCCGG-3' for 3'-RACE, respectively. DNA was amplified by 25 cycles of $94^{\circ} \mathrm{C}$ for $10 \mathrm{sec}, 68^{\circ} \mathrm{C}$ for $20 \mathrm{sec}$ and $72^{\circ} \mathrm{C}$ for $3 \mathrm{~min}$ in a PCR-reaction.

\subsection{Pichia pastoris Expression System}

Yeast hosts that can be used for expression studies Saccharomyces cerevisiae, Schizosaccharomyces pombe, Pichia pastoris, Hansenula polymorpha, Kluyveromyces lactis, and Yarrowia lipolytica. The first three are the most widely used. Yeasts are particularly attractive as expression hosts for a number of reasons. They can be rapidly grown on minimal (inexpensive) media. Recombinants can be easily selected by complementation, using any one of a number of selectable 
(complementation) markers. Expressed proteins can be specifically engineered for cytoplasmic localization or for extracellular export. And finally yeasts are exceedingly well suited for large-scale fermentation to produce large quantities of heterologous protein.

The methylotrophic yeasts, $H$. polymorpha and P. pastoris, are unique in that they will grow using methanol as the sole carbon source. In P. pastoris, growth in methanol is mediated by alcohol oxidase, as enzyme whose de novo synthesis is tightly regulated by the alcohol oxidase promoter $(A O X 1)$. The enzyme has a very low specific activity. To compensate for this, it is overproduced, accounting for more than 30 percent of total soluble protein in methanol-induced cells. Thus, by engineering a heterologous protein gene downstream of the genomic $A O X 1$ promoter, one can induce its overproduction.

Ricinus NR cDNA was inserted into the Sac II and Apa I site of the Pichia pastoris expression vector pPICZA (Invitrogen). The expression clone was transformed into $P$. pastoris strain GS115 by EasyComp ${ }^{\mathrm{TM}}$ Transformation, as described by EasySelect ${ }^{\mathrm{TM}}$ Pichia Expression Kit (Invitrogen, Groningen, the Netherlands).

Growth media and conditions for selection of transformants were as described by the manufacturer (Invitrogen). Zeocin ${ }^{\mathrm{R}}$ transformants were selected. Cells expressing NR protein were identified as follows: To induce NR gene expression, which was driven by the alcohol oxidase promoter of $P$. pastoris, transformants were first grown in modified BMG(H) (Su et al., 1997) (1.34\% [w/v] YNB, 1\% [v/v] glycerol, $100 \mathrm{mM}$ potassium phosphate, $\mathrm{pH} 6.0,4 \times 10^{-5} \%$ biotin, $0.2 \mathrm{mM}$ sodium molybdate and w/o $4 \times 10^{-5} \%$ histidine) to an $\mathrm{OD}_{600}$ of 2 to 6 . Cells were centrifuged and then resuspended in modified $\mathrm{BMM}(\mathrm{H})$ medium $(1.34 \%[\mathrm{w} / \mathrm{v}] \mathrm{YNB}, 0.5 \%[\mathrm{v} / \mathrm{v}]$ methanol, $100 \mathrm{mM}$ potassium phosphate, $\mathrm{pH} 6.0,4 \times 10^{-5} \%$ biotin, $0.2 \mathrm{mM}$ sodium molybdate and w/o $4 \times 10^{-5} \%$ histidine $)$ at $\mathrm{OD}_{600}$ of 1 and grown for up to $72 \mathrm{~h}$. Methanol $(0.5 \%[\mathrm{v} / \mathrm{v}])$ and sodium molybdate $(0.2 \mathrm{mM})$ were added to the culture every $24 \mathrm{~h}$. After a $48 \mathrm{~h}$ induction period the cells were collected by centrifugation to $\mathrm{OD}_{600}$ of $\sim 20$, frozen quickly in liquid $\mathrm{N}_{2}$ and stored at $-80^{\circ} \mathrm{C}$ until ready to assay. 


\subsection{Protein Protocols}

\subsubsection{Protein Determination}

The protein content of the samples was determined with BCA reagent (Pierce, Rockford, Ill, USA) and Bovine serum albumin (BSA) as a standard which is based on the method of Smith et al., 1985. Using the reaction of copper(II) with protein and the subsequent reaction of BCA with copper (I), a colormetric compound is formed which is quantified by spectroscopy.

\subsubsection{SDS-Polyacrylamide Gelelectrophoresis (SDS-PAGE)}

Protein separation by SDS-PAGE is used to determine the relative abundance of major proteins in a sample, their approximate molecular weights, and in what fractions they can be found. The purity of protein samples can be assessed. Different staining methods can be used to detect rare proteins.

Pichia protein samples were obtained by phenol extraction/ammonium acetate precipitation. The samples were boiled in sample buffer (Roti ${ }^{\circledR}$-Load 1; Roth, Karlsruhe, Germany) containing 2-mercaptoethanol which is a mild reducing agent for cleaving disulfide bonds to thiols, and SDS, an anionic detergent used for denaturation of native proteins. $20 \mu \mathrm{g}$ of the protein solution were loaded onto the polyacrylamide gel and separated at constant $30 \mathrm{~mA}$. As protein standards the $10 \mathrm{kDa}$ Protein Ladder (Gibco BRL) was used. Compositions of the gel and buffers were as follows (Neville, 1971):

Resolving gel: $14 \mathrm{~mL}$ of two $10 \%$ gels

$3.6 \mathrm{~mL} \mathrm{40 \%} \mathrm{Acrylamide/bisacrylamide} \mathrm{(29:1} \mathrm{mix)}$

$2.8 \mathrm{~mL}$ Tris-HCl pH 9.18

$0.14 \mathrm{~mL} 10 \%$ SDS

$7.35 \mathrm{~mL} \mathrm{H}_{2} \mathrm{O}$

$6.25 \mu \mathrm{L}$ TEMED

$22 \mu \mathrm{L} \mathrm{40 \%} \mathrm{Ammonium} \mathrm{persulfate}$

Stacking gel: $10 \mathrm{~mL}$ of 4 gels

$1.5 \mathrm{~mL} \mathrm{40 \%} \mathrm{Acrylamide/bisacrylamide} \mathrm{(29:1} \mathrm{mix)}$

$2.5 \mathrm{~mL}$ Tris- $\mathrm{H}_{2} \mathrm{SO}_{4} \mathrm{pH} 6.1$

$0.1 \mathrm{~mL} \mathrm{10 \%} \mathrm{SDS}$

$5.8 \mathrm{~mL} \mathrm{H}_{2} \mathrm{O}$

$10 \mu \mathrm{L}$ TEMED

$25 \mu \mathrm{L} 40 \%$ Ammonium persulfate 
Running buffers:

Lower: $424 \mathrm{mM}$ Tris-HCl pH 9.18

Upper: $41 \mathrm{mM}$ Tris-Boric acid pH 8.64; 0.1\% SDS

\subsubsection{Western Blot and Immunodetection of NR}

For transfer of proteins onto a nitrocellulose membrane (Schleicher und Schüll, Dassel, Germany) a semi-dry system (Biometra, Göttingen, Germany) was used. The transfer was performed at $0.8 \mathrm{~mA} / \mathrm{cm}^{2}$ for $1 \mathrm{~h}$.
Anode (Top)
$3 \times$ Whatman 3MM filter paper/Anode buffer 1
$3 \times$ Whatman 3MM filter paper/Anode buffer 2
Transfer membrane/Anode buffer 2
SDS-PAGE gel
$3 \times$ Whatman 3MM filter paper/Cathode buffer
Cathode (Bottom)

Cathode buffer: $40 \mathrm{mM}$ 6-Aminocapronic acid; 20\% Methanol

Anode buffer 1: $0.3 \mathrm{M}$ Tris pH 8.8; 20\% Methanol

Anode buffer 2: $25 \mathrm{mM}$ Tris $\mathrm{pH} 8.8 ; 20 \%$ Methanol

For NR protein detection the immunoenzymatic staining method was used. The membrane with the bound proteins was further treated as follows:

\begin{tabular}{l|l|l}
\hline Process & Buffer & Time \\
\hline Blocking & $5 \%$ milk powder in $1 \times$ TBS; $0.1 \%$ Tween 20 & $1 \mathrm{~h}$ at RT \\
\hline Washing & $1 \times$ TBS; $0.1 \%$ Tween 20 & $2 \times 5 \mathrm{~min}$ \\
\hline $\begin{array}{l}\text { Primary antisera } \\
\text { incubation }\end{array}$ & $1: 2000$ in $1 \times$ TBS; $0.1 \%$ Tween 20 & $1 \mathrm{~h}$ at RT \\
\hline Washing & $1 \times$ TBS; $0.1 \%$ Tween 20 & $3 \times 5 \mathrm{~min}$ \\
\hline $\begin{array}{l}2^{\text {nd }} \text { antibody-AP } \\
\text { incubation }\end{array}$ & $1: 3000$ in $1 \times$ TBS; $0.1 \%$ Tween 20 & $45 \mathrm{~min}$ at RT \\
\hline Washing & $1 \times$ TBS; $0.1 \%$ Tween 20 & $3 \times 5 \mathrm{~min}$ \\
\hline Staining & AP conjugate substrate kit & $5-30 \mathrm{~min}$ \\
\hline
\end{tabular}

$2^{\text {nd }}$ antibody: Alkaline phosphatase (AP) labeled goat anti-rabbit IgG

(Southern Biotechnology Associates, USA)

AP conjugate substrate kit: AP color reagent A and B; development buffer

(Bio-Rad, München, Germany)

\subsubsection{Ammonium Sulfate Fractionation}

Proteins are usually soluble in water solutions because they have hydrophilic amino acids on their surfaces. Increasing the salt concentration to a very high level will cause proteins to precipitate from solution without denaturation if done in a gentle manner. When salt, such as ammonium sulfate, is added to the protein solution, the salt ions 
attract the water molecules away from the protein; hence, the protein molecules are forced to interact with themselves and begin to aggregate. If this is carried out on ice, the proteins will precipitate without denaturation. Thereafter, the proteins can be collected by centrifugation and then redissolved in solution using a buffer with low salt content. All procedures have to be carried out at $4^{\circ} \mathrm{C}$. Ammonium sulfate is the most common salt used for this purpose because it is usually soluble in cold buffer.

$9 \mathrm{~g}$ of 4-day darkened Ricinus leaves were ground in liquid nitrogen and 3-fold (27 $\mathrm{mL}$ ) volume of extraction buffer (content see 4.9.2) was added to the fine powder. After grinding, the mixture was centrifuged at $14500 \mathrm{rpm}$ for $15 \mathrm{~min}$. The Supernatant was then filtered through a paper filter. Following the determination of the exact volume of the supernatant, the amount of ammonium sulfate corresponding to $35 \%$ (w/v) was slowly added to the supernatant while the latter was continuously stirred. The mixture was kept on a magnetic stirrer for additional $20 \mathrm{~min}$ prior to centrifugation at $14500 \mathrm{rpm}$ for $15 \mathrm{~min}$. After centrifugation, the pellet was resuspended in extraction buffer (Fraction 1) and kept on ice. The supernatant was used for further precipitation by adding an additional amount of ammonium sulfate to $53 \%(\mathrm{w} / \mathrm{v})$. Stirring and centrifugation procedures were repeated. The pellet was again resuspended in extraction buffer (Fraction 2), and kept on ice. The protein concentration of the two fractions was measured (see 4.8.1).

\subsection{NR activity Measurements}

\subsubsection{Determination of NR activity in yeast cells (in vivo)}

Pichia transformants were tested for their NR-expression levels. Aliquots of the cell culture were taken every $24 \mathrm{~h}$ during a $72 \mathrm{~h}$ induction period. The NR activity was measured after suspending Pichia transformants $\left(\mathrm{OD}_{600}=1\right)$ in $1 \mathrm{~mL}$ of $100 \mathrm{mM}$ HEPES buffer $\mathrm{pH} 7.3$ containing $50 \mathrm{mM} \mathrm{KNO}_{3}$. After a 30 -min incubation at $28^{\circ} \mathrm{C}$, nitrite released to the medium was determined as described below.

\subsubsection{Assay of NR activity in vitro}

For plant NRs: Leaf material from Ricinus and Arabidopsis was ground in liquid nitrogen and $1.5 \mathrm{~mL}$ (1.0 mL for Arabidopsis) of extraction buffer (100 mM HEPES, pH 7.6, $5 \mathrm{mM}$ DTT, $10 \mathrm{mM} \mathrm{MgCl} 2,10 \mu \mathrm{M}$ FAD, $10 \mu \mathrm{M}$ sodium molybdate, $50 \mu \mathrm{M}$ 
Leupeptin, $2 \mathrm{mM}$ Pefabloc, $0.02 \%$ casein, $0.5 \%$ polyvinylpolypyrolidone and $0.05 \%$ BSA) was added to $0.5 \mathrm{~g} \mathrm{FW}$. In the case of spinach, $1.0 \mathrm{~mL}$ of extraction buffer (without $0.02 \%$ casein, $0.5 \%$ polyvinylpolypyrolidone and $0.05 \% \mathrm{BSA}$ ) was added to $0.5 \mathrm{~g} \mathrm{FW}$. After grinding, the suspension was centrifuged at $13000 \mathrm{rpm}$ for $12 \mathrm{~min}$ at $4^{\circ} \mathrm{C}$. The supernatant was desalted on Sephadex G25 spin columns (1.6 mL resin volume for $650 \mu \mathrm{L}$ extract, $4^{\circ} \mathrm{C}$ ) equilibrated with extraction buffer.

For recombinant NRs: Frozen yeast cells $\left(\mathrm{OD}_{600}\right.$ of $\left.\sim 20\right)$ were thawed on ice and resuspended in $500 \mu \mathrm{L}$ extraction buffer containing $100 \mathrm{mM}$ HEPES, $\mathrm{pH}$ 7.6, $5 \mathrm{mM}$ DTT, $10 \mathrm{mM} \mathrm{MgCl}_{2}, 0.3 \%$ Triton X-100, $10 \mu \mathrm{M}$ FAD, $10 \mu \mathrm{M}$ sodium molybdate, 50 $\mu \mathrm{M}$ Leupeptin, $2 \mathrm{mM}$ Pefabloc and an additional protease inhibitor cocktail (Roche, Mannheim, Germany). An approximately equal volume of glass beads (450 to 600 $\mu \mathrm{m}$; Sigma) were added. The mixture was vortexed 8 times using 1-min bursts followed by 1-min cooling periods. The crude extract was centrifuged at $13000 \mathrm{rpm}$ for $12 \mathrm{~min}$ at $4^{\circ} \mathrm{C}$.

The following assays were carried out with aliquots of the supernatant:

(a) Determination of $N R_{\text {act }}: 100 \mu \mathrm{L}$ of Pichia extracts were mixed with either $100 \mu \mathrm{L}$ of desalted darkened-leaf extracts or extraction buffer. The mixture was incubated for $15 \mathrm{~min}$ at $24^{\circ} \mathrm{C}$ and then added to $800 \mu \mathrm{L}$ reaction buffer $(100 \mathrm{mM}$ HEPES, if not mentioned otherwise, $\mathrm{pH}$ 7.6, $5 \mathrm{mM}$ DTT, $10 \mathrm{mM} \mathrm{MgCl}_{2}, 10 \mu \mathrm{M}$ FAD, 10 $\mu \mathrm{M}$ sodium molybdate, $50 \mu \mathrm{M}$ Leupeptin, $2 \mathrm{mM}$ Pefabloc, $5 \mathrm{mM} \mathrm{KNO}_{3}$ and 0.2 $\mathrm{mM}$ NADH). The reaction was carried out at $24^{\circ} \mathrm{C}$. After $10 \mathrm{~min}$ the reaction was stopped by adding $125 \mu \mathrm{L}$ zinc acetate $(0.5 \mathrm{M})$.

(b) Determination of $N R_{\max }$ : The procedure was carried out as described above, except that the reaction buffer contained $10 \mathrm{mM}$ EDTA instead of $10 \mathrm{mM} \mathrm{MgCl}$.

Excess NADH was removed by $10 \mu \mathrm{M}$ phenazine methosulphate (PMS) treatment. The colorimetric determination of formed nitrite was carried out as described previously (Hageman and Reed, 1980).

\subsubsection{ATP-dependent Inactivation in vitro}

Leaf extracts: Ricinus used in this experiment were 3-week old plants. All plants were illuminated at about 10 a. m. for one hour before harvesting the leaves. The composition of extraction and reaction buffers was described above but all were 
adjusted to $\mathrm{pH}$ 7.3. $100 \mu \mathrm{L}$ of the leaf extracts from Arabidopsis, spinach and Ricinus with or without $2 \mathrm{mM}$ ATP plus $50 \mu \mathrm{M}$ Cantharidin were preincubated for $15 \mathrm{~min}$ at $24^{\circ} \mathrm{C}$. Subsequently, $900 \mu \mathrm{L}$ of reaction buffer containing either $10 \mathrm{mM} \mathrm{MgCl}_{2}$ or 10 $\mathrm{mM}$ EDTA was added to the incubation mixtures. After a 5-min incubation, the substrates ( $5 \mathrm{mM} \mathrm{KNO}_{3}$ and $\left.0.2 \mathrm{mM} \mathrm{NADH}\right)$ were added and the reaction was carried out for $5 \mathrm{~min}$ ( $3 \mathrm{~min}$ for spinach leaf extracts). Nitrite was assayed as before.

Mixtures of recombinant NR's and NR-free leaf extract: The desalted, NR-free extracts of Arabidopsis, Ricinus and spinach 4-day darkened leaves were used in the in vitro inactivation assay. $100 \mu \mathrm{L}$ of $P$. pastoris extracts containing either Arabidopsis NR2 or Ricinus NR were mixed with $100 \mu \mathrm{L}$ of plant leaf extracts or extraction buffer. The mixture was then incubated at $24^{\circ} \mathrm{C}$ for 15 min without or with ATP $(2 \mathrm{mM})$ plus $50 \mu \mathrm{M}$ Cantharidin in the presence of $10 \mathrm{mM} \mathrm{MgCl}_{2}$ in order to inactivate NR. $800 \mu \mathrm{L}$ of reaction buffer $\left(10 \mathrm{mM} \mathrm{Mg}^{2+}\right.$ or $10 \mathrm{mM}$ EDTA) was then added to the mixtures and incubated for $5 \mathrm{~min}$. Thereafter, $5 \mathrm{mM} \mathrm{KNO}_{3}$ and $0.2 \mathrm{mM}$ $\mathrm{NADH}$ were added and the reaction was carried out for $10 \mathrm{~min}$ and nitrite was determined as before.

\subsection{Gas Phase NO Measurements}

The principle for measuring nitrogen dioxide $\left(\mathrm{NO}_{2}\right)$ is the gas phase chemiluminescense reaction of nitric oxide $(\mathrm{NO})$ with ozone $\left(\mathrm{O}_{3}\right)$. The reactions between $\mathrm{NO}$ and an excess amount of $\mathrm{O}_{3}$ can be described by the following formulae:

$$
\begin{aligned}
& \mathrm{NO}+\mathrm{O}_{3} \rightarrow \mathrm{NO}_{2}+\mathrm{O}_{2} \\
& \mathrm{NO}+\mathrm{O}_{3} \rightarrow \mathrm{NO}_{2}{ }^{*}+\mathrm{O}_{2} \\
& \mathrm{NO}_{2} * \rightarrow \mathrm{NO}_{2}+\mathrm{hv} \\
& \mathrm{NO}_{2} *+\mathrm{M} \rightarrow \mathrm{NO}_{2}+\mathrm{M} \\
& \mathrm{NO}_{2} * \text { [ the excited nitrogen dioxide molecule } \\
& \mathrm{M} \text { : deactivating colliding partners }\left(\mathrm{N}_{2}, \mathrm{O}_{2}, \mathrm{H}_{2} \mathrm{O}\right)
\end{aligned}
$$

The spontaneous deactivation of $\mathrm{NO}_{2}$ occurs with emission of light [3]. By far the larger fraction of $\mathrm{NO}_{2} *$ loses its excitation energy without light emission by colliding with other molecules (M) [4]. In order to achieve a high yield of light the reaction of $\mathrm{NO}$ with $\mathrm{O}_{3}$ needs to take place under low pressure. The light intensity generated from the chemiluminescent reactions [2] [3] is proportional to the mixing ratio of NO. A photomultiplier tube is used to convert the light energy emitted from [3] into electrical 
impulses. The electrical impulses are counted over a chosen time interval. A microprocessor calculates the NO signal in ppb.

For experiments with Pichia transformants, $1 \mathrm{~mL}$ of the cells (48 $\mathrm{h}$ induction) were collected and resuspended in $1 \mathrm{~mL}$ of fresh BMG medium (see 4.7) in a $5 \mathrm{~mL}$ beaker. The cells were then placed in a plastic bottle with $200 \mathrm{~mL}$ air volume and were continuously stirred. A constant flow of measuring gas (purified air or nitrogen) of 1.5 $\mathrm{L} / \mathrm{min}$ was pulled through the plastic bottle and subsequently through the chemiluminescence detector (CLD 770 AL ppt, Eco-Physics, Dürnten, Switzerland, detection limit $20 \mathrm{ppt} ; 1$ min time resolution) by a vacuum pump connected to an ozone destroyer. The ozone generator of the chemiluminescence detector was supplied with dry oxygen (99\%). The measuring gas (air or nitrogen) was made NO free by conducting it through a custom-made charcoal column $(1 \mathrm{~m} \mathrm{long}, 3 \mathrm{~cm}$ internal diameter, particle size $2 \mathrm{~mm}$ ). After $5 \mathrm{~min}$ monitoring the baseline under the aerobic condition, $1 \mathrm{mM}$ nitrite was added to the cell culture as the substrate for recombinant NRs. NO emission was monitored for 5 to $10 \mathrm{~min}$ and then the measuring gas was switched to nitrogen to provide anoxic conditions. After 5 to 10 min the sample was brought back to air. Calibration was carried out with NO free air ( 0 ppt NO) and with various concentrations of NO (1 to $35 \mathrm{ppb}$ ) adjusted by mixing the calibration gas (500 ppb NO in nitrogen, Messer Griesheim, Darmstadt, Germany) with NO-free air. Flow controllers (FC-260, Tylan General, Eching, Germany) were used to adjust all gas flows. 


\subsection{List of Chemicals}

Chemicals (Enzymes)

6-Aminocapronic acid

$10 \times$ TBS

Acetic acid

Acrylamide/bisacrylamide

Agarose

Ammonium persulfate

Ammonium sulfate

ATP

Biotin

Boric acid

Bovine serum albumin (BSA)

Cantharidin

Casein

DEPC

Dextrose

DTT

EDTA

Ethidium Bromide

FAD

Glycerol

HEPES

Histidine

Leupeptin

Methanol

MOPS

$\mathrm{NADH}$

NADPH

Pefabloc

Phenol

PMS
Company

Fulka, Neu-Ulm

Bio-Rad, München

AppliChem, Darmstadt

Roth, Karlsruhe

ICN, Eschwege

Bio-Rad, München

Merck, Darmstadt

Sigma, Deisenhofen

Sigma, Deisenhofen

Grüssing, Filsum

Biomol, Hamburg

Biomol, Hamburg

Sigma, Deisenhofen

Roth, karlsruhe

Merck, Darmstadt

Biomol, Hamburg

Merck, Darmstadt

Roth, Karlsruhe

Sigma, Deisenhofen

Sigma, Deisenhofen

Gerbu, Gaiberg

Sigma, Deisenhofen

Biomol, Hamburg

Roth, Karlsruhe

Merck, Darmstadt

Biomol, Hamburg

Biomol, Hamburg

Biomol, Hamburg

Roth, Karlsruhe

Sigma, Deisenhofen 
$p$-nitro-blue tetrazolium chloride

Polyvinylpolypyrolidone (PVPP)

Potassium acetate

Potassium nitrate

Potassium phosphate

Restriction enzymes

Sephadex G-25

SDS

Sodium acetate

Sodium molybdate

Sulfanilamide

TEMED

Tris

Triton X-100

Tryptone

Tween 20

Yeast extract

Zinc acetate
Roth, Karlsruhe

Sigma, Deisenhofen

Fulka, Neu-Ulm

AppliChem, Darmstadt

Merck, Darmstadt

MBI, Heidelberg

Sigma, Deisenhofen

Roth, Karlsruhe

Sigma, Deisenhofen

Merck, Darmstadt

Serva, Heidelberg

Sigma, Deisenhofen

ICN, Eschwege

ICN, Eschwege

AppliChem, Darmstadt

Fulka, Neu-Ulm

ICN, Eschwege

Merck, Darmstadt 


\section{References}

Altschul S. F., Gish W., Miller W., Myers E. W. and Lipman D. J. (1990) Basic local alignment search tool. J. Mol. Biol. 215, 403-410.

Athwal, G.S., Huber, J.L. and Huber, S.C. (1998a) Biological significance of divalent metal ion binding to 14-3-3 proteins in relationship to nitrate reductase inactivation. Plant Cell Physiol. 39, 1065-1072.

Athwal, G.S., Huber, J.L. and Huber, S.C. (1998b) Phosphorylated nitrate reductase and 14-3-3 proteins: Site of interaction, effect of ions and evidence for an AMP-binding site on 14-3-3 proteins. Plant Physiol. 118, 1041-1048.

Athwal, G.S., Lombardo, C.R., Huber, J.L., Masters, S.C., Fu, H. and Huber, S.C. (2000) Modulation of 14-3-3 protein interactions with target polypeptides by physical and metabolic effectors. Plant Cell Physiol. 41, 523-533.

Bachmann, M., Huber, J.L., Liao, P.-C., Gage, D.A. and Huber, S.C. (1996a) The inhibitor protein of phosphorylated nitrate reductase from spinach (Spinacia oleracea) leaves is a 14-3-3 protein. FEBS Lett. 387, 127-131.

Bachmann, M., Huber, J.L., Athwal, G.S., Wu, K., Ferl, R.J. and Huber, S.C. (1996c) 14-3-3 proteins associate with the regulatory phosphorylation site of spinach leaf nitrate reductase in an isoform specific manner and reduce dephosphorylation of Ser-543 by endogenous protein phosphatases. FEBS Lett. 398, 26-30.

Bachmann, M., Shiraishi, N., Campbell, W.H. Yoo, B.C., Harmon, A.C. and Huber, S.C. (1996b) Identification of Ser-543 as the major regulatory phosphorylation site in spinach leaf nitrate reductase. Plant Cell, 8, 505-517.

Bachmann, M., McMichael, R.W., Huber, J.L., Kaiser, W.M. and Huber, S.C. (1995) Partial purification and characterization of a calcium-dependent protein kinase and an inhibitor protein required for the inactivation of spinach leaf nitrate reductase. Plant Physiol. 108, 1083-1091.

Barber, M.J. and Neame, P.J. (1990) A conserved cysteine in molybdenum oxotransferases. J. Biol. Chem. 265, 20912-20915.

Campbell, W.H. (1996) Nitrate reductase biochemistry comes of ages. Plant Physiol. 111, 355-361. 
Campbell, W.H. (1999) Nitrate reductase structure, function and regulation: bridging the gap between biochemistry and physiology. Annu. Rev. Plant Physiol. Plant Mol. Biol. 50, 277-303.

Cheng, C.-L., Acedo, G.N., Cristinsin, M and Conkling, M.A. (1992) Sucrose mimics the light induction of Arabidopsis nitrate reductase gene transcription. Proc. Natl. Acad. Sci. USA. 89, 1861-1864.

Cheng, C.-L., Dewolney, J., Kleinhofs, A. and Goodman, H.M. (1986) Cloning and nitrate induction of nitrate reductase mRNA. Proc. Natl. Acad. Sci. USA. 83, 6825-6828.

Crawford, N.M. (1995) Nitrate: Nutrient and signal for plant growth. Plant Cell. 7, 859-868.

Crawford, N.M., Campbell, W.H. and Davis, R. (1986) Nitrate reductase from squash: cDNA cloning and nitrate regulation Proc. Natl. Acad. Sci. USA. 83, 8073-8076.

Dean, J.V. and Harper, J.E. (1988) The conversion of nitrite to nitrogen oxide(s) by the constitutive NAD(P)H-nitrate reductase enzyme from soybean. Plant Physiol. 88, 389-395.

Deng, M., Moureaux, T. and Caboche, M. (1989) Tungstate, a molybdate analog inactivating nitrate reductase, deregulates the expression of the nitrate reductase structural gene. Plant Physiol. 91, 304-309.

Douglas, P., Moorhead, G., Hong, Y., Morrice, N. and MacKintosh, C. (1998) Purification of a nitrate reductase kinase from Spinacea oleracea leaves, and its identification as a calmodulin-domain protein kinase. Planta. 206, 435-442.

Douglas, P., Morrice, N. and Mackintosh, C. (1995) Identification of a regulatory phosphorylation site in the hinge 1 region of nitrate reductase from spinach (Spinacia oleracea) leaves. FEBS Lett. 377, 113-117.

Douglas, P., Pigaglio, E., Ferrer, A., Halford, N.G. and MacKintosh, C. (1997) Three spinach leaf nitrate reductase/3-hydroxy-3-methylglutaryl-CoA reductase kinases that are regulated by reversible phosphorylation and/or $\mathrm{Ca}^{2+}$ ions. Biochem. J. 325, 101-109.

Duke, J.A. (1983) Handbook of energy crops. An electronic publication, http://www.hort.purdue.edu/newcrop/duke_energy/dukeindex.html 
Dwivedi, U.N., Shiraishi, N. and Campbell, W.H. (1994) Identification of an "essential" cysteine of nitrate reductase via mutagenesis of its recombinant cytochrome b reductase domain. J. Biol. Chem. 269, 13785-13791.

Enroth, C., Eger, B.T., Okamoto, K., Nishino, T. and Pai, E.F. (2000) Crystal structures of bovine milk xanthine dehydrogenase and xanthine oxidase: structurebased mechanism of conversion. Proc. Natl. Acad. Sci. USA. 97, 10723-10728.

Friemann, A., Brinkmann, K. and Hachtel, W. (1991) Sequence of a cDNA encoding the bi-specific NAD(P)H-nitrate reductase from the tree Betula pendula and identification of conserved protein regions. Mol. Gen. Genet. 227, 97-105.

Galangau, F., Daniel-Vedele, F., Moureaux, T., Dorbe, M.F., Leydecker, M.T. and Caboche, M. (1988) Expression of leaf nitrate reductase genes from tomato and tobacco in relation to light-dark regimes and nitrate supply. Plant Physiol. 88, 383-388.

Garde, J., Kinghorn, J.R. and Tomsett, A.B. (1995) Sited-directed mutagenesis of nitrate reductase from Aspergillus nidulans. J. Biol. Chem. 270, 6644-6650.

Garrett, R.M. and Rajagopalan, K.V. (1994) Molecular cloning of rat liver sulfite oxidase. J. Biol. Chem. 269, 272-276.

Geiger, M., Walch-Liu, P., Engels, C., Harnecker, J., Schulze, E.-D., Ludewig, F., Sonnewald, U., Scheible, W.-R. and Stitt M. (1998) Enhanced carbon dioxide leads to a modified diurnal rhythm of nitrate reductase activity in older plants, and a large stimulation of nitrate reductase activity and higher levels of amino acids in young tobacco plants. Plant, Cell Environ. 21, 253-268.

Gelperin, D., Weigle, J., Nelson, K., Roseboom, P., Irie, K., Matsumoto, K. and Lemmon, S. (1995) 14-3-3 proteins: Potential roles in vesicular transport and Ras signaling in Saccharomyces cerevisiae. Proc. Natl. Acad. Sci. USA. 92, 1153911543.

Glaab, J. and Kaiser, W.M. (1995) Inactivation of nitrate reductase involves NR protein phosphorylation and subsequent binding of an inhibitor protein. Planta. $195,514-518$.

Glaab J, Kaiser WM (1996) The protein kinase, protein phosphatase and inhibitor protein of nitrate reductase are ubiquitous in higher plants and independent of nitrate reductase turnover. Planta. 199, 57-63. 
Gowri, G., Kenis, J.D., Ingemarsson, B., Redinbaugh, M.G. and Campbell, W.H. (1992) Nitrate reductase transcript is expressed in the primary response of maize to environmental nitrate. Plant Mol. Biol. 18, 55-64.

Hageman RH, Reed AJ (1980) Nitrate reductase from higher plants. Methods Enzymol. 69, 270-280.

Harris, N., Foster, J.M., Kumar, A., Davies, H., Gebhardt, C. and Wray, J.L. (2000) Two cDNAs representing alleles of the nitrate redustase gene of potato (Solanum tuberosum L. cv. Desirée): sequence analysis, genomic organization and expression. J. Exp. Bot. 51, 1017-1026.

Hoff, T., Truong, H.-N. and Caboche, M. (1994) The use of mutants and transgenic plants to study nitrate assimilation. Plant Cell Environ. 17, 489-506.

Howard, W.D. and Solomonson, L.P. (1982) Quaternary structure of assimilatory NADH:nitrate reductase from Chlorella. J. Biol. Chem. 257, 10243-10250.

Huber, J.L., Huber, S.C., Campbell, W.H. and Redinbaugh, M.G. (1992) Reversible light dark modulation of spinach leaf nitrate reductase activity involves protein phosphorylation. Arch. Biochem. Biophys. 296, 58-65.

Huber, J.L., Redinbaugh, M.G., Huber, S.C. and Campbell, W.H. (1994) Regulation of maize leaf nitrate reductase activity involves both gene expression and protein phosphorylation. Plant Physiol. 106, 1667-1674.

Hwang, C-F., Lin, Y., D'Souza, T. and Cheng, C-L. (1997) Sequences necessary for nitrate-dependent transcription of Arabidopsis nitrate reductase genes. Plant Physiol. 113, 853-862.

Hyde, G.E., Crawford, N.M. and Campbell, W.H. (1991) The sequence of squash NADH:nitrate reductase and its relationship to the sequences of other flavoprotein oxidoreductases. A family of flavoprotein pyridine nucleotide cytochrome reductases J. Biol. Chem. 266, 23542-23547.

Kaiser, W.M. and Brendle-Behnisch, E. (1991) Rapid modulation of spinach leaf nitrate reductase by photosynthesis. I. Modulation by $\mathrm{CO}_{2}$-availability. Plant Physiol. 96, 363-367.

Kaiser, W.M. and Förster, J. (1989) Low $\mathrm{CO}_{2}$ prevents nitrate reduction in leaves. Plant Physiol. 91, 970-974.

Kaiser, W.M. and Huber, S.C. (2001) Post-translation regulation of nitrate reductase: mechanism, physiological relevance and environmental triggers. J. Exp. Bot. 52, 1981-1989. 
Kaiser, W.M. and Spill, D. (1991) Rapid modulation of spinach leaf nitrate reductase by photosynthesis. II. In vitro modulation by ATP and AMP. Plant Physiol. 96, 368-375.

Kaiser, W.M., Spill, D. and Brendle-Behnisch, E. (1992) Adenine nucleotides are apparently involved in the light-dark modulation of spinach-leaf nitrate reductase. Planta. 186, 236-240.

Kaiser, W.M., Weiner, H. and Huber, S.C. (1999) Nitrate reductase in higher plants: A case study for transduction of environmental stimuli into control of catalytic activity. Physiol. Plant. 105, 385-390.

Kaiser, W.M., Weiner, H., Kandlbinder, A., Tsai, C-B., Rockel, P., Sonoda, M. and Planchet, E. (2002) Modulation of nitrate reductase: some new insights, an unusual case and a potentially important side reaction. J. Exp. Bot. 53, 875-882.

Kalakoutskii, K.L. and Fernandez, E. (1995) Chlamydomonas reinhardtii nitrate reductase complex has $105 \mathrm{kDa}$ subunits in the wild-type strain and a structural mutant. Plant Sci. 105, 195-206.

Kandlbinder, A., Weiner, H. and Kaiser, W.M. (2000) Nitrate reductase from leaves of Ricinus (Ricinus communis L.) and spinach (Spinacia oleracea L.) have different regulatory properties. J. Exp. Bot. 51, 1099-1105.

Kisker, C., Schindekin, H. and Rees, D.C. (1997) Molybdenum-cofactor-containing enzymes: structure and mechanism. Annu. Rev. Biochem. 66, 233-267.

Kleinhofs, A. and Warner, R.L. (1990) Advances in nitrate assimilation. In The Biochemistry of Plants (eds B.J. Miflin and P.J. Lea), pp. 89-120. Academic Press, San Diego, CA.

Klepper, L., Flesher, D. and Hagemann, R.H. (1971) Generation of reduced nicotinamide adenine dinucleotide for nitrate reduction in green leaves. Plant Physiol. 48, 580-590.

LaBrie, S.T. and Crawford, N.M. (1994) A glycine to aspartic acid change in the MoCo domain of nitrate reductase reduces both activity and phosphorylation levels in Arabidopsis. J. Biol. Chem. 269, 14497-14501.

Lam, H.-M., Coschigano, K.T., Oliveira, I.C., Melo-Oliveira, R. and Coruzzi, G.M. (1996) The molecular-genetics of nitrogen assimilation into amino acids in higher plants. Annu. Rev. Plant Physiol. Plant Mol. Biol. 47, 569-593.

Lillo, C. (1993) Magnesium and calcium inhibition of squash leaf NADH nitrate reductase. Plant Cell Physiol. 34, 1181-1185. 
Lillo, C. (1994) Light/dark regulation of higher plant nitrate reductase related to hysteresis and calcium/magnesium inhibition. Physiol. Plant. 91, 295-299.

Lillo, C., Kazazaic, S., Ruoff, P. and Meyer, C. (1997) Characterization of nitrate reductase from light- and dark-exposed leaves: comparison of different species and effects of 14-3-3 inhibitor protein. Plant Physiol. 114, 1377-1383.

Lillo, C. and Ruoff, P. (1992) Hysteretic behavior of nitrate reductase-evidence of an allosteric binding site for reduced pyridine nucleotides. J. Biol. Chem. 267, 1345613459.

Lin, Y., Hwang, C.F., Brown, J.B. and Cheng, C.L. (1994) 5' proximal regions of Arabidopsis nitrate reductase genes direct nitrate-induced transcription in transgenic tobacco. Plant Physiol. 106, 477-484.

Lu, G., Campbell, W.H., Schneider, G. and Lindqvist, Y. (1994) Crystal structure of the FAD-containing fragment of corn nitrate reductase at $2.5 \AA$ resolution: relationship to other flavoprotein reductases. Structure. 2, 809-821.

Lu, G., Lindqvist, Y., Schneider, G., Dwivedi, U.N. and Campbell, W.H. (1995) Structural studies on corn nitrate reductase. Refined structure of the cytochrome b reductase fragment at $2.5 \AA$, its ADP complex and an active site mutant and modeling of the cytochrome b domain. J. Mol. Biol. 248, 931-948.

MacKintosh, C. (1992) Regulation of spinach-leaf nitrate reductase by reversible phosphorylation. Biochem. Biophys. Acta 1137, 121-126.

MacKintosh, C., Douglas, C. and Lillo, C. (1995) Identification of a protein that inhibits the phosphorylated form of nitrate reductase from spinach (Spinacia oleracea) leaves. Plant Physiol. 107, 451-457.

MacKintosh, C. and Meek, S.E.M. (2001) Regulation of plant NR activity by reversible phosphorylation, 14-3-3 proteins and proteolysis. Cell. Mol. Life Sci. 58, 205-214.

Man, H-M., Abd-El Baki, G.K., Stegmann, P., Weiner, H. and Kaiser, W.M. (1999) The activation state of nitrate reductase is not always correlated with total nitrate reductase activity in leaves. Planta. 209, 462-468.

Melzer, J.M., Kleinhofs, A. and Warner, R.L. (1989) Nitrate reductase regulation: Effects of nitrate and light on nitrate reductase mRNA accumulation. Mol. Gen. Genet. 217, 341-346. 
Meyer, C., Levin, J.M., Roussel, J-M. and Rouze, P. (1991) Mutational and structural analysis of the nitrate reductase heme domain of Nicotiana plumbaginifolia. J. Biol. Chem. 266, 20561-20566.

Miyazaki, J., Juricek, M., Angelis, K., Schnorr, K.M., Kleinhofs, A. and Warner, R.L. (1991) Characterization and sequence of a novel nitrate reductase from barley. Mol. Gen. Genet. 228, 329-334.

Moorhead, G., Douglas, P., Cotelle, V., Harthill, J., Morrice, N., Meek, S., Deiting, U., Stitt, M., Scarabel, M., Aitken, A. and MacKintosh, C. (1999) Phosphorylation-dependent interactions between enzymes of plant metabolism and 14-3-3 proteins. Plant J. 18, 1-12.

Moorhead, G., Douglas, P., Morrice, N., Scarabel, M., Aitken, A. and MacKintosh, C. (1996) Phosphorylated nitrate reductase from spinach leaves is inhibited by 14-3-3 proteins and activated by fusiccocin. Curr. Biol. 96, 11041113.

Neville, D.M. (1971) Molecular weight determination of protein-dodecyl sulfate complexes by gel electrophoresis in a discontinuous buffer system. J. Biol. Chem. 246, 6328-6334.

Nussaume, L., Vincentz, M., Meyer, C., Boutin, J-P. and Caboche, M. (1995) Post-transcriptional regulation of nitrate reductase by light is abolished by an Nterminal deletion. Plant Cell. 7, 611-621.

Pearson, R.B. and Kemp, B.E. (1991) Protein kinase phosphorylation site sequences and consensus specificity motifs: tabulations. Methods Enzymol. 200, 62-81.

Perdomo, G., Navarro, F.J., Medina, B., Machín, F., Tejera, P. and Siverio, J.M. (2002) Tobacco Nia2 cDNA functionally complements a Hansenula polymorpha yeast lacking nitrate reductase. A new expression system for the study of plant proteins involved in nitrate assimilation. Plant Mol. Bio. 50, 405-413.

Pigaglio, E., Durand, N. and Meyer, C. (1999) A conserced acidic motif in the Nterminal domain of nitrate reductase is necessary for the inactivation of the enzyme in the dark by phosphorylation and 14-3-3 binding. Plant Physiol. 119, 219-229.

Pouteau, S., Chérel, I., Vaucheret, H. and Caboche, M. (1989) Nitrate reductase mRNA regulation in Nicotiana plumbaginifolia nitrate reductase-deficient mutants. Plant Cell. 1, 1111-1120. 
Predomo, G., Navarro, F.J., Medina, B., Machín, F., Tejera, P. And Siverio, J.M. (2002) Tobacco Nia2 cDNA functionally complements a Hansenula polymorpha yeast mutant lacking nitrate reductase. A new expression system for the study of plant proteins involved in nitrate assimilation. Plant Mol. Bio. 50, 405-413.

Provan, F., Aksland, L-M., Meyer, C. and Lillo, C. (2000) Deletion of the nitrate reductase N-terminal domain still allows binding of 14-3-3 proteins but affects their inhibitory properties. Plant Physiol. 123, 757-764.

Rajasekhar, V.K., Gowri, G. and Campbell, W.H. (1988) Phytochrome-mediated light regulation of nitrate reductase expression in squash cotyledons. Plant Physiol. $88,242-244$.

Riens, B. and Heldt, H.W. (1992) Decrease of nitrate reductase activity in spinach leaves during a light-dark transition. Plant Physiol. 98, 573-577.

Rockel, P., Strube, F., Rockel, A., Wildt, J. and Kaiser, W.M. (2002) Regulation of nitric oxide (NO) production by plant nitrate reductase in vivo and in vitro. $J$. Exp. Bot. 53, 103-110.

Schöndorf, T. and Hachtel, W. (1995) The choice of reducing substrate is related by the replacement of an alanine by a proline in the FAD domain of a bispecific NAD(P)H-nitrate reductase from birch. Plant Physiol. 108, 203-210.

Solomonson, L.P. and Barber, M.J. (1990) Assimilatory nitrate reductase-functional properties and regulation. Annu. Rev. Plant Physiol. Plant Mol. Biol. 41, 225-253.

Spill, D. and Kaiser, W.M. (1994) Partial purification of two proteins (100 kDa and $67 \mathrm{kDa}$ ) cooperating in the ATP-dependent inactivation of spinach leaf nitrate reductase. Planta. 192, 183-188.

Stitt, M. (1999) Nitrate regulation of metabolism and growth. Curr. Opin. Plant Biol. 2, $178-186$.

Strater, T. and Hachtel, W. (2000) Identification of light- and nitrate-responsive regions of the nitrate reductase promoter from birch. Plant Sci. 150, 153-161.

Su, W., Huber, S.C. and Crawford, N.M. (1996) Identification in vitro of a posttranslational regulatory site in the hinge region of Arabidopsis nitrate reductase. Plant Cell. 8, 519-527.

Su, W., Mertens, J.A., Kanamaru, K., Campbell, W.H. and Crawford, N.M. (1997) Analysis of wild-type and mutant plant nitrate reductase expressed in the methylotrophic yeast Pichia pastoris. Plant Physiol. 115, 1135-1143. 
Tischner, R. (2000) Nitrate uptake and reduction in higher and lower plants. Plant Cell Environ. 23, 1005-1024.

van Heusden, G.P.H., Wenzel, T.J., Lagendijk, E.L., de Steensma, H.Y. and van den Berg, J.A. (1992) Characterization of the yeast BMHI gene encoding a putative protein homologous to mammalian protein kinase II activators and protein kinase C inhibitors. FEBS Lett. 302, 145-150.

Vincentz, M. and Caboche, M. (1991) Constitutive expression of nitrate reductase allows normal growth and development of Nicotiana plumbaginifolia plants. ЕМВО J. 10, 1027-1035.

Vincentz, M., Moureaux, T., Leydecker, M.-T., Vaucheret, H. and Caboche, M. (1993) Regulation of nitrate and nitrite reductase expression in Nicotiana plumbaginifolia leaves by nitrogen and carbon metabolites. Plant J. 3, 1027-1035.

Wang, R., Guegler, K., LaBrie, S.T. and Crawford, N.M. (2000) Genomic analysis of a nutrient response in Arabidopsis reveals diverse expression patterns and novel metabolic and potential regulatory genes induced by nitrate. Plant Cell. 12, 14911509.

Weiner, H. and Kaiser, W.M. (2000) Binding of 14-3-3 proteins is not sufficient to inhibit nitrate reductase in spinach leaves. FEBS Lett. 480, 217-220.

Yamasaki, H. and Sakihama, Y. (2000) Simultaneous production of nitric oxide and peroxynitrite by plant nitrate reductase: in vitro evidence for the NR-dependent formation of active nitrogen species. FEBS Lett. 468, 89-92.

Zhang, N. and MacKown, C.T. (1993) Nitrate fluxes and nitrate reductase activity of suspension-cultured tobacco cells. Plant Physiol. 102, 851-857. 


\section{Appendix}

\subsection{Abbreviations}

\begin{tabular}{|c|c|}
\hline$\%$ & percent \\
\hline AICAR & 5-aminoimidazole-4-carboxiamide riboside \\
\hline Ala & alanine; A \\
\hline Arg & arginine; $\mathrm{R}$ \\
\hline Asp & aspartic acid; D \\
\hline AtNR2 & Arabidopsis thaliana NR2 \\
\hline ATP & adenosine 5 ' triphosphate \\
\hline BMG & buffered minimal glycerol \\
\hline $\mathrm{BMM}(\mathrm{H})$ & buffered minimal methanol (histidine) \\
\hline $\mathrm{bp}$ & base pair \\
\hline BSA & bovine \\
\hline CaMV 35S & Cauliflower mosaic virus $35 \mathrm{~s}$ promoter \\
\hline cDNA & complementary DNA \\
\hline $\mathrm{cm}^{2}$ & square centimeter \\
\hline Cys & cysteine; $\mathrm{C}$ \\
\hline $\mathrm{d}$ & day \\
\hline DNA & deoxyribonucleic acid \\
\hline dNTP & 2'-desoxyribonucleosid-5'-triphosphate \\
\hline DTT & 1, 4-dithiothreitol \\
\hline EDTA & ethylenediamine tetraacetate \\
\hline FAD & flavine adenine nucleotide \\
\hline FW & fresh weight \\
\hline $\mathrm{g}$ & gram \\
\hline Gln & glutamine; Q \\
\hline Glu & glutamic acid; E \\
\hline GOGAT & glutamate synthase \\
\hline GS & glutamine synthetase \\
\hline $\mathrm{h}$ & hour \\
\hline HEPES & N-2-Hydroxyethylpiperazine-N'-2-ethanesulfonic acid \\
\hline His & histidine; $\mathrm{H}$ \\
\hline $\mathrm{kDa}$ & kilo dalton \\
\hline LB & Luria-Bertani \\
\hline $\mathrm{M}$ & molar \\
\hline $\mathrm{mA}$ & milli Ampere \\
\hline $\min$ & minute \\
\hline $\mathrm{mL}$ & milliliter \\
\hline $\mathrm{mM}$ & millimolar \\
\hline MOPS & 4-morpholinic-propansulfonic acid \\
\hline mRNA & messenger RNA \\
\hline NADH & nicotinamide adenine dinucleotide (reduced) \\
\hline NADPH & nicotinamide adenine dinucleotide phosphate (reduced) \\
\hline NO & nitric oxide \\
\hline NR & nitrate reductase \\
\hline NRA & nitrate reductase activity \\
\hline OD & optical density \\
\hline
\end{tabular}




$\begin{array}{ll}\text { PAGE } & \text { polyacrylamide-gelelectrophoresis } \\ \text { PCR } & \text { polymerase chain reaction } \\ \text { pH } & \text { potential of Hydrogen, pH scale is logarithmic } \\ \text { phospho-NR } & \text { phosphorylated-nitrate reductase } \\ \text { PHYLIP } & \text { Phylogeny Inference Package } \\ \text { ppb } & \text { part per billion } \\ \text { Pro } & \text { proline;P } \\ \text { PVPP } & \text { polyvinylpolypyrrolidone } \\ \text { RACE } & \text { Rapid Amplification of cDNA Ends } \\ \text { RcNR } & \text { Ricinus communis NR } \\ \text { RNA } & \text { ribonucleic acid } \\ \text { RNase } & \text { ribonuclease } \\ \text { RT } & \text { room temperature } \\ \text { SD } & \text { standard deviation } \\ \text { SDS } & \text { sodium dodecyl sulfate } \\ \text { Ser } & \text { serine; S } \\ \text { TAE } & \text { Tris-acetate-EDTA } \\ \text { Taq } & \text { Thermus aquaticus } \\ \text { TBS } & \text { Tris buffered saline } \\ \text { TEMED } & \text { N,N,N,N-tetramethylaminomethane } \\ \text { Thr } & \text { threonine; T } \\ \mathrm{T}_{\mathrm{m}} & \text { annealing temperature } \\ \text { Tris } & \text { Tris-(hydroxymethyl)-aminomethane } \\ \text { V } & \text { volt } \\ \text { v/v } & \text { volume/volume } \\ \text { Val } & \text { valine; V } \\ \text { w/v } & \text { weight/volume } \\ \text { UV } & \text { ultraviolet } \\ & \end{array}$

\subsection{Oligo Nucleotide Primers}

\begin{tabular}{|llc|}
\hline Name & Nucleotide Sequence & $\mathbf{T}_{\mathbf{m}}$ \\
\hline & & \\
RcNR-S1 & 5'-ATTGGTGGAAAATGGTAAAGTGG -3' & 59.3 \\
AS-Arabidopsis & 5'-CACGAACAATCTCTTTGGCAC-3 ' & 62.7 \\
RcNR-S-RACE & 5'-GCTGAAGCATGGTGGTATAAGCCGG-3' & 66.3 \\
RcNR-AS-RACE & 5'-TCTCTTTGGCACCAAGGAGGTCCAG-3' & 66.3 \\
5'-AOX1 & 5'-GACTGGTTCCAATTGACAAGC-3' & 57.9 \\
3'-AOX1 & 5'-GCAAATGGCATTCTGACATCC -3' & 57.9 \\
RcNR-SF-2 & 5'-AAACCGCGGAATAATGGCGCCTCTGTGGACA & $>75$ \\
RcNR-ASF & 5CAGGC-3' & \\
& '-TAGAATACTAGCAATGAATTCTTGATATC-3' & 59.9 \\
\hline
\end{tabular}




\subsection{Vectors}

\subsection{1 pCR $^{\circledR}$ 2.1-TOPO}

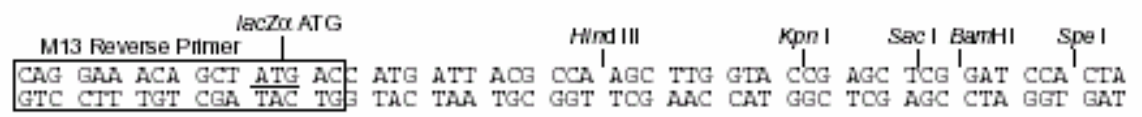
BSXI ECORI

GTA ACG GCC GCC AGT GTG ICTG GAA TTC GCC CTT PCR Product IATG GGC GAA TTC TGC

$\begin{array}{llllll}\text { EcoRV } & \text { BspXI } & \text { Not I } & \text { Xnol } & \text { NSI IXbal } & \text { Apal }\end{array}$ AGA TAT CCA TCA CAC TGG I CGg COG CTC GAg CAT GCA TCT AGA GGG I CCC AAT TCG CCC TAT

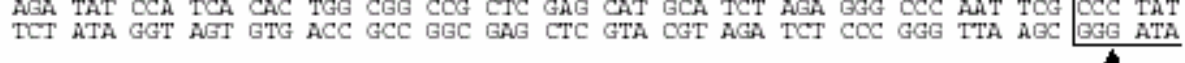

M13 Forward (-20) Primer \begin{tabular}{l} 
AGT GAG TCG TAT TA AAT TCA CTG GCC GTC GTT TTA GAA CGT CGT GAC TGG GAA AAC \\
TCA CTC AGC ATA AT TTA AGT GAC CGG CAG CAA AAT GIT GCA GCA CTG ACC CTT TIT \\
\hline
\end{tabular}

Comments for $\mathrm{pCR}^{\oplus 2.1-\mathrm{TOPO}}$

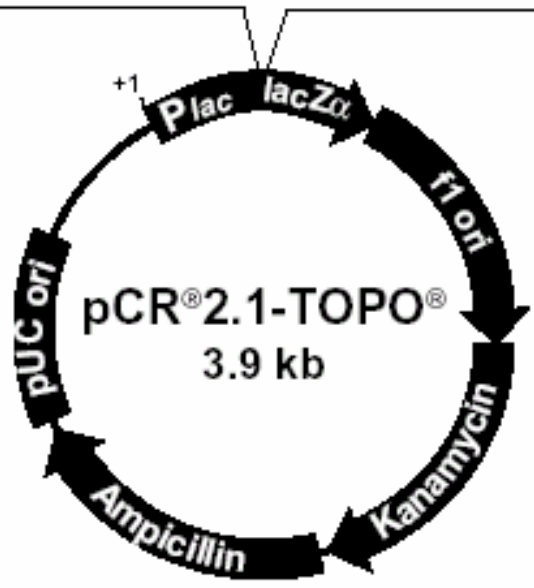

3931 nucleotides

LacZ $\alpha$ fragment: bases 1-547

M13 reverse priming site: bases 205-221

Multiple cloning site: bases 234-357

T7 promoter/priming site: bases $364-383$

M13 Forward (-20) priming site: bases 391-406

f1 origin: bases 548-985

Kanamycin resistance ORF: bases 1319-2113

Ampicillin resistance ORF: bases 2131-2991

pUC origin: bases 3136-3809

source: http://www.invitrogen.com/content/sfs/vectors/pcr2_1topo_map.pdf 


\subsection{2 pPICZA}

\section{Comments for pPICZ A:} 3329 nucleotides

$5^{\prime}$ AOX1 promoter region: bases 1-941

$5^{\prime}$ end of AOX1 mRNA: base 824

5' AOX1 priming site: bases $855-875$

Multiple cloning site: bases $932-1011$

c-myc epitope tag: bases 1012-1044

Polyhistidine tag: bases 1057-1077

3 ' AOX priming site: bases 1159-1179

$3^{\prime}$ end of mRNA: base 1250

AOX1 transcription termination region: bases 1078-1418

Fragment containing TEF1 promoter: bases 1419-1830

EM7 promoter: bases 1831-1898

Sh ble ORF: bases 1899-2273

CYC1 transcription termination region: bases 2274-2591

pUC origin: bases 2602-3275 (complementary strand)

\section{c-myc epitope 6 xHis}

One Nco I restriction enzyme site: 1898; One Sac I site: 209

Source: http://www.invitrogen.com/content/sfs/vectors/ppicz_map.pdf 


\subsection{3 pHILD2}

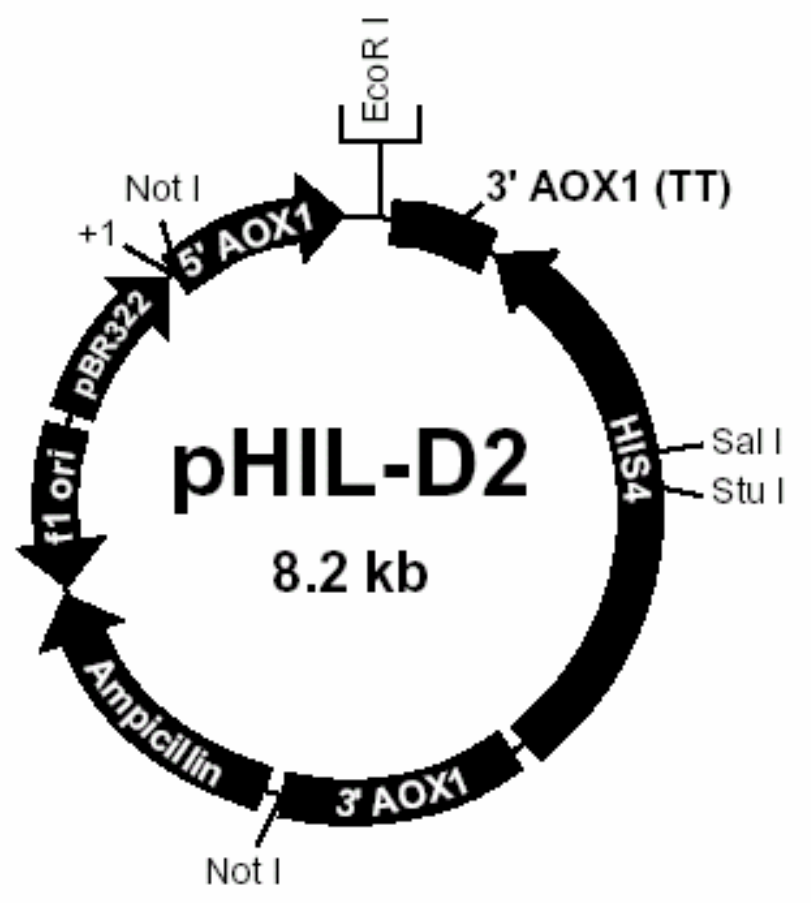

Comments for pHIL-D2:

8209 nucleotides

5' AOX1 promoter fragment: bases 14-941

5' AOX1 primer site: bases $868-888$

EcoR I Site: bases 956-961

3' AOX1 primer site: bases 1036-1056

3' AOX1 transcription

termination (TT) fragment: bases 963-1295

HIS4 ORF: bases 4223-1689

3' AOX1 fragment: bases 4578-5334

Ampicillin resistance gene: bases 5686-6546

f1 origin of replication: bases 7043-6588

pBR322 origin: bases 7138-7757

Source: http://www.invitrogen.com/content/sfs/vectors/phild2_map.pdf 


\subsection{Key invariant residues in Ricinus NR}

\begin{tabular}{|c|c|c|}
\hline Domain / Region & Key Residues & Function \\
\hline \multirow[t]{9}{*}{$M o-M P T$} & 8 & Nitrate reducing / Active site \\
\hline & Arg139 & Nitrate binding \\
\hline & His 141 & MPT binding \\
\hline & Cys 186 & Mo ligand \\
\hline & Arg191 & Nitrate binding \\
\hline & His 286 & MPT binding \\
\hline & Arg291 & MPT binding \\
\hline & Gly300 & Mo ligand \\
\hline & Lys304 & MPT binding \\
\hline \multirow[t]{3}{*}{ Dimer interface } & 2 & Formation of stable dimer \\
\hline & Glu352 & Ionic bond at interface \\
\hline & Lys391 & Ionic bond at interface \\
\hline \multirow[t]{2}{*}{ Hinge 1} & 1 & Regulatroy \\
\hline & Ser526 & Phosphorylated \\
\hline \multirow[t]{3}{*}{ Cytochrome b } & 2 & Heme-Fe binding \\
\hline & His 569 & Heme-Fe ligand \\
\hline & His 592 & Heme-Fe ligand \\
\hline \multirow[t]{6}{*}{$F A D$} & 5 & FAD binding / Active site \\
\hline & Arg709 & Binds FAD \\
\hline & Tyr711 & Binds FAD \\
\hline & Gly742 & Binds FAD \\
\hline & Ser745 & Binds FAD \\
\hline & Lys 748 & Binds NADH \\
\hline \multirow[t]{4}{*}{$N A D H$} & 3 & NADH binding / Actice site \\
\hline & Gly791 & Binds NADH \\
\hline & Cys 886 & Active site \\
\hline & Phe914 & C-terminal \\
\hline
\end{tabular}




\subsection{Amino acid sequence alignments (N-terminus)}

\begin{tabular}{|c|c|c|c|}
\hline Ricinus & : & TLNGV--VRPF KSG----------PTHRSDSP IRI & \\
\hline quash & : & GV--VRSF KNG----------PNHR A DSPVR & \\
\hline hicory & & NRSFSPN-----------HRRS & \\
\hline ONR1 & & $--\mathrm{RSF} \mathrm{KP}--------------\mathrm{RSI}$ & \\
\hline TobaccoNR2 & & $5-----\mathrm{RSF}$ KP $--------------\mathrm{RSD}$ & \\
\hline Rape-NR1 & : & NGG-VVHSFKPP----------LVPSPS- & \\
\hline Rape-NR2 & : & JG--VVRSFKPP----------PIPSP- & \\
\hline $\mathrm{cch}$ & : & PSGVVRT----PFSNH------------HRSDSPVRN & \\
\hline ÁtNR1 & 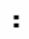 & $---T M N G--V A H A F$ KPP----------LVPSPRSF DRHRHQN & \\
\hline AtNR2 & : & LEPGLNG--VVRSYKPP-----------VPGRSD & \\
\hline otato & & LEPGLSGV--GRNF KP--------------RPDSPVR-GCNF & \\
\hline Tomato & & LEPGLSGV--GRTF KP--------------RPDSPVR-GC & \\
\hline unia & : & V--VRSF KP--------------RSDSPVR-GCNF & \\
\hline Barley & : & P-TARAPGSN---------GIRRRADSPVR-GC & \\
\hline iean & : & -- VURSCGQD----------LKPSLP-------LD & \\
\hline oybean-1 & : & 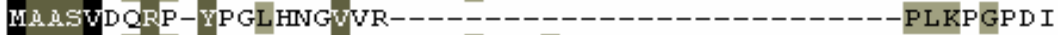 & \\
\hline Soybean-2 & 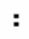 & $--V V R A C G P D----------F N T P L P---$ & \\
\hline Rice-NR1 & : & GSAP-VRGAASSNGAKAYPP ANGIPRRADSPVR-GCGF & \\
\hline Zeamays & & RLP YPDLPVD------------ILRRSSVR-GSGF & \\
\hline
\end{tabular}

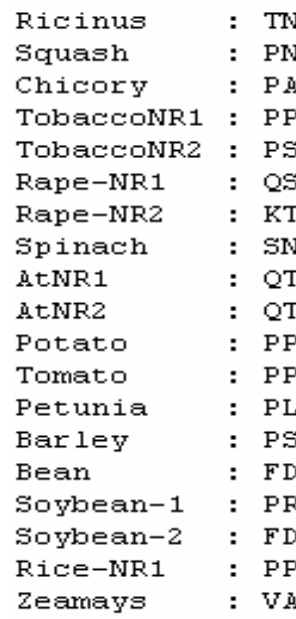

Ricinus Squash

Chicory
TobaccoNR TobaccoNR2 Rape-NR1 Rape-NR2 Spinach it NR 1 atNR2 Potato Tomato Petunia Bar ley Bean Soybean-1 Sovbean-2 Rice-NR1 zeamays 


\subsection{Amino acid sequence alignments (without $\mathrm{N}$-terminus)}

Three prosthetic domains are marked by a shadow. Identical sequences are indicated by a dot, and gaps introduced for alignment purpose by a dash. Unique amino acid residue of Ricinus NR is labeled in blue color. T. platyph: Tilia platyphyllos, N. sylvest: Nicotiana sylvestris, N. tabacum: Nicotiana tabacum.

Ricinus
AtNR2
Spinach
AtNR1
Lotus
Bean
Soybean
Peach
Squash
Birch
T. platyph
N. sylvest
N. tabacum
Petunia
Tomato
Potato
Brassica
Maize

Ricinus

AtNR2

Spinach

AtNR1

Lotus

Bean

Soybean

Peach

Squash

Birch

T. platyph

N. sylvest

N. tabacum

Petunia

Tomato

Potato

Brassica

Maize

Ricinus

AtNR2

Spinach

AtNR1

Lotus

Bean

Soybean

Peach

Squash

Birch

T. platyph

N. sylvest

N. tabacum

Petunia

Tomato

Potato

Brassica

Maize

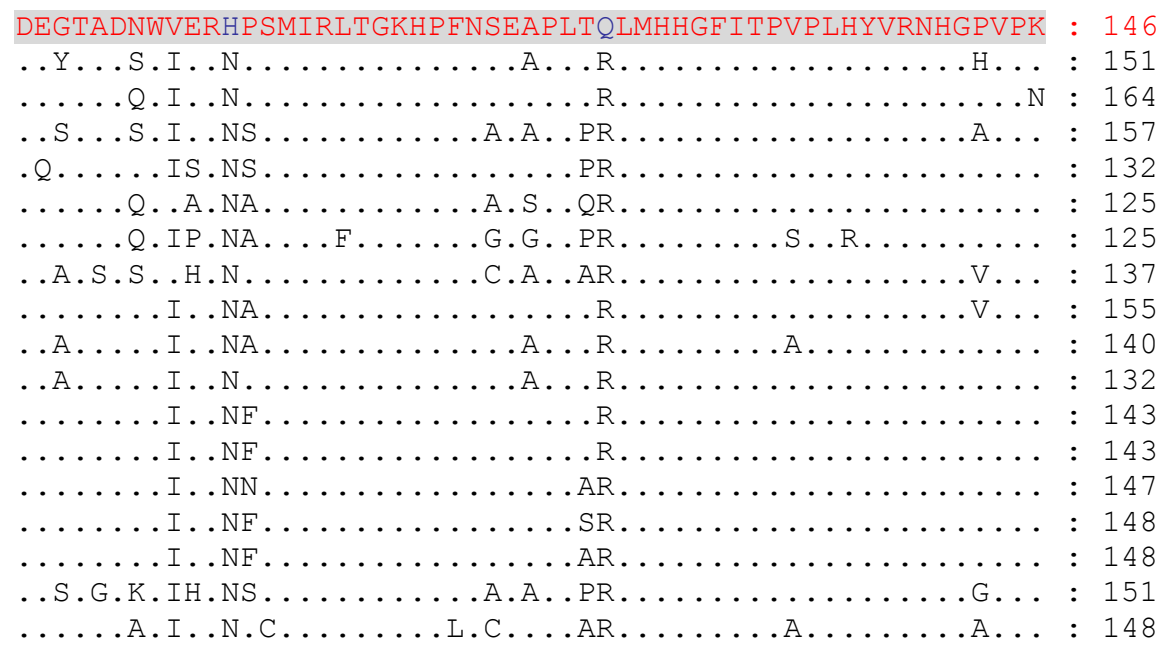

ASWKDWTVEICGLVKKPTRFTMDQLVNDFPSRELPVTLVCAGNRRKEQNMVKQTI : 201

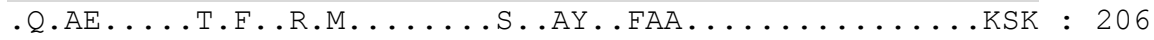

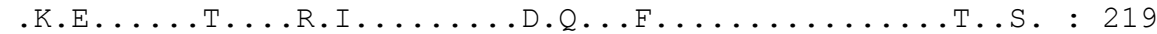

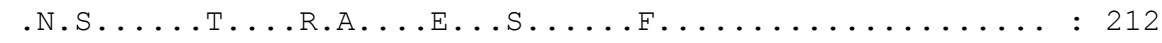

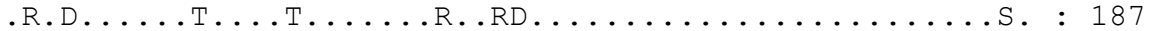

.N.E........R.....R.R................... : 180

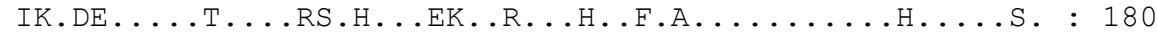

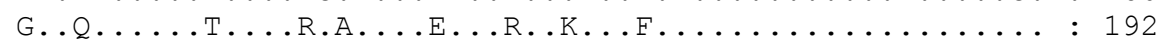

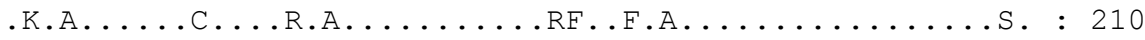

.R.E.......R.A...R..T.R................ : 195

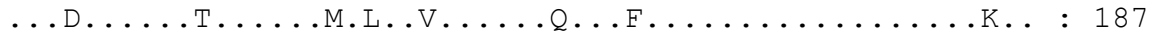

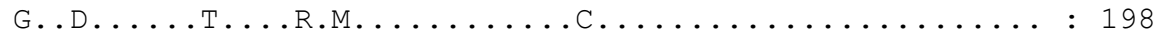

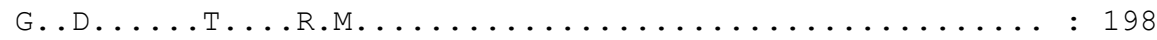

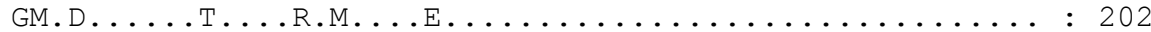

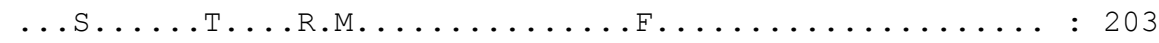

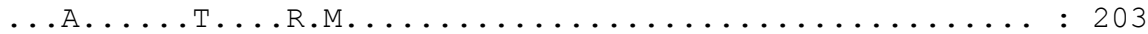

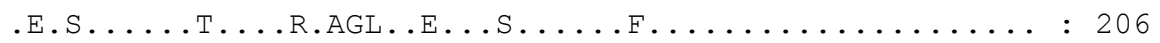

GD.AT.......R.A.L..E.ARD..AV.I...A.........: 203

GFNWGAAGVSNSVWRGVPLHFVLKRCGIYSRKKGALNVCFEGAEDLPGGG---GS : 253

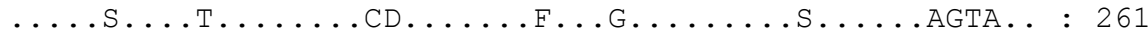

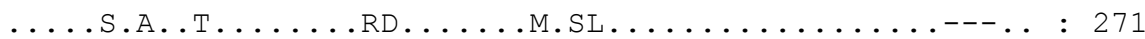

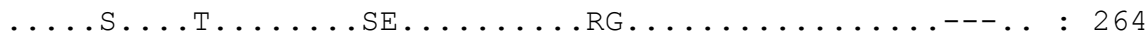

............S.RH ...R.Q..SR..H.........-..: 239

.......T.....RH...................-.. : 232

............RH.....LA.M..MY.S.......-...: 232

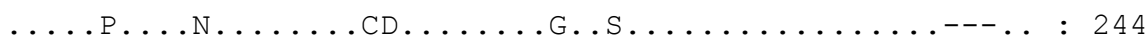

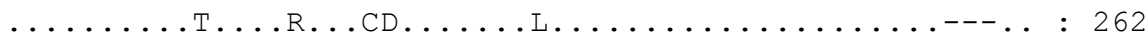

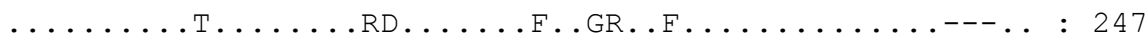

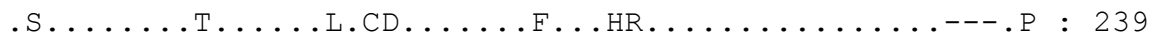

$\ldots \ldots$.........RA...................-.. : 250

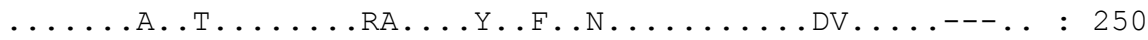

............RA.................... : 254

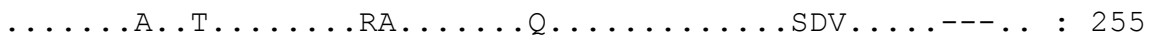

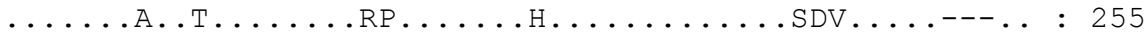

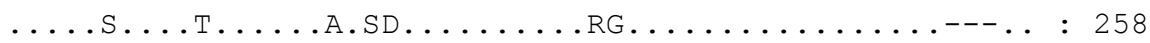

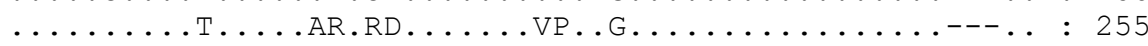


Ricinus

AtNR2

Spinach

AtNR1

Lotus

Bean

Soybean

Peach

Squash

Birch

T. platyph

N. sylvest

N. tabacum

Petunia

Tomato

Potato

Brassica

Maize

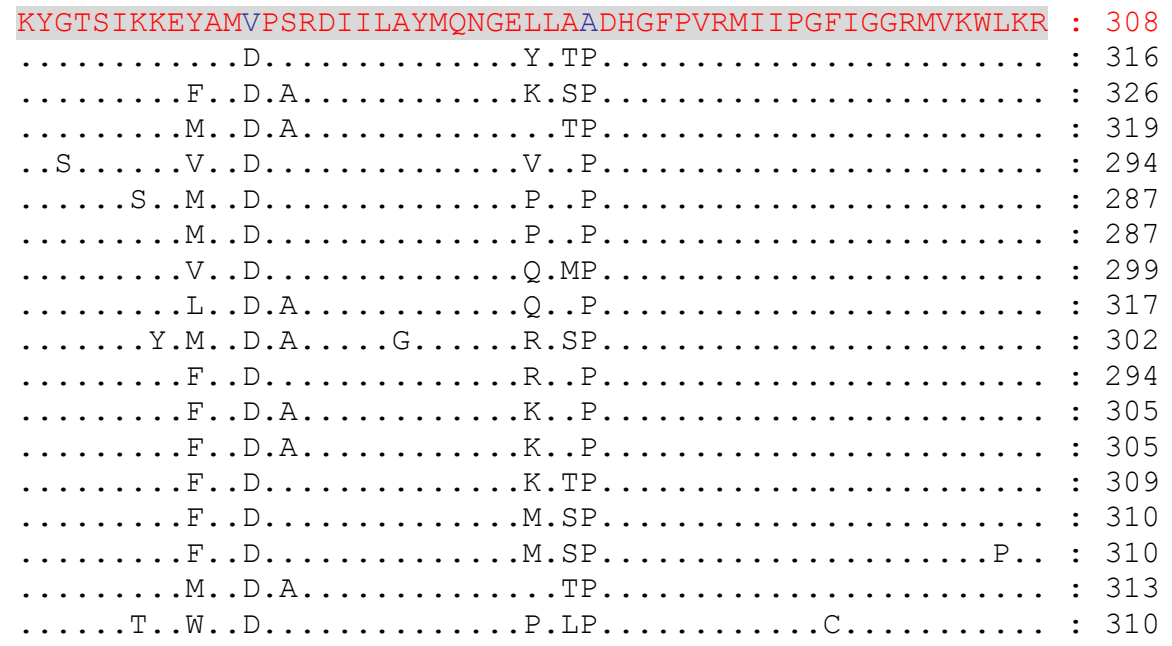

IIVTTKESDNYYHYKDNRVLPSHVDAELANAEAWWYKPEYIINELNINSVITTPS : 363

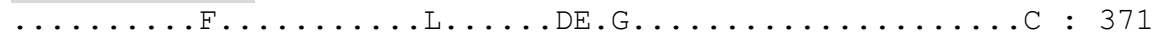

AtNR2

Spinach

AtNR1

Lotus

Bean

Soybean

Peach

Squash

Birch

T. platyph

N. sylvest

N. tabacum :

Petunia

Tomato

Potato

Brassica

Maize

Ricinus

AtNR2

Spinach

AtNR1

Lotus

Bean

Soybean

Peach

Squash

Birch

T. platyph

N. sylvest

N. tabacum

Petunia

Tomato

Potato

Brassica

Maize

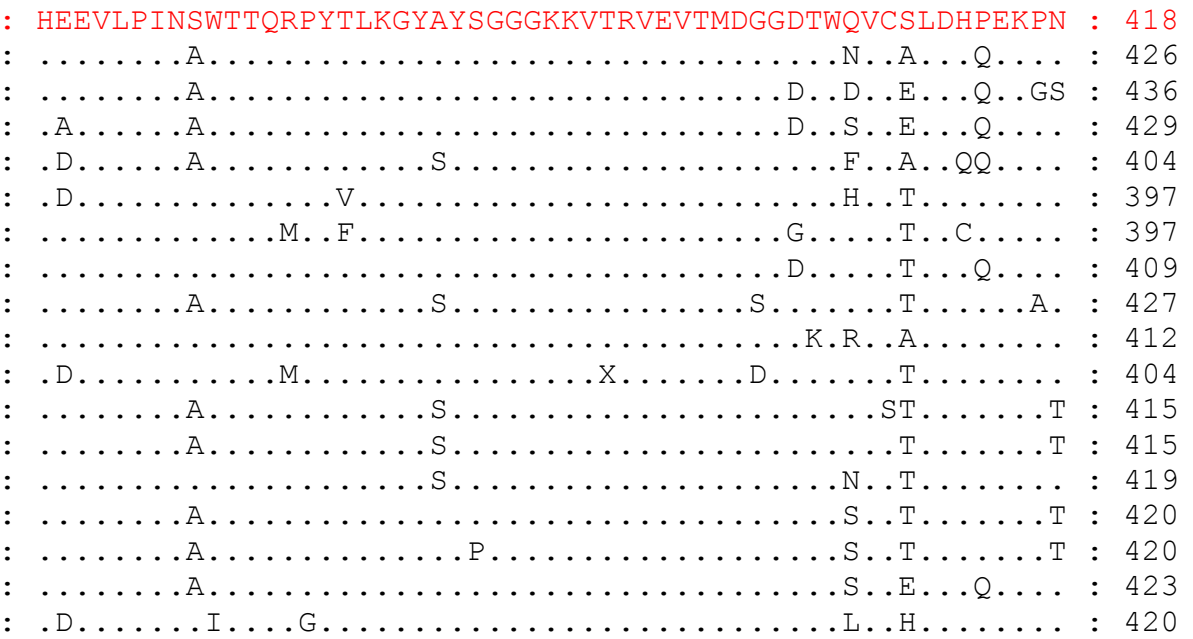


Ricinus

AtNR2

Spinach

AtNR1

Lotus

Bean

Soybean

Peach

Squash

Birch

T. platyph

N. sylvest

N. tabacum

Petunia

Tomato

Potato

Brassica

Maize

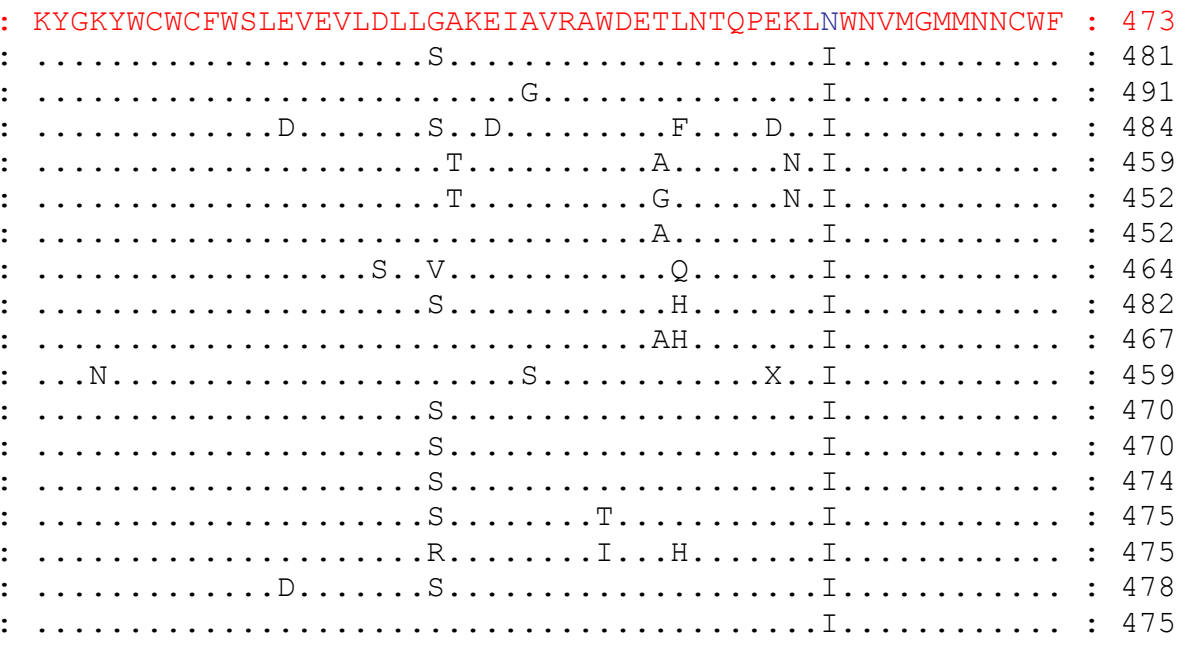

RIKTNVCKRHKGEIGIVEEHPTVPANQSGGWMAKERHLEISSENHP-ILKKSVST : 527

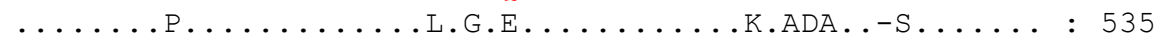

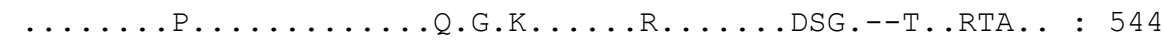
................................. 538

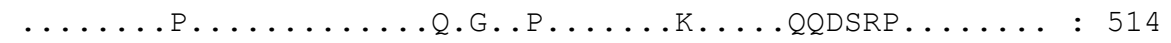
$\ldots \ldots \ldots$......................EAKPS.....: 506

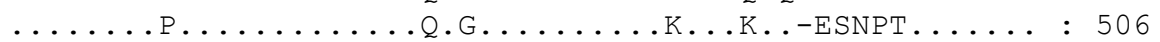

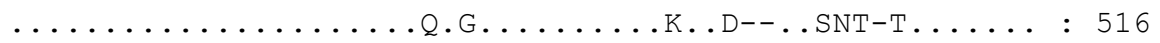
................................ 536 ........................R.KN.T..DANQ-S.....: 521

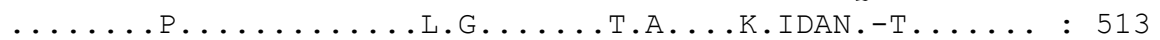

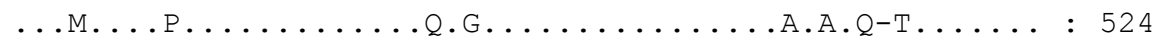
..M....................... 524 .......................... 528 ........................ 529 ..MKCV.P....................... 529 ................................... 532 ..V...P.........G.....R.K..TAEAAA.-G.R.T. : 529
Ricinus AtNR2 Spinach AtNR1 Lotus Bean Soybean Peach Squash Birch T. platyph N. sylvest N. tabacum Petunia Tomato Potato Brassica Maize

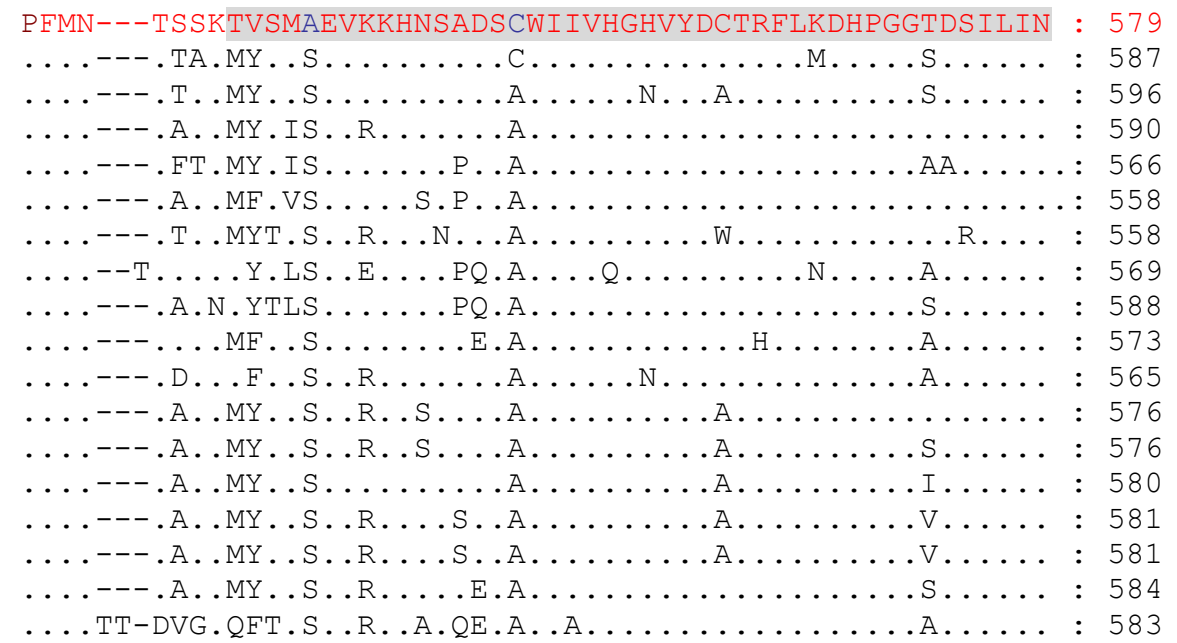


Ricinus

AtNR2

Spinach

AtNR1

Lotus

Bean

Soybean

Peach

Squash

Birch

T. platyph

N. sylvest:

N. tabacum

Petunia

Tomato

Potato

Brassica

Maize

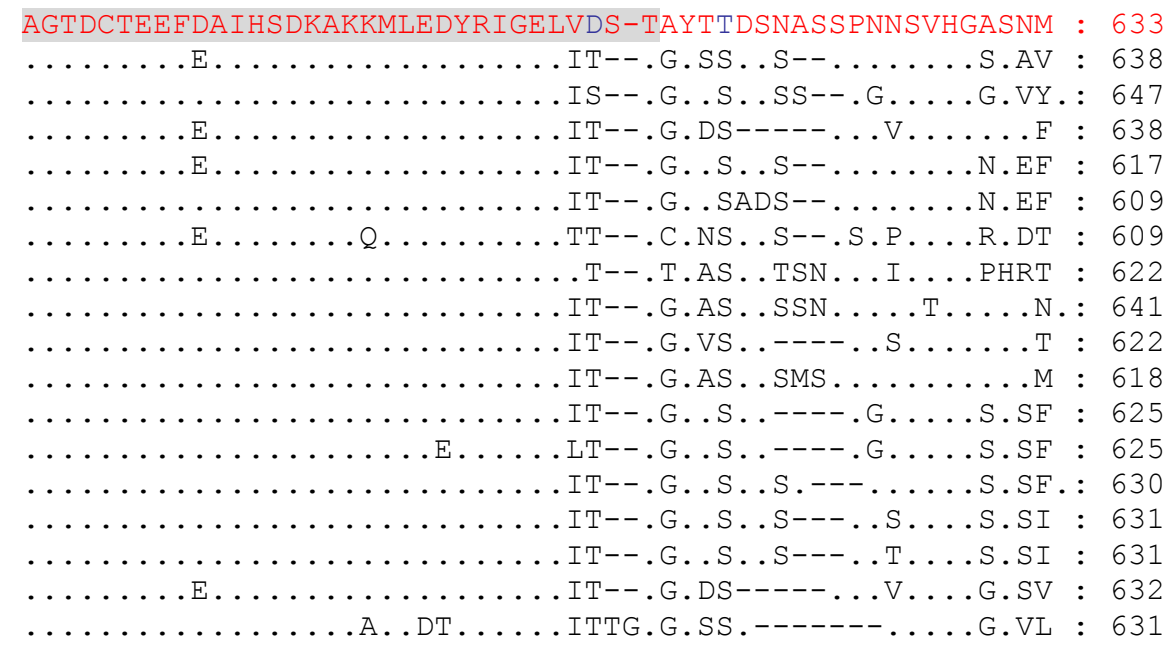

AGTDCTEEFDAIHSDKAKKMLEDYRIGELVDS-TAYTTDSNASSPNNSVHGASNM : 633

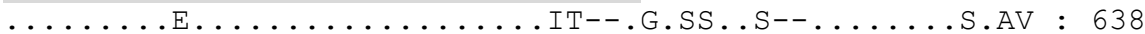

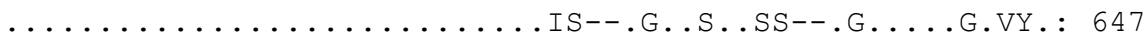

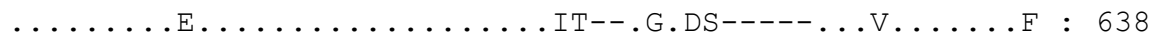

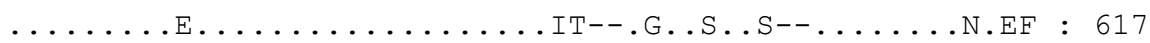

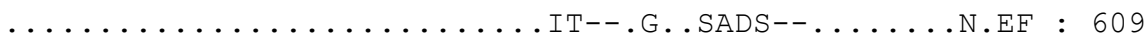

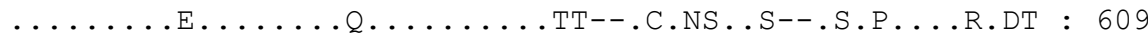

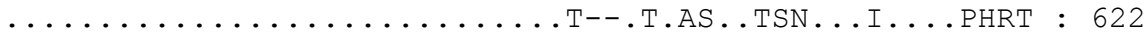

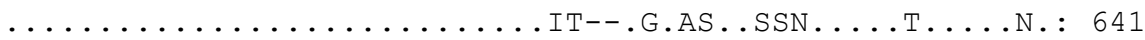

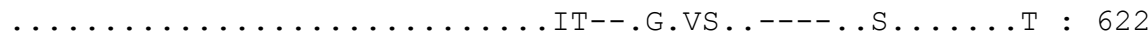

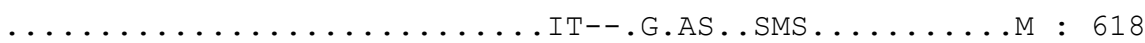

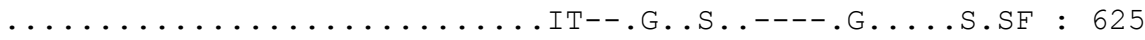

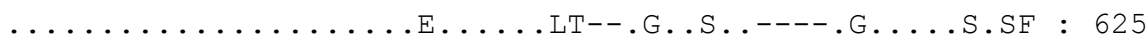

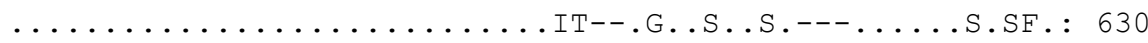

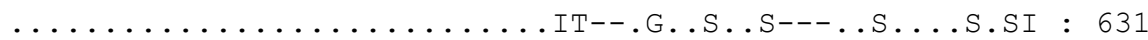

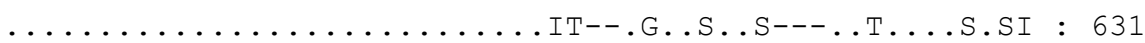

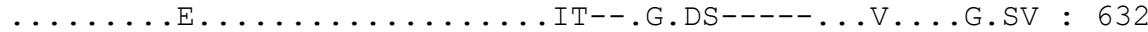
...................ITTG.G.SS.------.....VL : 631

Ricinus AtNR2 Spinach AtNR1 Lotus Bean Soybean Peach Squash Birch T. platyph : N. sylvest N. tabacum : Petunia Tomato Potato Brassica Maize

\section{Ricinus} AtNR2 Spinach AtNR1 Lotus Bean Soybean Peach Squash Birch T. platyph N. sylvest N. tabacum Petunia Tomato Potato Brassica Maize

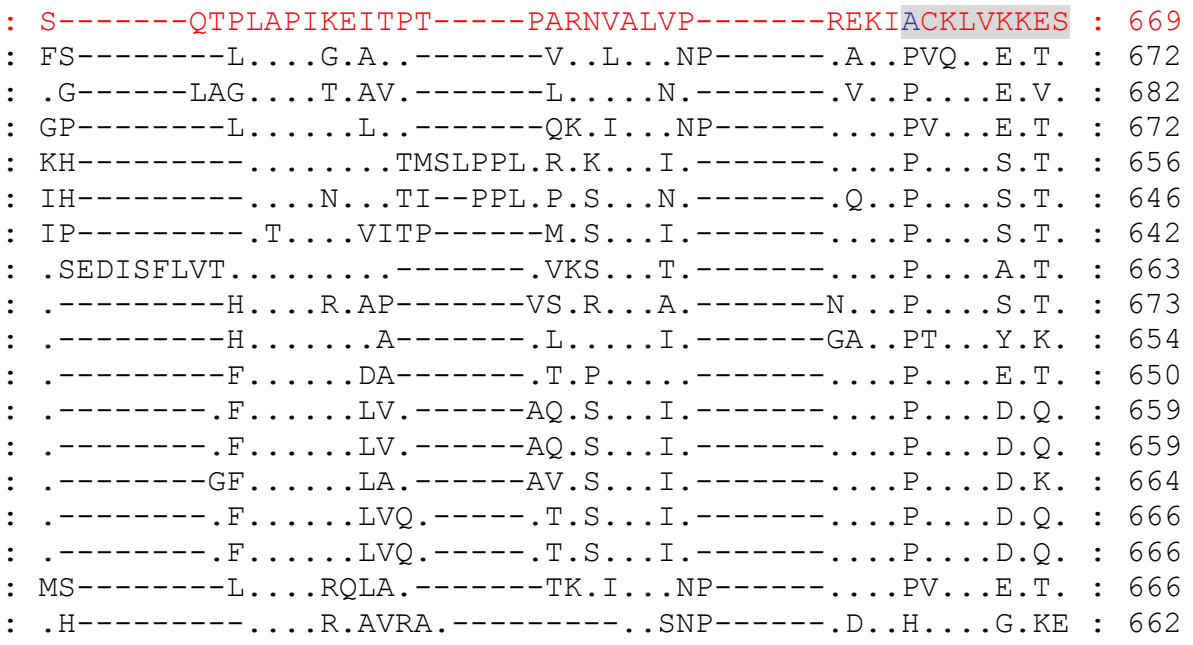


Ricinus

AtNR2

Spinach

AtNR1

Lotus

Bean

Soybean

Peach

Squash

Birch

T. platyph

N. sylvest

N. tabacum

Petunia

Tomato

Potato

Brassica

Maize

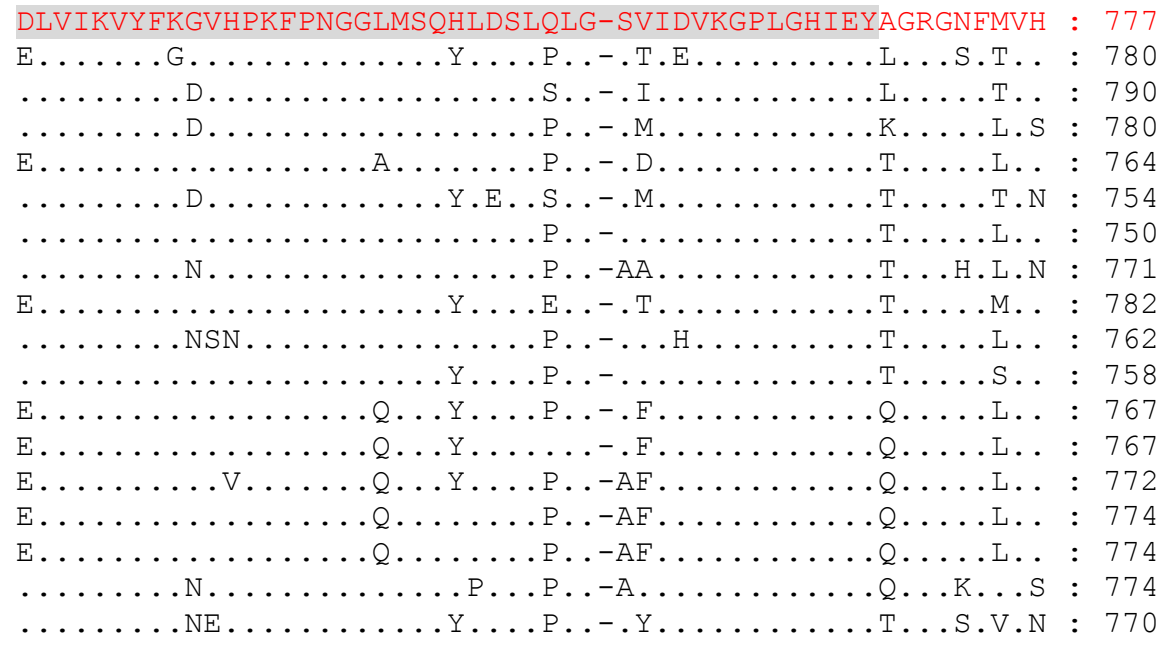

Ricinus AtNR2 Spinach AtNR1

Lotus

Bean

Soybean

Peach

Squash

Birch

T. platyph

N. sylvest

N. tabacum Petunia

Tomato

Potato

Brassica

Maize

Ricinus

AtNR2

Spinach

AtNR1

Lotus

Bean

Soybean

Peach

Squash

Birch

T. platyph

N. sylvest

N. tabacum

Petunia

Tomato

Potato

Brassica

Maize

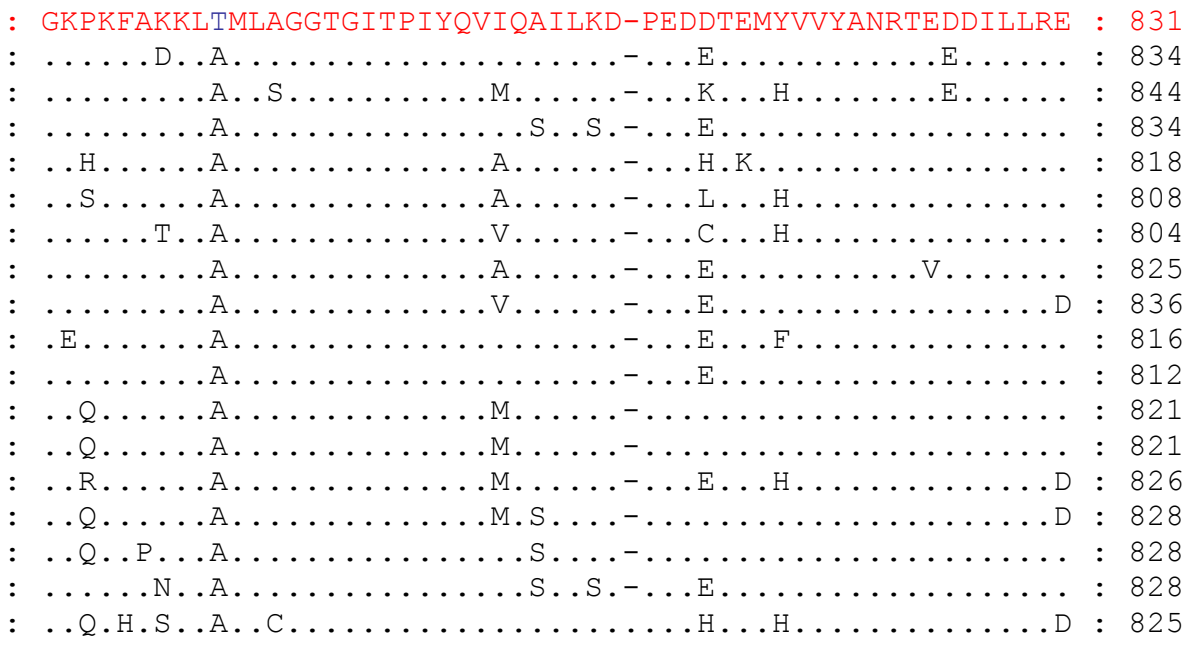

: ELDSWAKEHHERLKVWYVVQES--IKEGWQYSVGFITENILREHVPEGSD-DTLA : 883 : ...G.EQYPD......ES---A...A.T...........L.GSA. : 886

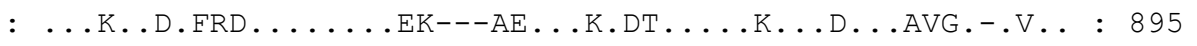
: .EG..SK.K.......EI---A...S.............LEGES . : 886 : ..T..KYED.F.....ET---A...G.............AG.-.A..: 869

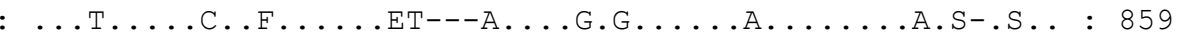

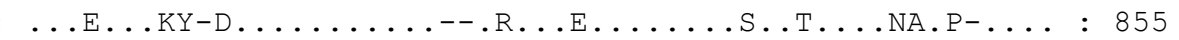

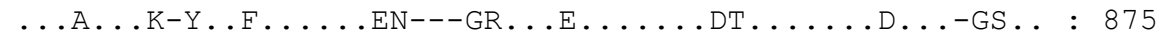

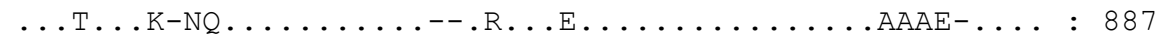
...D..K-.......K..--KR..E....R.S............: 867 ...G..K-.D........-TRK..E.L....R.......K-...: 863

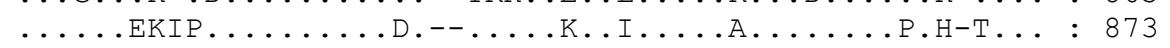
....EKIP..........-...K..L...........H-T..: 873 ....VVKLP...........................LP.Q-T.. : 878

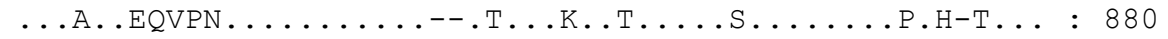

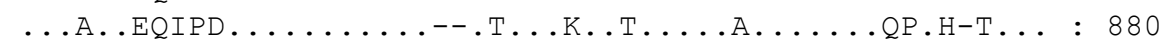
..EG..SK.PD .....EI---A...E.T...........LEGES . : 880 : ..R..A.PD.......DQV.PE...K.................: 879 
Ricinus : LACGPPPMIQFAVQPNLEKMNYDIKNSLLVF : 914

AtNR2 : ...............EDF.I. : 917

Spinach : .T..............EQ..I. : 926

AtNR1 $:$. $\ldots \ldots \ldots \ldots \ldots \ldots$..... : 917

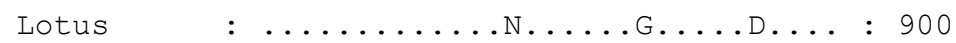

Bean $\quad:$ T.................... 890

Soybean $\quad:$ T..............TQ.N... 886

Peach $\quad:$................TTD....: 906

Squash $\quad: \ldots \ldots \ldots \ldots \ldots \ldots \ldots \ldots \ldots$. 918

Birch : ...A.S...E.RL..........II. : 898

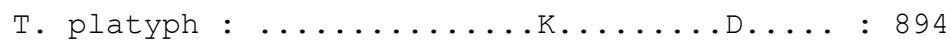

N. sylvest : ....................... : 904

N. tabacum : ...................... : 904

Petunia $\quad: \ldots \ldots \ldots \ldots \ldots$................ 909

Tomato $:$.................EE...: 911

Potato $\quad: \ldots \ldots \ldots \ldots \ldots$...........EE... : 911

Brassica : ..................ED... : 911

Maize $:$........................ : 910 
6.7 Phylogenies analysis (Full-length NRs)

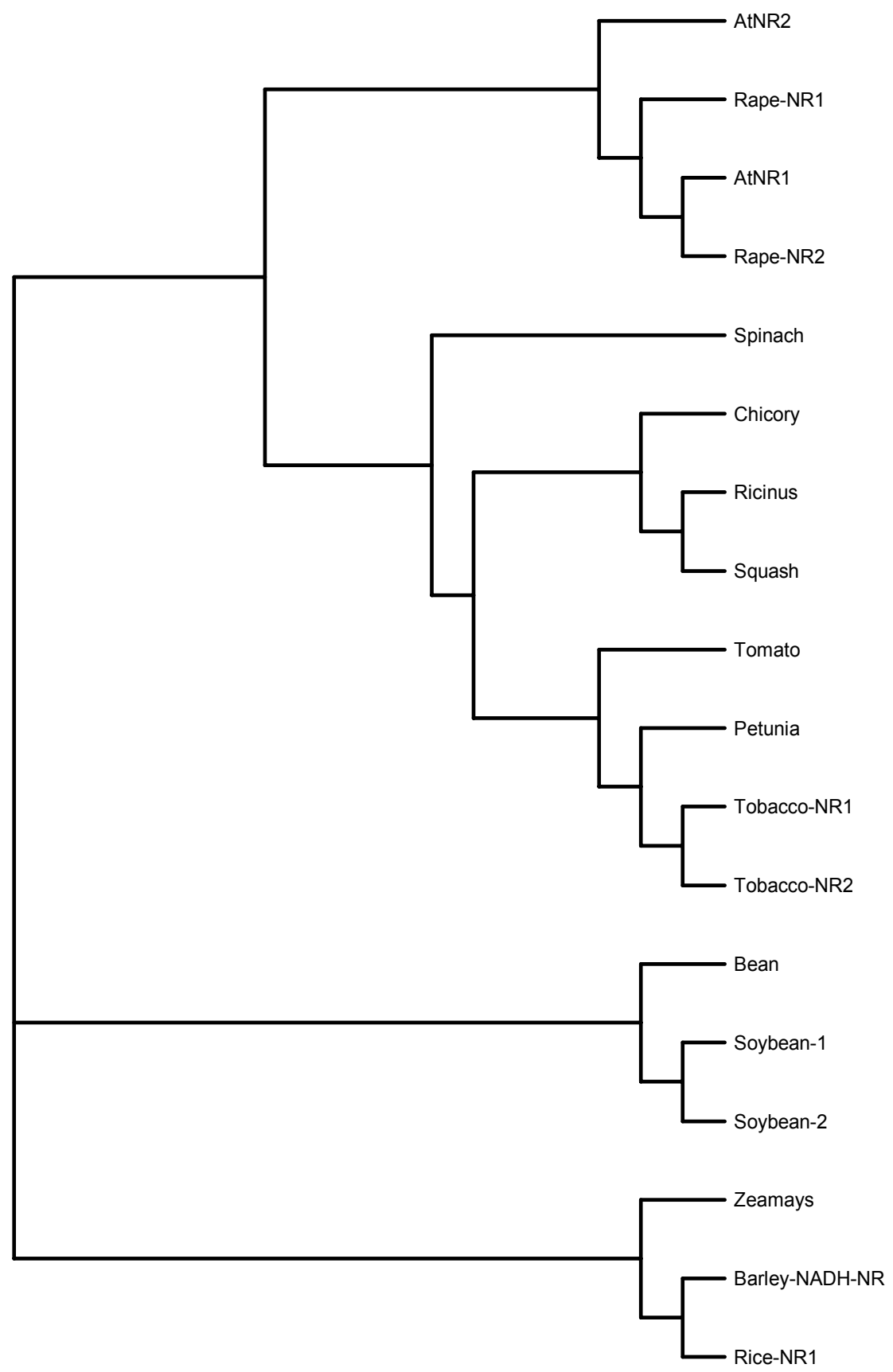




\subsection{Phylogenies analysis (N-terminus of NRs)}

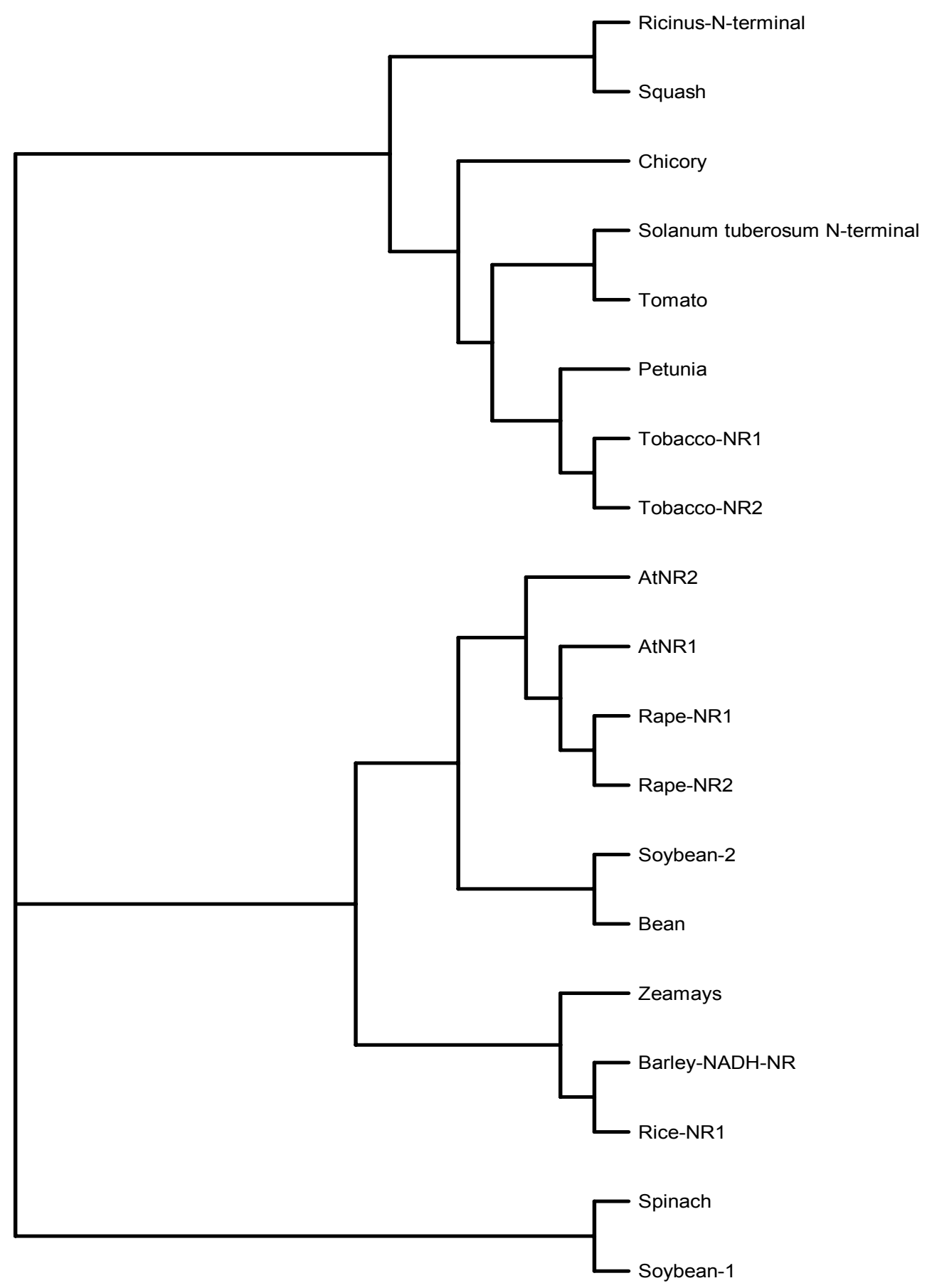




\section{Acknowledgements}

To my supervisors, my deep appreciation to Prof. Dr. Werner M. Kaiser and Prof. Dr. Ralf Kaldenhoff. Each was invaluable to my Ph.D. work and this thesis with their extraordinary direction and clarity of vision. I can only hope this thesis can express my profound gratitude.

To Dr. Martin Eckert, for his great generosity and whose contribution at a very early stage in my Ph.D. work helped to make this thesis possible.

To Dr. Nigel M. Crawford, for kindly giving the Arabidopsis NR2 Pichia transformant.

To Beate Otto, who took time to offer substantial suggestions and help to my experiments.

To Dr. Maria Stoimenova, we could have always made a bet on everything, especially on a diet between two meals. It's a great fun to have nice conversation with you.

To Elisabeth Planchet and Dr. Masatoshi Sonoda, it's a great pleasure to discuss with both of you every time we are back from the Thursday's seminar and especially about the extremely hot NO stories.

To Maria Lesch, I could not imagine that if you were not in our lab. Thank you for always willing to help me in need.

To Eva Wirth, thank you for the company on our regular jogging events, no matter it was raining or snowing. I do enjoy taking exercise because of you.

To members in AG Kaldenhoff, thank you for your friendship and for the BBQ from time to time.

To DAAD, without its financial support all would not be possible.

The staying in Germany has come into being through the great help of a number of people. I wish to express my appreciation to all of you, whether or not I have remembered you here. 


\section{Curriculum Vitae}

\section{Personal Data}

Name: Chyn-Bey Tsai

Nationality: Taiwan

Birthday: 14 Jan 1973

Marital status: single

\section{Education}

1999-2003 Ph.D. student at University of Würzburg, Würzburg, Germany Research project: Molecular cloning and characterization of nitrate reductase from Ricinus communis L.

Supervisors: Prof. Dr. Werner M. Kaiser

Prof. Dr. Ralf Kaldenhoff

1997-1999 Private study at Taichung City Buddhist Lotus Organization

1995-1997 Master of Science

Institute of Life Science, National Tsing-Hua University, Hsinchu, Taiwan

Research project: Quantitation and analysis of neuron growth inhibitory factor (Metallothionine III) gene transcripts

Supervisor: Dr. Lih-Yuan Lin

1991-1995 Bachelor of Science

Department of Botany, National Chung-Hsing University, Taichung, Taiwan

Research experience: working on a research subject: "Changes in nitrogen metabolism of Carica papaya L. under hypoxia stress" with Dr. Song-Iuan Liaw

1988-1991 National Taichung Girls' Senior High School

\section{Award and Scholarship}

1995 Received the Research Creativity Award from the National Science Council as an undergraduate at the Department of Botany, $\mathrm{NCHU}$ 


\section{Publication List}

Tsai C-B, Kaiser WM and Kaldenhoff R (2003) Molecular cloning and characterization of nitrate reductase from Ricinus communis L. heterologously expressed in Pichia pastoris. Submitted for publication to Planta on 21.01.2003

Kaiser WM, Weiner H, Kandlbinder A, Tsai C-B, Rockel P, Sonoda M, and Planchet E (2002) Modulation of nitrate reductase: some new insights, an unusual case and a potentially important side reaction. J. Exp. Bot 53: 875-882

\section{Printed Documentation:}

Tsai C-B, Kaldenhoff R, and Kaiser WM (2001) On the Way to Understand the Molecular Basis for Species-Specific Differences in the Regulatory Properties of Nitrate Reductase of Higher Plants. In: Tagungsdokumentation von DAADBioForum-Berlin. DOK\&MAT 42: 119-121

\section{Presentations:}

DAAD-BioForum, Berlin 2001. Regulatory properties of nitrate reductase from Ricinus communis L.

Rhein-Main-Botaniker-Kolloquium, Heidelberg 2002. Special regulatory properties of nitrate reductase in Ricinus communis L.: heterologous expression of NR in Pichia pastoris.

\section{Poster Presentation:}

Fifth International Symposium, Nitrate Assimilation: Molecular and Genetic Aspects, NAMGA 2002, Córdoba, Spain. Regulatory Properties of Nitrate Reductase from Ricinus communis L. 


\section{ERKLÄRUNG}

Hiermit erkläre ich, dass ich die vorliegende Dissertation in allen Teilen selbst angefertigt und keine anderen als die angegebenen Quellen und Hilfsmittel verwendet habe.

Ich habe die Dissertation weder in gleicher noch in ähnlicher Form in anderen Prüfungsverfahren vorgelegt.

Ich erkläre weiterhin, dass ich bislang noch keine weiteren akademischen Grade erworben oder zu erwerben versucht habe.

Würzburg, Februar 2003 